UNIVERSIDADE DE SÃO PAULO

ESCOLA DE ENGENHARIA DE SÃO CARLOS

DEPARTAMENTO DE ENGENHARIA ELÉTRICA E DE COMPUTAÇÃO

JULLIAN CEZAR ZAN

METOdologia PARA RESTABELECIMENTO DE ENERGIA EM SiSTEMAS DE DISTRIBUIÇÃo CONSIDERANDO REGULADORES DE TENSÃO, BANCOS DE CAPACITORES E AS

CARACTERÍSTICAS OPERACIONAIS de VÁRIOS TiPOS DE CHAVES SECCIONADORAS 



\section{Metodologia para Restabelecimento de Energia em Sistemas de Distribuição considerando Reguladores de Tensão, Bancos de Capacitores e as Características Operacionais de Vários Tipos de Chaves Seccionadoras}

Dissertação apresentada à Escola de Engenharia de São Carlos, da Universidade de São Paulo, para obtenção do Título de Mestre em Ciências, Programa de Engenharia Elétrica.

Área de Concentração: Sistemas Elétricos de Potência

Orientador: Prof. Dr. João Bosco Augusto London Jr.

São Carlos

2015

\footnotetext{
${ }^{1}$ Trata-se da versão corrigida da dissertação. A versão original se encontra disponível na EESC/USP que aloja o Programa de Pós-Graduação de Engenharia Elétrica.
} 
AUTORIZO A REPRODUÇÃO TOTAL OU PARCIAL DESTE TRABALHO, POR QUALQUER MEIO CONVENCIONAL OU ELETRÔNICO, PARA FINS DE ESTUDO E PESQUISA, DESDE QUE CITADA A FONTE.

$27 m$

Zan, Jullian Cezar

Metodologia para restabelecimento de energia em sistemas de distribuição considerando reguladores de tensão, bancos de capacitores e as características operacionais de vários tipos de chaves seccionadoras / Jullian Cezar Zan; orientador João Bosco Augusto London

Dissertação (Mestrado) - Programa de Pós-Graduação

em Engenharia Elétrica e Área de Concentração em Sistemas Elétricos de Potência -- Escola de Engenharia

1. Reconfiguração de Redes. 2. Restabelecimento de Energia. 3. Sistemas de Distribuição de Energia Elétrica. 4. Regulador de Tensão. 5. Bancos de 


\section{FOLHA DE JULGAMENTO}

Candidato: Engenheiro JULLIAN CEZAR ZAN.

Título da dissertação: "Metodologia para restabelecimento de energia em sistemas de distribuição considerando reguladores de tensão, bancos de capacitores e as características operacionais de vários tipos de chaves seccionadoras".

Data da defesa: 20/11/2015

Comissão Julgadora:

Resultado:

Prof. Associado João Bosco Augusto London Junior (Orientador)

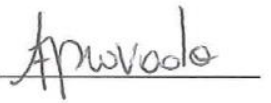

(Escola de Engenharia de São Carlos/EESC)

Prof. Dr. Eduardo Gontijo Carrano

Aprovado

(Universidade Federal de Minas Gerais/UFMG)

Prof. Associado Eduardo Nobuhiro Asada

APROVADO

(Escola de Engenharia de São Carlos/EESC)

Coordenador do Programa de Pós-Graduação em Engenharia Elétrica: Prof. Associado Luis Fernando Costa Alberto

Presidente da Comissão de Pós-Graduação: Prof. Associado Paulo César Lima Segantine 

Aos meus pais, Gildo e Roseli, e ao meu irmão, Willian. 



\section{Agradecimentos}

A Deus, fonte de toda força e fé para trilhar mais esta etapa da minha vida.

Aos meus pais, Gildo e Roseli e ao meu irmão, Willian, pelo amor, apoio e incentivo em todos os momentos da minha vida.

Ao meu orientador, professor Dr. João Bosco Augusto London Jr., pela paciência, pelas discussões, amizade e verdadeira orientação em cada passo deste trabalho.

À Camila, pela paciência, carinho, e apoio dedicados em todos os momentos. Por sempre estar ao meu lado, motivando com alegria para seguir em frente e por toda ajuda realizada no mestrado, sem medir esforços.

A todos os colegas do LACO (Laboratório de Análise Computacional), pelo apoio e convivência. Em especial, ao Leandro Tolomeu Marques, por não medir esforços em ajudar, ouvir e discutir durante as dificuldades da pesquisa.

A todos os integrantes do projeto P\&D com a COPEL, pelos dados disponibilizados da distribuidora, pelo apoio financeiro, pelas discussões e pela colaboração para o desenvolvimento deste mestrado.

A todos os colegas e amizades feitas em São Carlos, pelos bons momentos compartilhados. Em especial, aos amigos de graduação Aline e Elian e ao Marcelo, pelo incentivo e amizade.

A todos os colaboradores da USP que, direta ou indiretamente, me apoiaram para a realização do mestrado.

À FAPESP, pelo apoio financeiro.

Meu muito obrigado. 



\section{RESUMO}

ZAN, J. C. Metodologia para Restabelecimento de Energia em Sistemas de Distribuição considerando Reguladores de Tensão, Bancos de Capacitores e as Características Operacionais de Vários Tipos de Chaves Seccionadoras. 2015. Dissertação (Mestrado) - Escola de Engenharia de São Carlos, Universidade de São Paulo, São Carlos, 2015.

Esta dissertação tem por objetivo o desenvolvimento, e implantação em computador, de uma metodologia para tratamento do problema de restabelecimento de energia em sistemas de distribuição de grande porte (com milhares de linhas, barras de carga e chaves seccionadoras), que permita a obtenção de Planos de Restabelecimento de Energia (PREs) adequados considerando a existência de reguladores de tensão, bancos de capacitores e de diferentes tipos de chaves seccionadoras. A metodologia proposta deverá considerar as características de operação de diferentes tipos de chaves seccionadoras (existência de telecomando, possibilidade de abertura com carga e/ou em curto circuito, etc.) para obtenção de PREs. Vale lembrar que usualmente as metodologias desenvolvidas para obtenção de PREs consideram a existência apenas de chaves automáticas e não automáticas, não considerando outras características de funcionamento das chaves seccionadoras. Tendo em vista que o problema a ser tratado é combinatório, com múltiplos objetivos e restrições, a metodologia proposta será baseada em Algoritmos Evolutivos, em técnicas de otimização multi-objetivo e na estrutura de dados denominada Representação Nó-Profundidade (RNP). A RNP será utilizada para representar computacionalmente, de forma eficiente, a topologia elétrica dos sistemas de distribuição. Para validar a metodologia proposta serão realizadas simulações computacionais com sistemas de distribuição reais de grande porte.

Palavras-Chave: Reconfiguração de Redes, Restabelecimento de Energia, Sistemas de Distribuição de Energia Elétrica, Regulador de Tensão, Bancos de Capacitores, Chaves Seccionadoras. 



\begin{abstract}
ZAN, J. C. Methodology for Service Restoration in Distribution Systems considering Voltage Regulators, Capacitors Banks and Operating Characteristics of Various Types of Sectionalizing Switches. 2015. Dissertation (M.S. Degree) School of Engineering of Sao Carlos, University of Sao Paulo, São Carlos, 2015.
\end{abstract}

This dissertation aims to develop a methodology to provide adequate Energy Restoration Plans (ERPs) in contingency situations to large-scale distribution systems (with thousands of lines, load buses and sectionalizing switches), considering the existence of voltage regulators, capacitors banks and different types of sectionalizing switches. The proposed methodology considers the operational characteristics of different types of sectionalizing switches (existence of remote control, possibility of open-load and/or short-circuit, etc.) for the purpose of obtaining ERPs. Usually the developed methodologies consider only the existence of remotely controlled and manually controlled switches, excluding other operational characteristics of the sectionalizing switches. As the service restoration problem is combinatory with multiple objectives and constraints, the proposed methodology is based on Evolutionary Algorithms, multiobjective optimization techniques and on the data structure named Node-Depth Encoding. The Node-Depth Encoding is used to computationally represent, in an efficient way, the topology of the distribution systems. The proposed methodology is validated through computational simulations performed in real large-scale distribution systems.

Keywords: Network Reconfiguration, Service Restoration, Distribution Systems, Voltage Regulator, Capacitor Bank, Sectionalizing Switches. 



\section{LISTA DE FIGURAS}

FIGURA 2.1: REPRESENTAÇÃO DE UM SISTEMA DE DISTRIBUIÇÃO.................................... 8

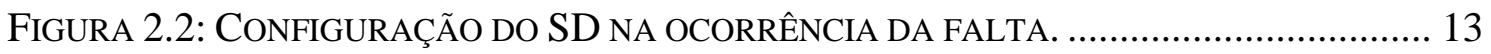

FIGURA 2.3: CONFIGURAÇÃO COM O SETOR FALTOSO ISOLADO......................................... 14

FIGURA 2.4: CONFIGURAÇÃO COM AS CARGAS À JUSANTE DO SETOR FALTOSO

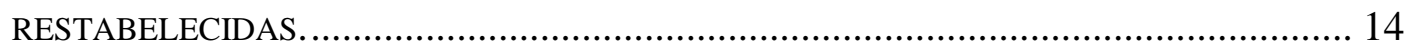

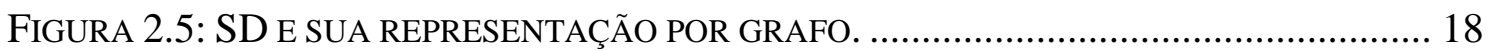

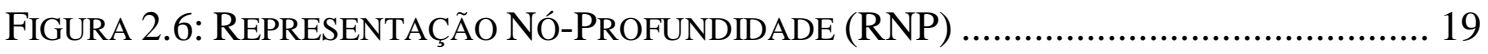

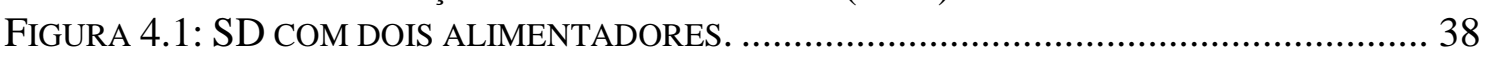

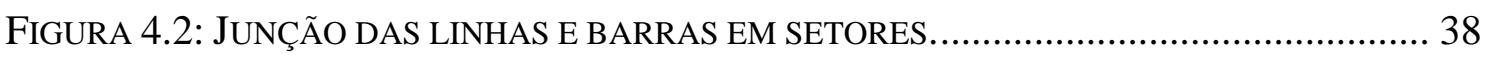

FIGURA 4.3: GRAFO REPRESENTANDO SETORES DO SD DA FIGURA 4.2 ......................... 39

FIGURA 4.4: ÁRVORE DO SETOR D, COM OS NÓS ADJACENTES DOS SETORES: B (À

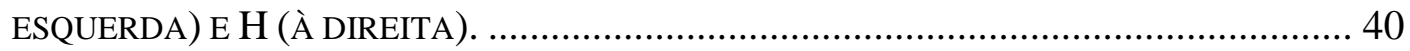

Figura 4.5: DiAgrama UNIFILAR DO SD-MARÍliA - SETOR ANALISAdO (EM DESTAQUE).

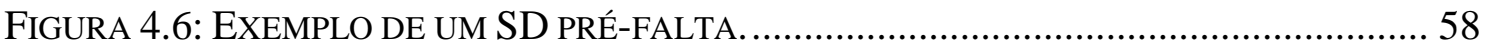

FigURA 4.7: SETOR J EM FALTA ISOLADO PELA ABERTURA DAS CHAVES 1, 2 E 3 ............. 59

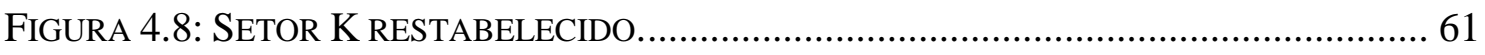

FIGURA 4.9: ESTADO FINAL DA REDE APÓS A TENTATIVA DA PRIMEIRA COMBINAÇÃO

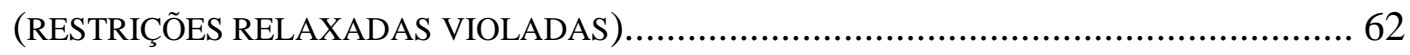

FIGURA 4.10: ESTADO FINAL DA REDE APÓS A TENTATIVA DA SEGUNDA COMBINAÇÃO

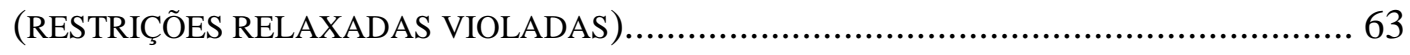

FIGURA 4.11: ESTADO FINAL DA REDE APÓS A TENTATIVA DA TERCEIRA COMBINAÇÃO

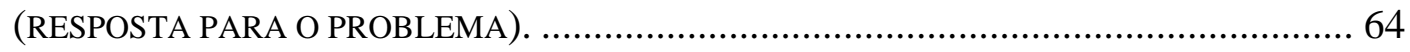

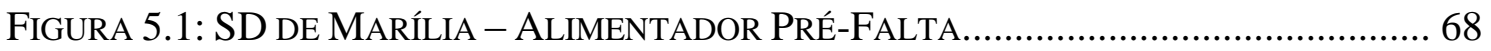

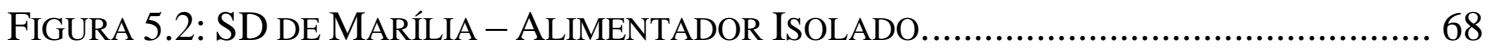

FIGURA B.1: SD DO EXEMPLO DIDÁTICO DE 4 BARRAS. ................................................. 109 



\section{LISTA DE TABELAS}

TABELA 2.1: TIPOS E CARACTERÍSTICAS OPERACIONAIS DAS CHAVES SECCIONADORAS .. 11

TABELA 2.2: TIPOS AGRUPADOS E CARACTERÍSTICAS OPERACIONAIS DAS CHAVES

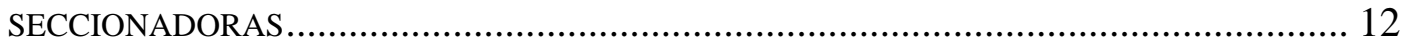

TABEla 3.1: CONJUNTO DE PARES DE CHAVES ALTERADAS (MARQUES, 2013)............... 34

TABELA 3.2: CONJUNTO DE CHAVES ALTERADAS ATUALIZADO PELA EXCLUSÃO DA CHAVE

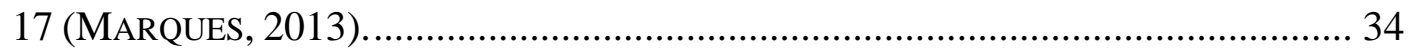

TABELA 3.3: SEQUÊNCIA DE CHAVEAMENTO NA QUAL O PAR REARRANJADO ENCONTRA-SE NA PRIMEIRA DAS DUAS LINHAS (MARQUES, 2013). ............................................ 35

TABELA 3.4: SEQUÊNCIA DE CHAVEAMENTO NA QUAL O PAR REARRANJADO ENCONTRA-SE NA SEGUNDA DAS DUAS LINHAS (MARQUES, 2013)............................................ 35

TABELA 4.1: LIMITES DAS POSIÇÕES DOS TAPS EM FUNÇÃO DO CARREGAMENTO DO RT . 46 TABELA 4.2: PARÂMETROS ELÉTRICOS GERAIS DO FC DESENVOLVIDO .......................... 48 TABELA 4.3: LISTA DE MANOBRAS DO MELHOR INDIVÍDUO APÓS O PROCESSO EVOLUTIVO.

TABELA 5.1:VALORES DAS MANOBRAS, DAS RESTRIÇÕES OPERACIONAIS E DAS PERDAS ATIVAS PARA AS SOLUÇÕES FINAIS DO CASO 1.

TABELA 5.2: VALORES DAS MANOBRAS, DAS RESTRIÇÕES OPERACIONAIS E DAS PERDAS ATIVAS PARA AS SOLUÇÕES FINAIS DO CASO 2. .................................................... 70

TABELA 5.3:PARÂMETROS GERAIS DO FC PROPOSTO VERSUS CPFL PARA O CASO 1 ...... 71

TABELA 5.4:PARÂMETROS GERAIS DO FC PROPOSTO VERSUS CPFL PARA O CASO 2 ..... 71 TABELA 5.5:VALORES MÉDIOS DAS RESTRIÇÕES OPERACIONAIS PARA OS CASOS 1 E 2 ... 71 TABELA 5.6:VALORES DAS MANOBRAS, DAS RESTRIÇÕES OPERACIONAIS E DAS PERDAS ATIVAS PARA A MELHOR SOLUÇÃO APÓS O PROCESSO EVOLUTIVO.

TABELA 5.7:VALORES DAS MANOBRAS, DAS RESTRIÇÕES OPERACIONAIS E DAS PERDAS ATIVAS PARA A SOLUÇÃO FINAL.

TABELA 5.8:ORDEM DA SEQUÊNCIA DE CHAVEAMENTO QUE DEVE SER REALIZADA PELOS OPERADORES DO SISTEMA.

TABELA 5.9: VALORES DAS MANOBRAS, DAS RESTRIÇÕES OPERACIONAIS E DAS PERDAS ATIVAS PARA A MELHOR SOLUÇÃO APÓS O PROCESSO EVOLUTIVO.

TABELA 5.10: VALORES DAS MANOBRAS, DAS RESTRIÇÕES OPERACIONAIS E DAS PERDAS ATIVAS PARA A SOLUÇÃO FINAL.

TABELA 5.11: ORDEM DA SEQUÊNCIA DE CHAVEAMENTO QUE DEVE SER REALIZADA PELOS OPERADORES DO SISTEMA.

TABELA 5.12: VALORES DAS MANOBRAS, DAS RESTRIÇÕES OPERACIONAIS E DAS PERDAS ATIVAS PARA A MELHOR SOLUÇÃO APÓS O PROCESSO EVOLUTIVO.

TABELA 5.13: VALORES DAS MANOBRAS, DAS RESTRIÇÕES OPERACIONAIS E DAS PERDAS ATIVAS PARA A SOLUÇÃO FINAL.

TABELA 5.14: ORDEM DA SEQUÊNCIA DE CHAVEAMENTO QUE DEVE SER REALIZADA PELOS OPERADORES DO SISTEMA............................................................................ 78

TABELA 5.15: VALORES DAS MANOBRAS, DAS RESTRIÇÕES OPERACIONAIS E DAS PERDAS ATIVAS PARA A PRIMEIRA CONFIGURAÇÃO FACTÍVEL.

TABELA 5.16: VALORES DAS MANOBRAS, DAS RESTRIÇÕES OPERACIONAIS E DAS PERDAS ATIVAS PARA A MELHOR SOLUÇÃO APÓS O PROCESSO EVOLUTIVO. 80

TABELA 5.17: VALORES DAS MANOBRAS, DAS RESTRIÇÕES OPERACIONAIS E DAS PERDAS ATIVAS PARA A SOLUÇÃO FINAL. 
TABELA 5.18: VALORES DAS MANOBRAS, DAS RESTRIÇÕES OPERACIONAIS E DAS PERDAS ATIVAS PARA A MELHOR RESPOSTA ENTRE AS 100 EXECUÇÕES.

TABELA 5.19: VALORES DAS MANOBRAS, DAS RESTRIÇÕES OPERACIONAIS E DAS PERDAS ATIVAS PARA A PRIMEIRA CONFIGURAÇÃO FACTÍVEL.

TABELA 5.20: VALORES DAS MANOBRAS, DAS RESTRIÇÕES OPERACIONAIS E DAS PERDAS ATIVAS PARA A MELHOR SOLUÇÃO APÓS O PROCESSO EVOLUTIVO.

TABELA 5.21: VALORES DAS MANOBRAS, DAS RESTRIÇÕES OPERACIONAIS E DAS PERDAS ATIVAS PARA A PRIMEIRA CONFIGURAÇÃO FACTÍVEL.

TABELA 5.22: VALORES DAS MANOBRAS, DAS RESTRIÇÕES OPERACIONAIS E DAS PERDAS ATIVAS PARA A MELHOR SOLUÇÃO APÓS O PROCESSO EVOLUTIVO.

TABELA 5.23: VALORES DAS MANOBRAS, DAS RESTRIÇÕES OPERACIONAIS E DAS PERDAS ATIVAS PARA A SOLUÇÃO FINAL.

TABELA 5.24: VALORES DAS MANOBRAS, DAS RESTRIÇÕES OPERACIONAIS E DAS PERDAS ATIVAS PARA A MELHOR RESPOSTA ENTRE AS 100 EXECUÇÕES.

TABELA 5.25: VALORES DAS MANOBRAS, DAS RESTRIÇÕES OPERACIONAIS E DAS PERDAS ATIVAS PARA A PRIMEIRA CONFIGURAÇÃO FACTÍVEL.

TABELA 5.26: VALORES DAS MANOBRAS, DAS RESTRIÇÕES OPERACIONAIS E DAS PERDAS ATIVAS PARA A MELHOR SOLUÇÃO APÓS O PROCESSO EVOLUTIVO.

TABELA 5.27: VALORES DAS MANOBRAS, DAS RESTRIÇÕES OPERACIONAIS E DAS PERDAS ATIVAS PARA A SOLUÇÃO FINAL.

TABELA 5.28: VALORES DAS MANOBRAS, DAS RESTRIÇÕES OPERACIONAIS E DAS PERDAS ATIVAS PARA A MELHOR RESPOSTA ENTRE AS 100 EXECUÇÕES.

TABELA 5.29: VALORES DAS MANOBRAS, DAS RESTRIÇÕES OPERACIONAIS E DAS PERDAS ATIVAS PARA A PRIMEIRA CONFIGURAÇÃO FACTÍVEL.

TABELA 5.30: VALORES DAS MANOBRAS, DAS RESTRIÇÕES OPERACIONAIS E DAS PERDAS ATIVAS PARA A MELHOR SOLUÇÃO APÓS O PROCESSO EVOLUTIVO.

TABELA 5.31: VALORES DAS MANOBRAS, DAS RESTRIÇÕES OPERACIONAIS E DAS PERDAS ATIVAS PARA A SOLUÇÃO FINAL.

TABELA 5.32: VALORES DAS MANOBRAS, DAS RESTRIÇÕES OPERACIONAIS E DAS PERDAS ATIVAS PARA A MELHOR RESPOSTA ENTRE AS 100 EXECUÇÕES.

TABELA B.1: TENSÕES COMPLEXAS NAS BARRAS APÓS CONVERGÊNCIA DO FC. ............ 119

TABELA C.1: VALORES DAS MANOBRAS, DAS RESTRIÇÕES OPERACIONAIS E DAS PERDAS ATIVAS PARA A PRIMEIRA CONFIGURAÇÃO FACTÍVEL.

TABELA C.2: VALORES DAS MANOBRAS, DAS RESTRIÇÕES OPERACIONAIS E DAS PERDAS ATIVAS PARA A MELHOR SOLUÇÃO APÓS O PROCESSO EVOLUTIVO.

TABELA C.3: VALORES DAS MANOBRAS, DAS RESTRIÇÕES OPERACIONAIS E DAS PERDAS ATIVAS PARA A SOLUÇÃO FINAL.

TABELA C.4: VALORES DAS MANOBRAS, DAS RESTRIÇÕES OPERACIONAIS E DAS PERDAS ATIVAS PARA A MELHOR RESPOSTA ENTRE AS 100 EXECUÇÕES.

TABELA C.5: VALORES DAS MANOBRAS, DAS RESTRIÇÕES OPERACIONAIS E DAS PERDAS ATIVAS PARA A PRIMEIRA CONFIGURAÇÃO FACTÍVEL.

TABELA C.6: VALORES DAS MANOBRAS, DAS RESTRIÇÕES OPERACIONAIS E DAS PERDAS ATIVAS PARA A MELHOR SOLUÇÃO APÓS O PROCESSO EVOLUTIVO.

TABELA C.7: VALORES DAS MANOBRAS, DAS RESTRIÇÕES OPERACIONAIS E DAS PERDAS ATIVAS PARA A SOLUÇÃO FINAL.

TABELA C.8: VALORES DAS MANOBRAS, DAS RESTRIÇÕES OPERACIONAIS E DAS PERDAS ATIVAS PARA A MELHOR RESPOSTA ENTRE AS 100 EXECUÇÕES.

TABELA C.9: VALORES DAS MANOBRAS, DAS RESTRIÇÕES OPERACIONAIS E DAS PERDAS ATIVAS PARA A PRIMEIRA CONFIGURAÇÃO FACTÍVEL. 
TABELA C.10: VALORES DAS MANOBRAS, DAS RESTRIÇÕES OPERACIONAIS E DAS PERDAS ATIVAS PARA A MELHOR SOLUÇÃO APÓS O PROCESSO EVOLUTIVO.

TABELA C.11: VALORES DAS MANOBRAS, DAS RESTRIÇÕES OPERACIONAIS E DAS PERDAS ATIVAS PARA A SOLUÇÃO FINAL.

TABELA C.12: VALORES DAS MANOBRAS, DAS RESTRIÇÕES OPERACIONAIS E DAS PERDAS ATIVAS PARA A MELHOR RESPOSTA ENTRE AS 100 EXECUÇÕES.

TABELA C.13: VALORES DAS MANOBRAS, DAS RESTRIÇÕES OPERACIONAIS E DAS PERDAS ATIVAS PARA A PRIMEIRA CONFIGURAÇÃO FACTÍVEL.

TABELA C.14: VALORES DAS MANOBRAS, DAS RESTRIÇÕES OPERACIONAIS E DAS PERDAS ATIVAS PARA A MELHOR SOLUÇÃO APÓS O PROCESSO EVOLUTIVO.

TABELA C.15: VALORES DAS MANOBRAS, DAS RESTRIÇÕES OPERACIONAIS E DAS PERDAS ATIVAS PARA A SOLUÇÃO FINAL.

TABELA C.16: VALORES DAS MANOBRAS, DAS RESTRIÇÕES OPERACIONAIS E DAS PERDAS ATIVAS PARA A MELHOR RESPOSTA ENTRE AS 100 EXECUÇÕES.

TABELA C.17: VALORES DAS MANOBRAS, DAS RESTRIÇÕES OPERACIONAIS E DAS PERDAS ATIVAS PARA A PRIMEIRA CONFIGURAÇÃO FACTÍVEL.

TABELA C.18: VALORES DAS MANOBRAS, DAS RESTRIÇÕES OPERACIONAIS E DAS PERDAS ATIVAS PARA A MELHOR SOLUÇÃO APÓS O PROCESSO EVOLUTIVO.

TABELA C.19: VALORES DAS MANOBRAS, DAS RESTRIÇÕES OPERACIONAIS E DAS PERDAS ATIVAS PARA A SOLUÇÃO FINAL.

TABELA C.20: VALORES DAS MANOBRAS, DAS RESTRIÇÕES OPERACIONAIS E DAS PERDAS ATIVAS PARA A MELHOR RESPOSTA ENTRE AS 100 EXECUÇÕES.

TABELA C.21: VALORES DAS MANOBRAS, DAS RESTRIÇÕES OPERACIONAIS E DAS PERDAS ATIVAS PARA A PRIMEIRA CONFIGURAÇÃO FACTÍVEL.

TABELA C.22: VALORES DAS MANOBRAS, DAS RESTRIÇÕES OPERACIONAIS E DAS PERDAS ATIVAS PARA A MELHOR SOLUÇÃO APÓS O PROCESSO EVOLUTIVO.

TABELA C.23: VALORES DAS MANOBRAS, DAS RESTRIÇÕES OPERACIONAIS E DAS PERDAS ATIVAS PARA A SOLUÇÃO FINAL.

TABELA C.24: VALORES DAS MANOBRAS, DAS RESTRIÇÕES OPERACIONAIS E DAS PERDAS ATIVAS PARA A MELHOR RESPOSTA ENTRE AS 100 EXECUÇÕES.

TABELA C.25: VALORES DAS MANOBRAS, DAS RESTRIÇÕES OPERACIONAIS E DAS PERDAS ATIVAS PARA A PRIMEIRA CONFIGURAÇÃO FACTÍVEL.

TABELA C.26: VALORES DAS MANOBRAS, DAS RESTRIÇÕES OPERACIONAIS E DAS PERDAS ATIVAS PARA A MELHOR SOLUÇÃO APÓS O PROCESSO EVOLUTIVO.

TABELA C.27: VALORES DAS MANOBRAS, DAS RESTRIÇÕES OPERACIONAIS E DAS PERDAS ATIVAS PARA A PRIMEIRA CONFIGURAÇÃO FACTÍVEL.

TABELA C.28: VALORES DAS MANOBRAS, DAS RESTRIÇÕES OPERACIONAIS E DAS PERDAS ATIVAS PARA A MELHOR SOLUÇÃO APÓS O PROCESSO EVOLUTIVO.

TABELA C.29: VALORES DAS MANOBRAS, DAS RESTRIÇÕES OPERACIONAIS E DAS PERDAS ATIVAS PARA A PRIMEIRA CONFIGURAÇÃO FACTÍVEL.

TABELA C.30: VALORES DAS MANOBRAS, DAS RESTRIÇÕES OPERACIONAIS E DAS PERDAS ATIVAS PARA A MELHOR SOLUÇÃO APÓS O PROCESSO EVOLUTIVO.

TABELA C.31: VALORES DAS MANOBRAS, DAS RESTRIÇÕES OPERACIONAIS E DAS PERDAS ATIVAS PARA A PRIMEIRA CONFIGURAÇÃO FACTÍVEL.

TABELA C.32: VALORES DAS MANOBRAS, DAS RESTRIÇÕES OPERACIONAIS E DAS PERDAS ATIVAS PARA A MELHOR SOLUÇÃO APÓS O PROCESSO EVOLUTIVO.

TABELA C.33: VALORES DAS MANOBRAS, DAS RESTRIÇÕES OPERACIONAIS E DAS PERDAS ATIVAS PARA A PRIMEIRA CONFIGURAÇÃO FACTÍVEL.

TABELA C.34: VALORES DAS MANOBRAS, DAS RESTRIÇÕES OPERACIONAIS E DAS PERDAS ATIVAS PARA A MELHOR SOLUÇÃO APÓS O PROCESSO EVOLUTIVO. 
TABELA C.35: VALORES DAS MANOBRAS, DAS RESTRIÇÕES OPERACIONAIS E DAS PERDAS ATIVAS PARA A PRIMEIRA CONFIGURAÇÃO FACTÍVEL. 141

TABELA C.36: VALORES DAS MANOBRAS, DAS RESTRIÇÕES OPERACIONAIS E DAS PERDAS ATIVAS PARA A MELHOR SOLUÇÃO APÓS O PROCESSO EVOLUTIVO.

TABELA C.37: VALORES DAS MANOBRAS, DAS RESTRIÇÕES OPERACIONAIS E DAS PERDAS ATIVAS PARA A PRIMEIRA CONFIGURAÇÃO FACTÍVEL.

TABELA C.38: VALORES DAS MANOBRAS, DAS RESTRIÇÕES OPERACIONAIS E DAS PERDAS ATIVAS PARA A MELHOR SOLUÇÃO APÓS O PROCESSO EVOLUTIVO.

TABELA C.39: VALORES DAS MANOBRAS, DAS RESTRIÇÕES OPERACIONAIS E DAS PERDAS ATIVAS PARA A PRIMEIRA CONFIGURAÇÃO FACTÍVEL.

TABELA C.40: VALORES DAS MANOBRAS, DAS RESTRIÇÕES OPERACIONAIS E DAS PERDAS ATIVAS PARA A MELHOR SOLUÇÃO APÓS O PROCESSO EVOLUTIVO.

TABELA C.41: VALORES DAS MANOBRAS, DAS RESTRIÇÕES OPERACIONAIS E DAS PERDAS ATIVAS PARA A PRIMEIRA CONFIGURAÇÃO FACTÍVEL.

TABELA C.42: VALORES DAS MANOBRAS, DAS RESTRIÇÕES OPERACIONAIS E DAS PERDAS ATIVAS PARA A MELHOR SOLUÇÃO APÓS O PROCESSO EVOLUTIVO.

TABELA C.43: VALORES DAS MANOBRAS, DAS RESTRIÇÕES OPERACIONAIS E DAS PERDAS ATIVAS PARA A PRIMEIRA CONFIGURAÇÃO FACTÍVEL.

TABELA C.44: VALORES DAS MANOBRAS, DAS RESTRIÇÕES OPERACIONAIS E DAS PERDAS ATIVAS PARA A MELHOR SOLUÇÃO APÓS O PROCESSO EVOLUTIVO. 


\section{LISTA DE SIGLAS}

AE-Algoritmo Evolutivo.

AEMO - Algoritmo Evolutivo Multi-Objetivo.

AEMT-Algoritmo Evolutivo Multi-objetivo em Tabelas.

BC-Banco de Capacitores.

CAO - do inglês, Change Ancestor Operator.

CCM-Chaves Controladas Manualmente.

CCR-Chaves Controladas Remotamente.

FC-Fluxo de Carga.

NA-Normalmente Aberto.

NF-Normalmente Fechado.

PAO - do inglês, Preserve Ancestor Operator.

PRE-Plano de Restabelecimento de Energia.

RNP - Representação Nó-Profundidade.

RT - Regulador de Tensão.

SD - Sistema de Distribuição de Energia Elétrica.

SE - Subestação Elétrica. 



\section{SUMÁRIO}

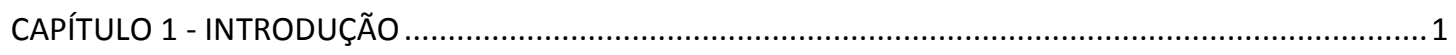

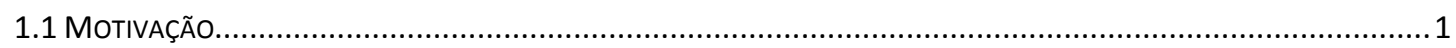

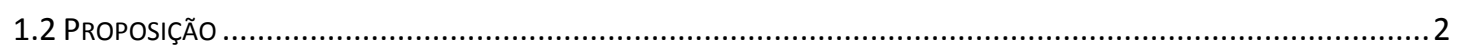

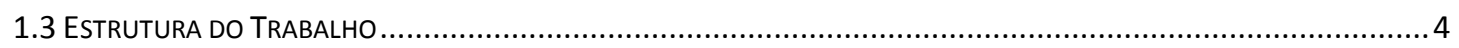

CAPÍTULO 2 - RESTABELECIMENTO DE ENERGIA EM SISTEMAS DE DISTRIBUIÇÃO ………………….....

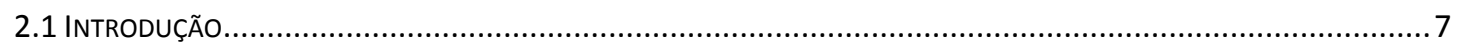

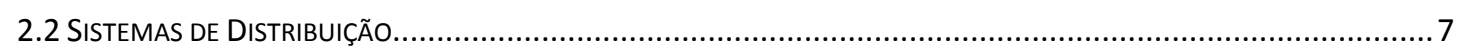

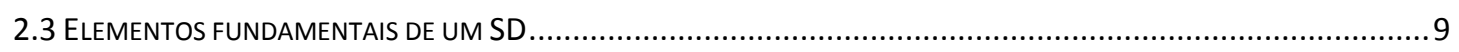

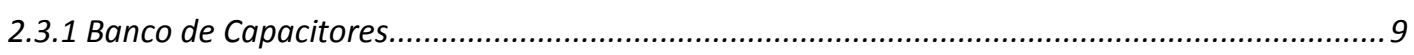

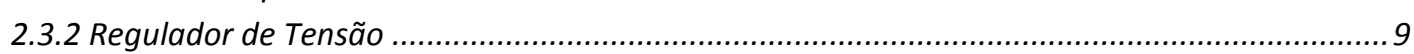

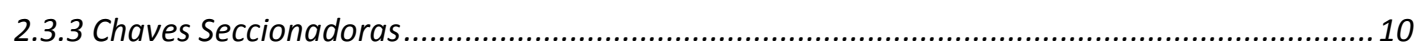

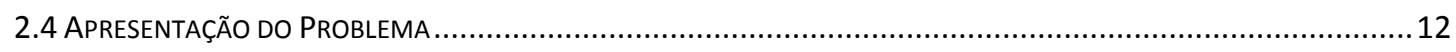

2.5 Modelagem do Problema através da Utilização de Algoritmos EVolutivos e da Representação Nó-

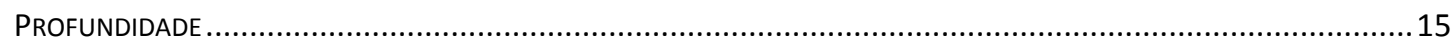

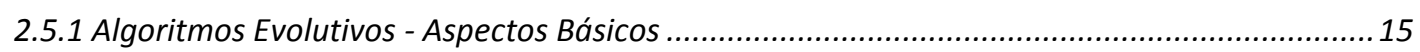

2.5.2 Algoritmos Evolutivos no Contexto de Restabelecimento de Energia......................................16

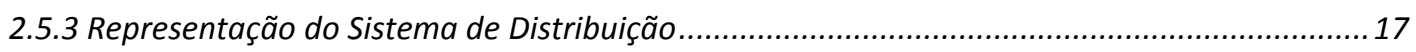

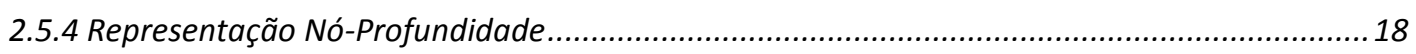

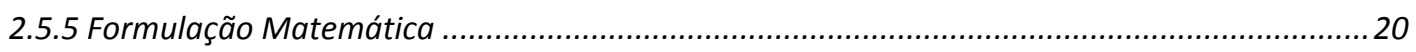

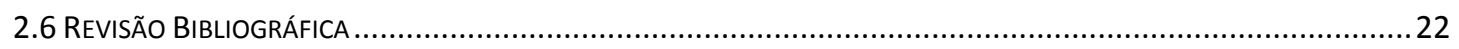

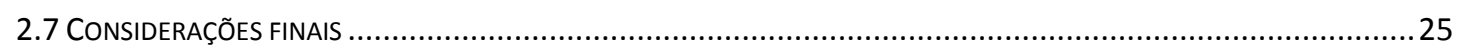

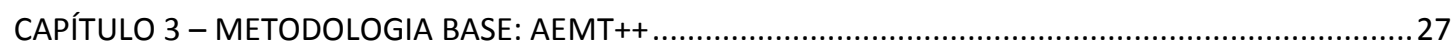

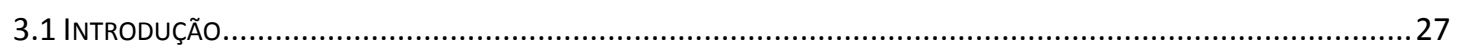

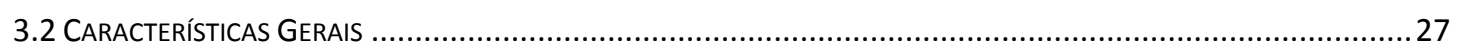

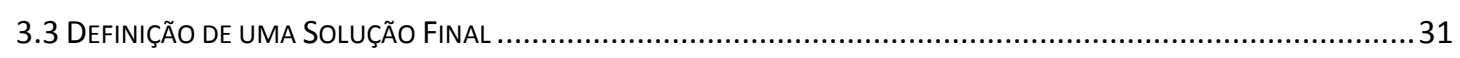

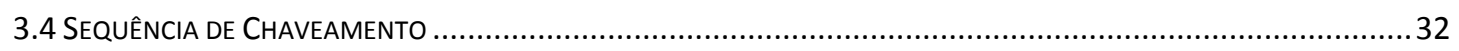

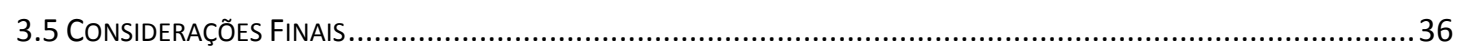

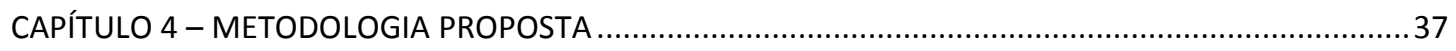

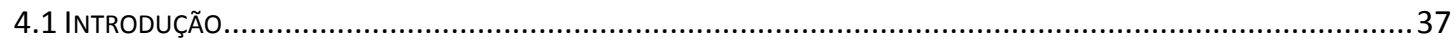

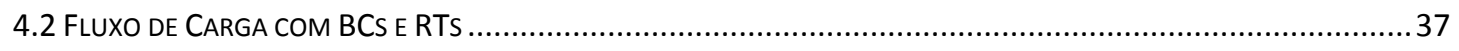

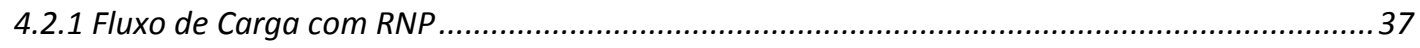

4.2.2 FC de varredura direta/inversa - Método soma das correntes ...............................................40

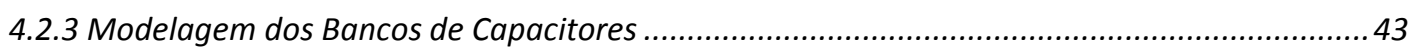

4.2.4 Modelagem dos Reguladores de Tensão e do ajuste automático dos taps ...............................43

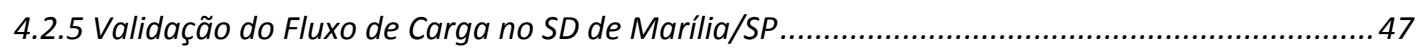

4.3 Metodologia Proposta PARA O PRoblema de ReStabelecimento de ENeRGIA ..........................................49

4.3.1 Tabelas consideradas na metodologia proposta e priorização entre os diferentes tipos de chaves seccionadoras. ........................................................................................................ 49

4.3.2 Características gerais da metodologia proposta. ................................................................5 51

4.3.3 Definição de Sequência de Chaveamento ..............................................................................5

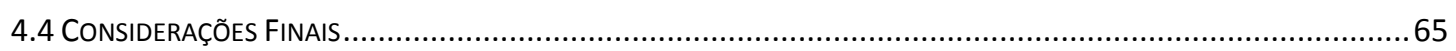

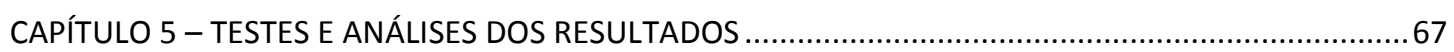




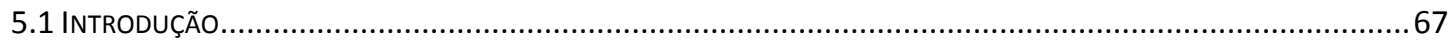

5.2. TeSte 1 - Metodologia Proposta considerando a existênCIA DE BCS E RTS (SD MARÍLIA/SP) ..................67

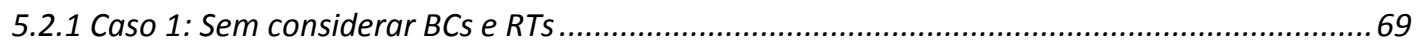

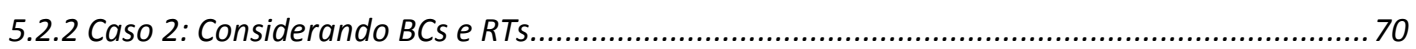

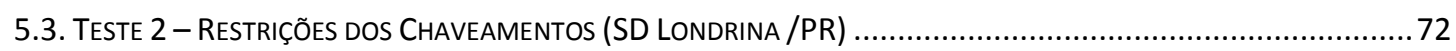

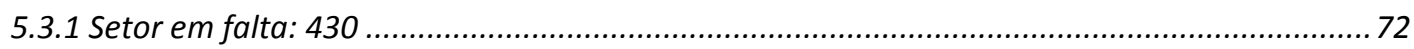

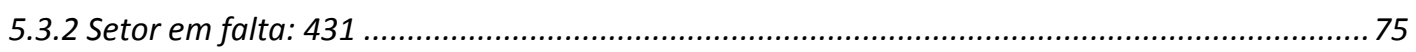

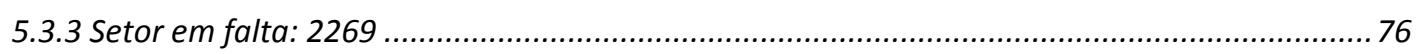

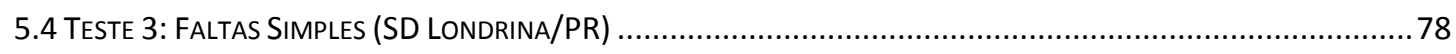

5.4.1 Setor crítico em falta: 2684 (teste que proporcionou os melhores resultados) ....................... 79

5.4.2 Setor crítico em falta: 3036 (teste que proporcionou os piores resultados) ...........................8 82

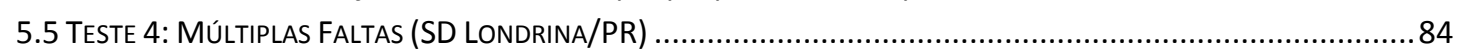

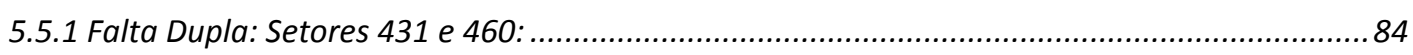

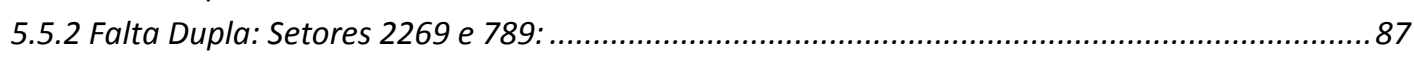

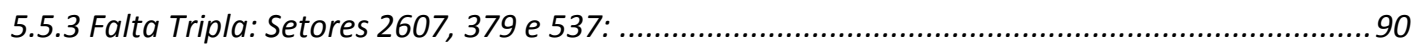

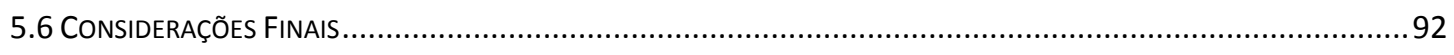

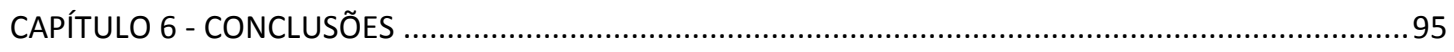

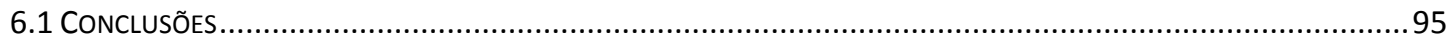

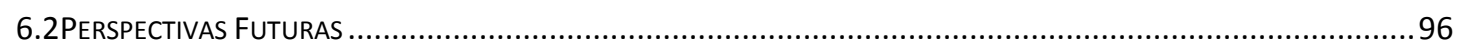

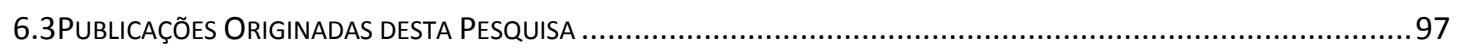

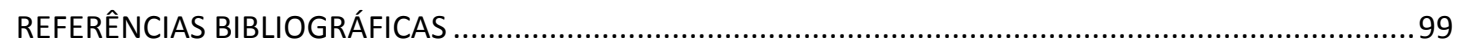

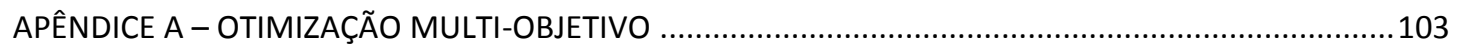

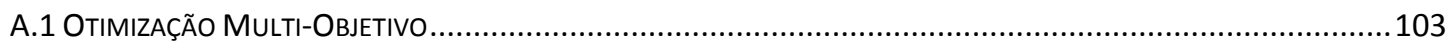

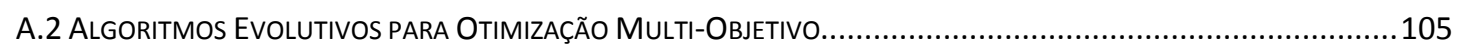

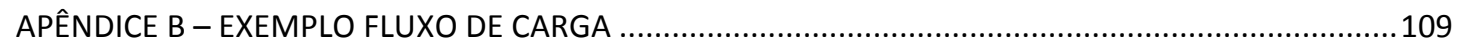

APÊNDICE C - RESULTADOS PARA FALTAS SIMPLES NO SD DE LONDRINA. ....................................121

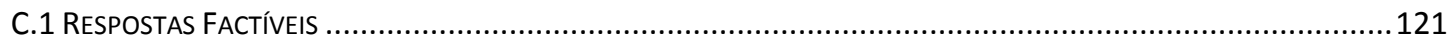

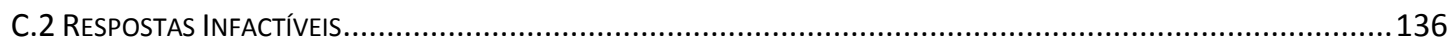




\section{Capítulo 1 - Introdução}

\subsection{Motivação}

Com o intuito de reduzir o pagamento de multas e aumentar a satisfação dos consumidores, as empresas concessionárias de energia elétrica buscam constantemente reduzir os índices relacionados à frequência dos desligamentos: FEC (Frequência Equivalente por Consumidor) e FIC (Frequência Individual por Consumidor), bem como reduzir os índices relacionados ao tempo de desligamento: DEC (Duração Equivalente por Consumidor), DIC (Duração Individual por Consumidor) e DMIC (Duração Máxima Individual por Consumidor).

Exemplificando essa busca pela redução dos indicadores pode-se citar a substituição dos cabos "nus" de média tensão por cabos protegidos ou, em alguns casos, por cabos isolados, instalação de chaves que podem ser operadas remotamente e a inclusão de equipamentos microprocessados que possibilitam o religamento automático das linhas. Além desses exemplos, técnicas computacionais para tratar o problema de restabelecimento de energia vêm sendo desenvolvidas para auxiliar os operadores do sistema no processo de recomposição da parte "sã" da rede elétrica.

A obtenção de forma computacionalmente eficiente de Planos de Restabelecimento de Energia (PREs) adequados, faz-se notavelmente necessária para lidar com faltas permanentes em Sistemas de Distribuição (SDs). Ou seja, depois de o setor (blocos de linhas e barras separados por chaves seccionadoras) em falta ter sido identificado e isolado pela atuação da proteção e do operador do sistema, torna-se necessário a obtenção de um PRE apropriado para restabelecer energia aos setores sem falta que ficaram sem fornecimento de energia.

Para tratar do problema de restabelecimento de energia em SDs reais de grande porte, geralmente as metodologias computacionais acabam desprezando a existência de alguns equipamentos (como chaves e barras de carga, reguladores de tensão e bancos de capacitores), para reduzir a dimensão e a complexidade do problema, tratando chaves com características operacionais distintas da mesma maneira. Através dessas simplificações essas metodologias possibilitam a obtenção de PREs de forma computacionalmente eficiente, mas diminui a confiabilidade desses PREs, sendo muitas vezes inviáveis de implantação prática. 
Face ao exposto, propõe-se o desenvolvimento e implantação em computador de uma metodologia de reconfiguração de redes, para tratamento do problema de restabelecimento de energia em SDs reais de grande porte, que vai considerar a existência de bancos de capacitores, reguladores de tensão e de todas as chaves e barras de carga existentes no sistema, tratando de forma distinta as chaves seccionadoras de acordo com as suas características operacionais.

\subsection{Proposição}

Embora já tenha sido alvo de diversas pesquisas científicas, o problema de restabelecimento de energia em SDs representa ainda um desafio para os pesquisadores e profissionais da área. Uma das maneiras de comprovar essa afirmativa é o fato de muitos centros de operação, de companhias de distribuição de energia, dependerem ainda exclusivamente da experiência dos operadores e da sua familiaridade com o sistema para obtenção de PREs.

Conforme apresentado em (Ferreira, 2010), essas companhias necessitam de ferramentas computacionais de maior agilidade e flexibilidade para auxiliar os seus operadores na difícil tarefa de obtenção de PREs após a ocorrência de faltas permanentes.

As metodologias recentemente desenvolvidas pelo grupo de pesquisa do Laboratório de Análise Computacional em Sistemas Elétricos de Potência (LACO-SEP) da Escola de Engenharia de São Carlos/Universidade de São Paulo (EESC/USP) possibilitam a representação dos SDs reais considerando todas as suas chaves e barras. Em (Marques, 2013) foi desenvolvida uma metodologia que considera e prioriza o atendimento de consumidores especiais e a utilização de chaves controladas remotamente, determinando ainda a sequência de chaveamento necessária para implantação do PRE obtido. Em (Borges, 2013) foi desenvolvida uma metodologia que possibilita a isolação do trecho em falta e a obtenção de PREs tratando o mesmo problema com menor dimensão. Entretanto, essas metodologias não consideram a existência de reguladores de tensão e de bancos de capacitores, nem mesmo as diferentes características operacionais das chaves, como, por exemplo, a possibilidade de abertura com carga e/ou curto circuito. Observe que a característica de operação das chaves é um fator de fundamental importância para implantação prática de PREs, pois existem chaves que não podem ser operadas (abertas ou fechadas) com certas 
quantidades de carga, assim, nestas condições, essas chaves ficam restringidas e dependem da operação de outras chaves do sistema.

O grande diferencial das metodologias desenvolvidas pelo grupo de pesquisa do LACO-SEP em relação às metodologias presentes na literatura é a possibilidade de tratar o problema de restabelecimento em SDs de grande porte considerando todas as barras e chaves da rede.

Esta dissertação propõe a obtenção de uma metodologia para obtenção de PREs para SDs reais de grande porte, que vai considerar objetivos, restrições e aspectos práticos ainda não considerados pelas metodologias já desenvolvidas pelo grupo de pesquisa do LACO-SEP, ou seja, a existência de reguladores de tensão, bancos de capacitores e de diferentes tipos de chaves seccionadoras.

Na prática, o problema de restabelecimento de energia envolve o processo de identificação, localização e isolação (via manobras de chaves seccionadoras) dos setores defeituosos (setores em falta). Entretanto, assim como a maioria dos trabalhos já desenvolvidos na área, a metodologia proposta nesta dissertação considera que o problema de restabelecimento emerge após a identificação e isolação dos setores em falta.

O problema de restabelecimento de energia possui dois objetivos principais (Curcic et al., 1996): (i) minimizar o número de setores "sãos" (setores que não estão em falta mas que foram desligados em função da isolação dos setores em falta) fora de serviço (sem energia); e (ii) minimizar o tempo para implementação do processo de restabelecimento de energia (ou seja, o tempo para implementação do PRE). Tendo em vista que o tempo para implementação do PRE depende da quantidade de chaves a serem manobradas, o problema de restabelecimento de energia consiste em minimizar o número de operações de chaveamentos que resultam em uma configuração com o mínimo de setores "sãos" fora de serviço sem violar as restrições operacionais e de radialidade da rede.

Face ao exposto, o problema de restabelecimento de energia é um problema multi-objetivo, contudo, fazendo uso da Representação Nó-Profundidade (RNP) e dos seus operadores genéticos, propostos em (Delbem et al., 2004), a metodologia proposta tratará o problema minimizando apenas o número de manobras. Isto em razão de a RNP e seus operadores genéticos garantirem a obtenção de configurações radiais capazes de fornecer energia para todas as partes de um SD possíveis de serem conectadas por meio de chaves (Santos et al., 2010); 
Apesar de tratar o problema como sendo mono-objetivo, a metodologia proposta faz uso de uma abordagem multi-objetiva, desenvolvida pelo grupo de pesquisa do LACO-SEP com base no método de Tabelas (Benayon et al., 1971).

A metodologia proposta nesta dissertação baseia-se na metodologia denominada AEMT++, desenvolvida em Marques (2013), que faz uso da RNP e do Algoritmo Evolutivo Multi-objetivo em Tabelas (AEMT) proposto em Santos et al. (2010).

Fazendo uso da RNP e do AEMT, o AEMT++ considera e prioriza o atendimento de consumidores especiais e a utilização de chaves controladas remotamente, determinando ainda a sequência de chaveamento necessária para implantação do PRE obtido. Entretanto, para obtenção da metodologia proposta, devese fazer várias modificações e melhorias no AEMT++ (Marques, 2013), a fim de que a metodologia permita a obtenção de PREs considerando a existência de reguladores de tensão, bancos de capacitores e de diferentes princípios operacionais das chaves seccionadoras.

Vale ressaltar que esta pesquisa faz parte do projeto de P\&D 2866-0272/2012 intitulado "Otimização do Processo de Restabelecimento de Energia em Tempo Real Utilizando Técnicas de Redes Inteligentes (Smart Grids) e Apoio à Decisão dos Operadores dos Centros de Operação da Distribuição", que está em execução (projeto com duração de 36 meses e que teve seu início em junho de 2013). A equipe de trabalho conta com a participação de professores e estudantes de pós-graduação da Universidade de São Paulo (USP) e da Universidade Federal de Goiás (UFG), além de engenheiros da Copel Distribuidora S/A. Esta dissertação é de grande importância para o desenvolvimento desse projeto de $\mathrm{P} \& \mathrm{D}$, pois permitirá a obtenção de uma metodologia para obtenção de PREs considerando a existência de equipamentos presentes em SDs reais.

A metodologia proposta foi aplicada em dois SDs reais de grande porte, o SD da Copel da cidade de Londrina/PR (que não possui regulador de tensão) e o SD da CPFL da cidade de Marília/SP (que possui regulador de tensão), e os resultados obtidos foram bastante satisfatórios, possibilitando a validação prática da metodologia proposta.

\subsection{Estrutura do Trabalho}

Esta dissertação encontra-se dividida em 7 capítulos, onde a Introdução corresponde ao primeiro.

No capítulo 2 define-se, de uma maneira mais formal, o problema de 
restabelecimento de energia, apresentam-se alguns equipamentos elétricos presentes nos SDs e por fim destaca-se uma revisão bibliográfica sobre o tema.

No capítulo 3 apresenta-se a metodologia AEMT++ (Marques, 2013), tomada como base para desenvolvimento da metodologia proposta.

No capítulo 4 encontra-se a metodologia proposta.

No capítulo 5 apresentam-se os resultados da aplicação da metodologia proposta nesta dissertação de mestrado.

As conclusões deste trabalho, bem como as sugestões para trabalhos futuros, estão no capítulo 6.

E, por fim, encontram-se as referências bibliográficas que serviram de base ao desenvolvimento deste trabalho.

Esta dissertação conta ainda com três Apêndices, os quais apresentam respectivamente: uma explicação sobre otimização multi-objetivo, um exemplo do fluxo de carga proposto e resultados para diversas faltas simples no SD de Londrina. 



\section{Capítulo 2 - Restabelecimento de Energia em Sistemas de Distribuição}

\subsection{Introdução}

Neste capítulo apresenta-se, inicialmente, a estrutura de um SD e alguns elementos fundamentais para operação de SDs. Em seguida, o problema de restabelecimento de energia será apresentado detalhadamente, juntamente com a sua formulação baseada na utilização da RNP em conjunto com Algoritmos Evolutivos (AEs), conforme proposto em (Sanches et al., 2014). Por fim, será apresentada uma revisão bibliográfica, destacando alguns dos principais trabalhos sobre o tema.

\subsection{Sistemas de Distribuição}

O SD tem como principal função receber a energia elétrica do sistema de transmissão e entregá-la aos consumidores finais, sendo constituído basicamente por linhas (cabos), equipamentos de proteção, de transformação e de manobra. Os SDs podem ser divididos em duas redes (Kagan et al., 2005):

$\checkmark$ Rede de Distribuição Primária: também conhecido como sistema de média tensão, opera geralmente na faixa de $11,9 \mathrm{kV}$ a $34,5 \mathrm{kV}$. Essa rede atende os consumidores primários (indústrias de médio porte, conjuntos comerciais, grandes hospitais, shopping centers, instalações de iluminação pública, etc.) e os transformadores de distribuição que, por sua vez, suprem os Sistemas de Distribuição Secundária ou de baixa tensão. Esses sistemas são usualmente operados na configuração radial, ou seja, sem a formação de anéis (ou malhas) na rede. Essa característica ajuda em relação ao ajuste da proteção e no gerenciamento do sistema, porém é um problema em relação à confiabilidade e à continuidade do fornecimento de energia elétrica. Por esta razão, esses sistemas são projetados com possibilidade de transferência de blocos de cargas entre circuitos (alimentadores), agrupando vários pontos de carga em blocos (setores), separados por chaves seccionadoras que operam no estado Normalmente Aberto (NA) ou Normalmente Fechado (NF). Assim, através do processo de reconfiguração de redes, ou seja, da abertura e fechamento de chaves 
seccionadoras alterando a topologia elétrica da rede, torna-se possível isolar setores com defeito e realizar a troca de cargas entre alimentadores e subestações (SEs);

$\checkmark$ Rede de Distribuição Secundária: também conhecido como distribuição de baixa tensão, no Brasil geralmente opera com tensões de 220/127V ou 380/220V. Essa rede atende os consumidores de baixa tensão, pequenos comércios e indústrias e, principalmente, os consumidores residenciais. Essa parte do sistema de distribuição usualmente não conta com recursos para o atendimento de contingências;

A Figura 2.1 apresenta um SD identificando a Rede Primária e Secundária:

Figura 2.1: Representação de um sistema de distribuição

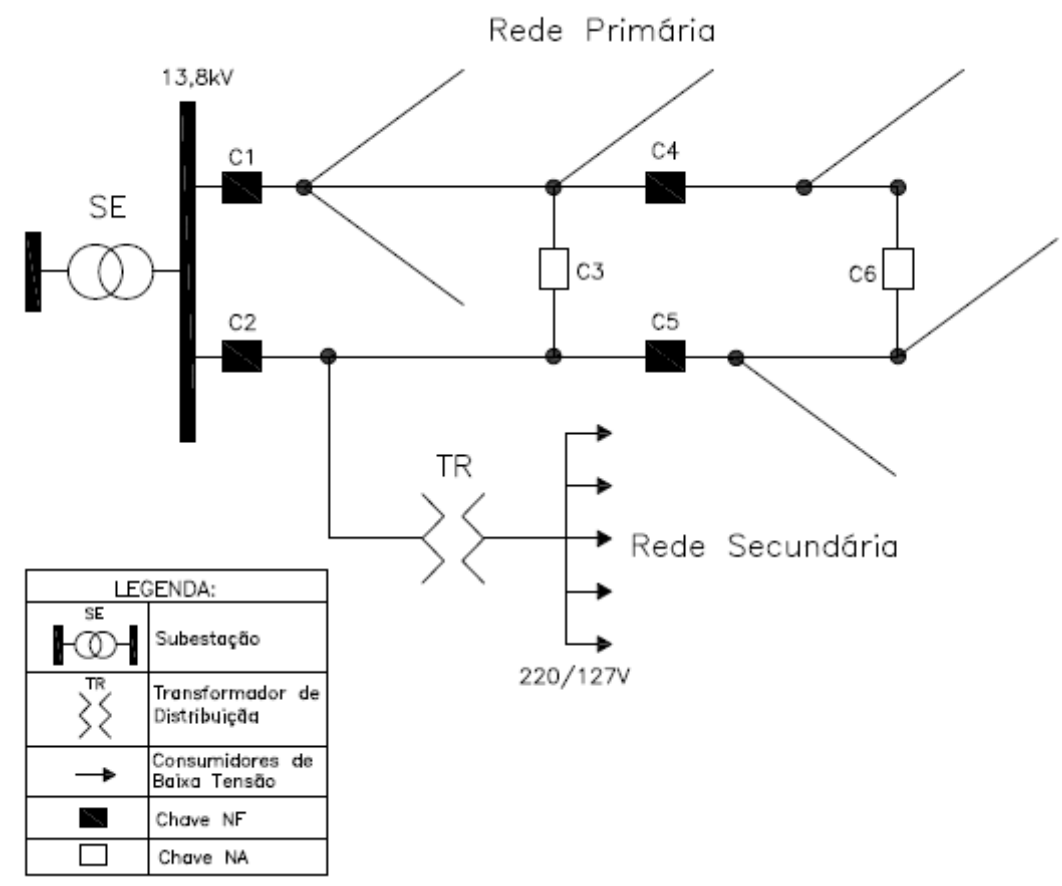

Fonte: Elaborado pelo autor.

O presente trabalho trata do problema de restabelecimento de energia em SDs Radiais de média tensão (Rede de Distribuição Primária), justamente pela particularidade de ser possível alterar a topologia elétrica dessa rede através do processo de reconfiguração de redes. 


\subsection{Elementos fundamentais de um SD}

O presente trabalho basicamente divide-se em duas etapas para atender os objetivos propostos. Na primeira etapa deve-se considerar os diferentes tipos de chaves seccionadoras e suas particularidades no problema de restabelecimento de energia e na segunda etapa considerar os Bancos de Capacitores (BCs) e os Reguladores de Tensão (RTs) no cálculo do Fluxo de Carga (FC) através da estrutura de dados RNP. O cálculo do FC está inserido dentro da metodologia para restabelecimento de energia e o mesmo é essencial para se obter os parâmetros elétricos de cada configuração da rede. Assim, em cada uma destas etapas encontram-se equipamentos elétricos do SD de grande importância para o tratamento do problema.

Em relação ao $\mathrm{FC}$, os elementos fundamentais a serem considerados no SD são as linhas existentes nos alimentadores (fios, cabos), com suas impedâncias, os reguladores de tensão e os bancos de capacitores. Para o problema de restabelecimento de energia, via reconfiguração de redes, além dos equipamentos já citados, incluem-se as chaves seccionadoras, seus estados de operação e suas particularidades operacionais.

A seguir são apresentados os equipamentos citados acima, já que os mesmos apresentam peculiaridades importantes para o desenvolvimento deste trabalho.

\subsubsection{Banco de Capacitores}

As cargas, em sua maioria, apresentam características indutivas, ou seja, demandam potência reativa indutiva do sistema. Os BCs são fontes de potência reativa, ajudando, dessa forma, a compensar a potência reativa demandada pelas cargas e consequentemente corrigem o fator de potência. Além disso, dependendo do local onde são instalados, ajudam também na regulação de tensão do sistema e na redução da corrente que circula pelos condutores à sua montante.

Em consequência a esta redução da corrente pelos condutores à montante, a instalação dos BCs trazem outros benefícios como: a redução do carregamento da subestação, a redução do carregamento da rede e a redução das perdas elétricas totais.

\subsubsection{Regulador de Tensão}

O RT é um autotransformador e sua função principal no SD é controlar a tensão ao longo dos alimentadores, mais especificamente, a tensão das barras à jusante de sua instalação. O RT possui um tap variável em seu enrolamento secundário que 
proporciona o ajuste da relação de transformação do equipamento, regulando a tensão de barras à jusante de sua instalação.

Tipicamente o RT é usado para elevar a tensão em um intervalo de até $10 \%$ e pode ser operado em modo manual, ou então, em modo automático. Na operação automática (mais utilizada), o mecanismo de controle do regulador ajusta automaticamente os taps para assegurar que a tensão monitorada mantenha-se dentro de uma faixa de tensão. Este controle de ajuste do tap é utilizado na implementação do FC deste trabalho, onde o tap é ajustado iterativamente e estimado quando chega-se a convergência do cálculo do FC.

\subsubsection{Chaves Seccionadoras}

Segundo a NBR-6935, chave seccionadora é um dispositivo mecânico que na posição aberta assegura uma distância de isolamento e, em posição fechada, mantém a continuidade do circuito elétrico nas condições especificadas.

Para o problema de restabelecimento de energia, via reconfiguração de redes, as chaves seccionadoras são elementos fundamentais, pois possibilitam a transferência de carga entre os alimentadores, alterando a topologia (ou configuração) da rede como um todo.

Em relação à posição normal de operação das chaves seccionadoras, estas podem ser dispostas em chaves NAs e em chaves NFs. As primeiras apresentam o estado aberto em sua configuração original. Já as últimas apresentam o estado fechado para a mesma configuração.

De maneira sucinta, as chaves seccionadoras podem ser classificadas em: sem carga, com carga e com curto-circuito (Camillo, 2013). As chaves para operação sem carga são denominadas de chaves a seco e, embora denominadas sem carga, estas podem interromper correntes de excitação de transformadores (a vazio), pequenas correntes capacitivas de linhas sem carga ou ainda pequenas correntes de carga. As chaves a seco consideradas neste trabalho são: chaves seccionadoras unipolares (comumente chamadas de chaves faca) e chaves fusíveis laminadas. Estas chaves são todas operadas manualmente.

As chaves para operação com carga são equipamentos com a capacidade de extinguir o arco elétrico gerado pela interrupção abrupta das correntes de carga (predominantemente indutivas). Estes meios de extinção podem ser: óleos isolantes, gás 
SF6 (Hexafluoreto de Enxofre), câmaras à vácuo, entre outros. Neste estudo são consideradas as chaves operáveis sob carga do tipo chave a óleo tripolar, chave a óleo monopolar e chave tripolar com isolação a gás. Vale ressaltar que as chaves com carga podem ser Chaves Controladas Remotamente (CCRs), também conhecidas como chaves automáticas, ou ainda Chaves Controladas Manualmente (CCMs), conhecidas como chaves manuais.

De maneira análoga às chaves com carga, existem, nos SDs, chaves que podem operar sob a condição de curto-circuito e geralmente são alocadas no início dos alimentadores. Estes tipos de chaves são denominadas religadores e também podem ser manuais ou automáticas. Os religadores automáticos operam quando detectam correntes de curto-circuito, desligando e religando automaticamente o alimentador um número predeterminado de vezes (geralmente até três vezes).

Como citado anteriormente, o presente trabalho faz parte de um projeto de pesquisa e desenvolvimento (P\&D) da Copel (Companhia Paranaense de Energia), assim obteve-se informações desta concessionária sobre as particularidades de operação das chaves. As chaves a seco, tanto as seccionadoras unipolares como as fusíveis laminadas, podem ser abertas com até $120 \mathrm{kVA}$ de carga à sua jusante e fechadas com até $720 \mathrm{kVA}$. Já as chaves para operação com carga e com curto podem ser operadas sob qualquer situação de carga.

Neste trabalho serão considerados as chaves seccionadoras apresentadas na Tabela 2.1. Observe que nessa tabela apresentam-se, ainda, as características operacionais de cada tipo de chave.

Tabela 2.1: Tipos e características operacionais das chaves seccionadoras

\begin{tabular}{c|ccccc}
\hline Tipo & Abertura sob Carga & Fechamento sob carga & Curto & CCM & CCR \\
\hline Faca & $120 \mathrm{kVA}$ & $720 \mathrm{kVA}$ & NÃO & SIM & \\
Fusível & $120 \mathrm{kVA}$ & $720 \mathrm{kVA}$ & NÂO & SIM & \\
Óleo & SIM & SIM & NÂO & SIM & \\
Gás & SIM & SIM & NÂO & SIM & \\
Gás Automática & SIM & SIM & NÂO & & SIM \\
Religador & SIM & SIM & SIM & & SIM \\
Religador & SIM & SIM & SIM & SIM & \\
\hline
\end{tabular}

Sintetizando as informações da Tabela 2.1, podemos agrupar os tipos de chaves da seguinte maneira: 
$\checkmark$ CCMs tipo seca: Chave tipo faca e fusível;

$\checkmark$ CCMs com operação sob carga: Chave a óleo e chave a gás;

$\checkmark$ CCMs com operação sob curto: Religador;

$\checkmark$ CCRs com operação sob carga: Gás Automática;

$\checkmark$ CCRs com operação sob curto: Religador;

Assim, com o intuito de facilitar a compreensão, no decorrer do texto será adotada a nomeação dos tipos de chaves como apresentado na Tabela 2.2:

Tabela 2.2: Tipos agrupados e características operacionais das chaves seccionadoras

\begin{tabular}{l|ccccc}
\hline \multicolumn{1}{c|}{ Tipo } & Abertura sob Carga & Fechamento sob carga & Curto & CCM & CCR \\
\hline CCM Seca & $120 \mathrm{kVA}$ & $720 \mathrm{kVA}$ & NÂO & SIM & \\
CCM com carga & SIM & SIM & NÂO & SIM & \\
CCM com curto & SIM & SIM & SIM & SIM & \\
CCR com carga & SIM & SIM & NÂO & & SIM \\
CCR com curto & SIM & SIM & SIM & & SIM \\
\hline
\end{tabular}

É importante lembrar que as metodologias anteriores, tomadas como base para desenvolvimento deste trabalho, não consideravam os limites de carga à jusante das CCMs Secas, que usualmente são a maioria das chaves seccionadoras encontradas em um SD real. Assim, a consideração das características específicas no tratamento do problema de restabelecimento de energia é de suma importância para uma possível implantação prática de metodologia para obtenção de PREs.

\subsection{Apresentação do Problema}

A obtenção de forma computacionalmente eficiente de PREs adequados faz-se notavelmente necessária para lidar com faltas permanentes em SDs. Define-se como falta permanente aquela que não é restabelecida através das tentativas dos religadores automáticos (ver seção 2.3.3), ou seja, necessita-se enviar uma equipe até o local para a correção do problema, e geralmente, esta ação demanda um tempo.

Assim, após a ocorrência de faltas permanentes em um SD, a fim de minimizar o impacto destas, busca-se isolar os setores defeituosos (setores atingidos pela falta) e restabelecer rapidamente o fornecimento de energia aos setores não defeituosos que ficaram sem energia devido ao isolamento dos setores defeituosos à montante (lembrando que os SDs operam usualmente de forma radial). Desta forma, o problema de restabelecimento de energia consiste em determinar uma estratégia de controle, para 
restabelecer a energia às cargas que não estão nos setores defeituosos, mas que ficaram sem energia devido ao isolamento daqueles setores, respeitando os limites operacionais do sistema. Essa estratégia de controle, que recebe o nome de Reconfiguração de Redes, corresponde a uma transição da topologia (ou configuração) do SD, realizada através de manobras de abertura e fechamento de chaves seccionadoras NF e NA, respectivamente, para alimentar o setor não defeituoso por outro caminho ou fonte. Importa destacar que o procedimento de Reconfiguração de Redes em SDs pode ser aplicado também para tratamento de outros problemas em SDs, como: redução de perdas elétricas por efeito Joule, balanceamento de cargas entre alimentadores e melhoria do perfil de tensão.

Com o intuito de exemplificar o processo de restabelecimento de energia, considere a Figura 2.2, que ilustra um SD (rede primária) com: três alimentadores, três SEs, sete chaves NFs, quatro chaves NAs e diversas barras de passagem e de carga, onde nas últimas encontram-se os transformadores de distribuição.

Figura 2.2: Configuração do SD na ocorrência da falta.

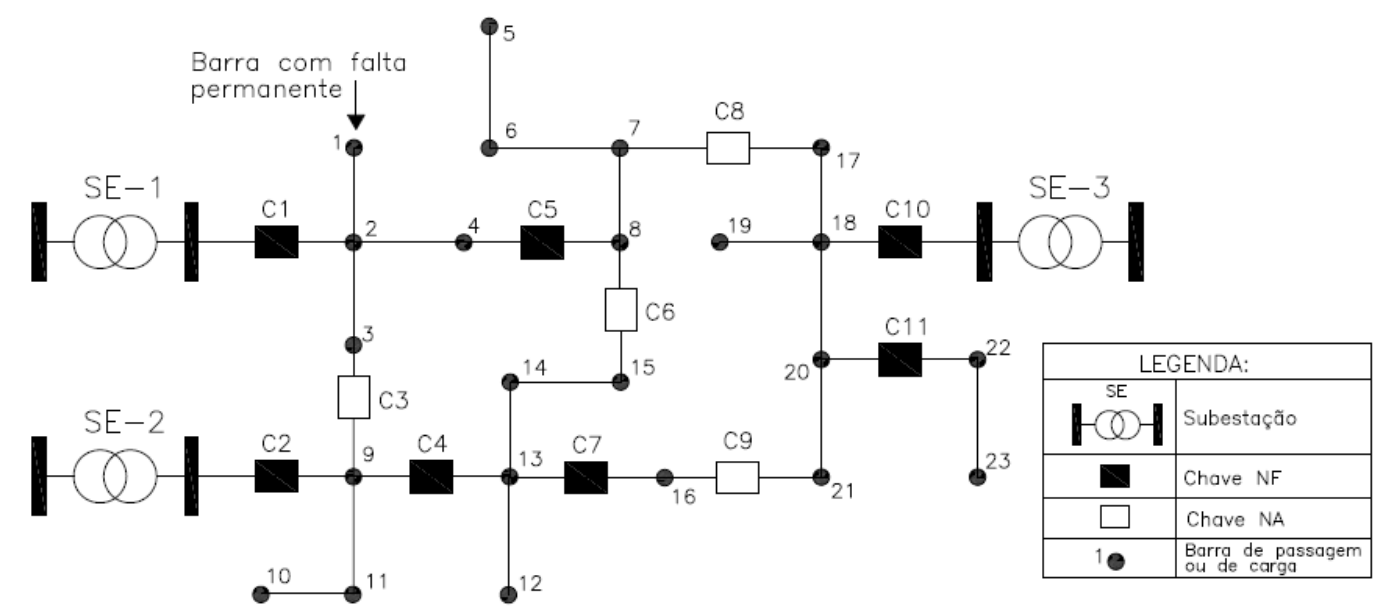

Fonte: Elaborado pelo autor.

Considera-se que haja uma falta permanente na barra 1 (indicada na Figura 2.2), assim por meio da proteção do sistema o alimentador da SE-1 é totalmente desligado e as chaves NFs C1 e C5 são abertas para isolar o setor de carga faltoso, composto pelas barras: 1, 2, 3 e 4. Esta nova configuração é apresentada na Figura 2.3: 
Figura 2.3: Configuração com o setor faltoso isolado.

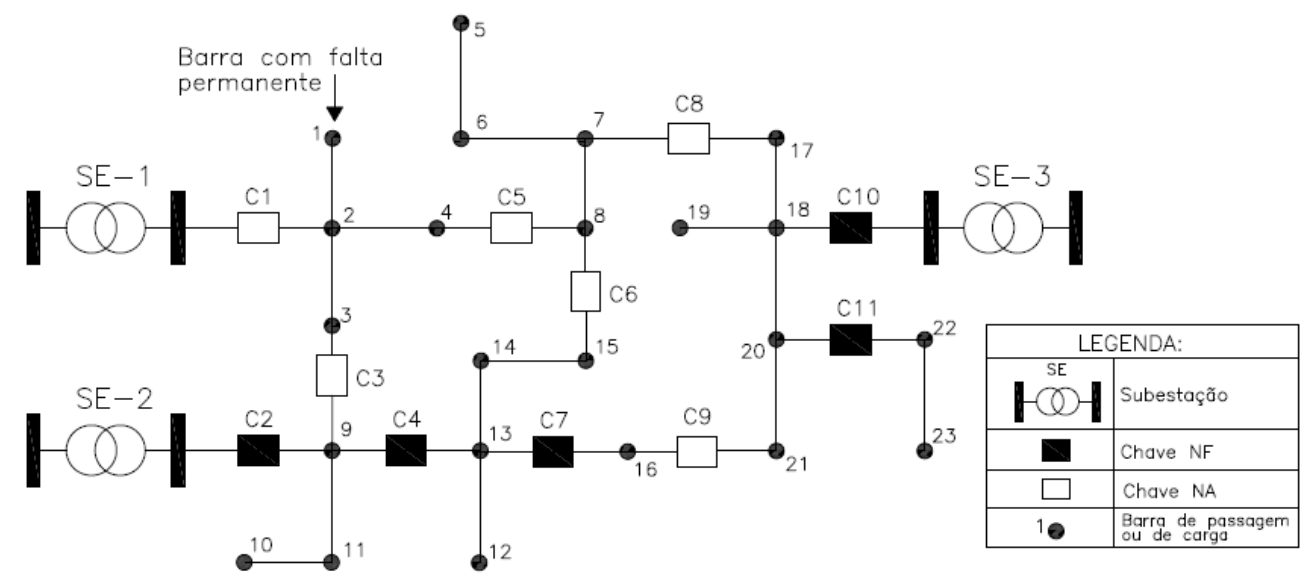

Fonte: Elaborado pelo autor.

Nota-se, ainda na Figura 2.3, que após a isolação da falta o setor composto pelas barras 5, 6, 7 e 8 (barras à jusante da falta) não apresenta problema algum e mesmo assim ficou sem fornecimento de energia elétrica. Esse problema pode ser resolvido, por exemplo, através do fechamento da chave NA C8 (ou C6), restabelecendo energia para aquele setor, conforme ilustrado na Figura 2.4. Entretanto, em função da quantidade de cargas transferidas para o Alimentador da SE-3, do nível de tensão nas barras, do carregamento nas linhas e do carregamento da SE-3 (do transformador dessa SE), é possível que as restrições operacionais não sejam atendidas sendo necessárias manobras adicionais.

Figura 2.4: Configuração com as cargas à jusante do setor faltoso restabelecidas.

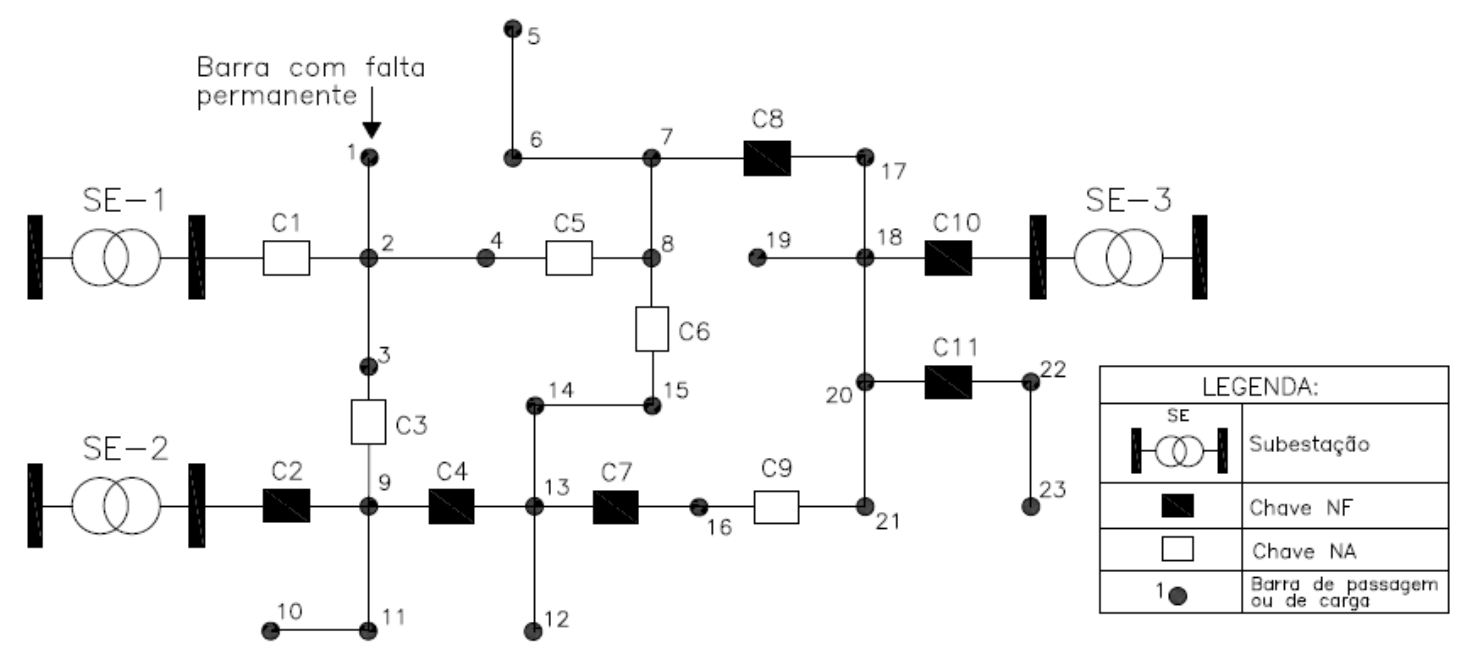

Fonte: Elaborado pelo autor. 
Ante o exposto, um PRE adequado envolve os seguintes objetivos (Sanches et al., 2014):

$\checkmark$ Minimização do número de consumidores fora de serviço (sem energia);

$\checkmark$ Minimização do número de operações de chaveamento.

E deve obedecer às seguintes restrições de operação:

$\checkmark$ Ausência de sobrecarga na rede e nas subestações (transformadores);

$\checkmark$ Manutenção dos níveis de tensão dentro dos intervalos exigidos;

$\checkmark$ Manutenção da radialidade da rede;

$\checkmark$ Determinação em tempo real.

Assim, o problema de restabelecimento de energia pode ser classificado como um problema de otimização combinatória multi-objetivo (ver Apêndice A) com múltiplas restrições, sendo que alguns dos objetivos são conflitantes entre si.

\subsection{Modelagem do Problema através da Utilização de Algoritmos Evolutivos e da Representação Nó-Profundidade}

Tendo em vista que a metodologia proposta baseia-se em AEs e da RNP, nesta seção será apresentada uma formulação geral do problema de restabelecimento de energia e, em seguida, uma formulação baseada na utilização de AEs e RNP. Porém, inicialmente, apresentar-se-ão algumas informações básicas necessárias para apresentar essas formulações.

\subsubsection{Algoritmos Evolutivos - Aspectos Básicos}

AEs são métodos de otimização inspirados nos princípios da Seleção Natural (Teoria de Darwin) que, geralmente, utilizam técnicas e conceitos da genética.

O princípio básico dos AEs é o seguinte: dada uma população inicial de indivíduos (isto é, um conjunto de soluções candidatas), pressões do ambiente desencadeiam um processo de seleção natural (ou seja, um processo que privilegia as melhores soluções candidatas até então encontradas), causando um incremento na adequação dos indivíduos (soluções candidatas).

Dessa forma, dada uma função a ser otimizada (seja maximizada ou minimizada), gera-se aleatoriamente um conjunto de soluções candidatas (uma 
população), isto é, elementos pertencentes ao domínio da função. Em seguida, aplicando a função a ser otimizada, verifica-se a qualidade das soluções candidatas geradas, atribuindo-lhes um valor que mede sua adequação ao problema, chamada fitness ou adequação.

Com base na fitness, algumas das melhores soluções candidatas são selecionadas para darem origem a um novo conjunto de soluções candidatas (uma nova geração), pela aplicação de operadores genéticos (Exemplos: recombinação e/ou mutação).

A recombinação é um operador genético aplicado em duas ou mais soluções candidatas (chamadas pais) resultando em uma ou mais novas soluções (chamadas descendentes ou filhos). A mutação geralmente é aplicada em uma solução candidata a fim de gerar outra. Ao final desse processo, as novas soluções candidatas (descendentes) competem com as soluções da geração anterior, com base na fitness, para assumir um lugar na nova população. Esse processo é iterativo até que se encontre uma solução candidata que seja suficientemente qualificada ou até que um critério de parada seja atendido.

\subsubsection{Algoritmos Evolutivos no Contexto de Restabelecimento de Energia}

No contexto do problema em pauta, os indivíduos (ou soluções candidatas) representam configurações do SD. Dessa forma, através da abertura e fechamento de chaves seccionadoras obtém-se uma população inicial de configurações. Em seguida, realiza-se uma análise, de cada configuração gerada, para verificar a sua factibilidade e adequação ao problema de restabelecimento de energia (a fitness da solução). Para ser factível, uma solução deve atender às restrições operacionais do problema (conforme apresentado na seção 2.4.), como, por exemplo, a característica radial da rede e os limites operacionais dos equipamentos.

Define-se a adequação (ou fitness) de cada configuração, em função dos objetivos a serem minimizados ou maximizados. De acordo com o problema de restabelecimento apresentado na seção 2.4 , seria o número de consumidores sem energia e o número de manobras necessárias para implantação de cada configuração gerada. As melhores configurações (ou soluções candidatas) são então selecionadas para dar origem a um novo conjunto de configurações, através da aplicação de operadores genéticos. Tais operadores realizam basicamente alterações nos estados das chaves 
seccionadoras, gerando novas configurações a partir das configurações geradas anteriormente.

Para avaliar a fitness de cada configuração gerada por um AE, é necessário a execução de um fluxo de carga (FC) e de metodologias eficientes para contagem do número de manobras necessárias para implantação de cada configuração. Dessa forma, haja vista a necessidade de avaliação de uma grande quantidade de configurações, tornasse necessário a utilização de estruturas de dados eficientes, para representação da topologia elétrica dos SDs, que possibilitem o desenvolvimento e/ou aplicação de operadores genéticos gerando exclusivamente configurações radiais, bem como de eficientes algoritmos para o cálculo do FC.

Por se tratar de um problema com natureza multi-objetiva, algumas das metodologias desenvolvidas utilizam AEs mono-objetivo, que convertem um problema de otimização multi-objetivo em um problema mono-objetivo. Outras fazem uso de AEs Multi-Objetivo (AEMOs), que permitem o tratamento de diversos objetivos simultaneamente.

\subsubsection{Representação do Sistema de Distribuição}

Para problemas envolvendo Reconfiguração de Redes, o SD pode ser visto como um conjunto de setores (cada setor é composto pela junção de barras e linhas) interconectados por chaves. Assim, para problemas de Restabelecimento de Energia o SD é geralmente representado por grafos, isto é, um conjunto de nós conectados por arestas.

A Figura 2.5(a) apresenta um SD com três alimentadores, igual ao da Figura 2.2. A Figura 2.5(b) apresenta o mesmo SD representado por grafos, onde os nós representam os setores e as arestas representam as chaves seccionadoras. As arestas tracejadas representam chaves seccionadoras NAs e as arestas preenchidas representam as chaves NFs. 
Figura 2.5: SD e sua representação por grafo.

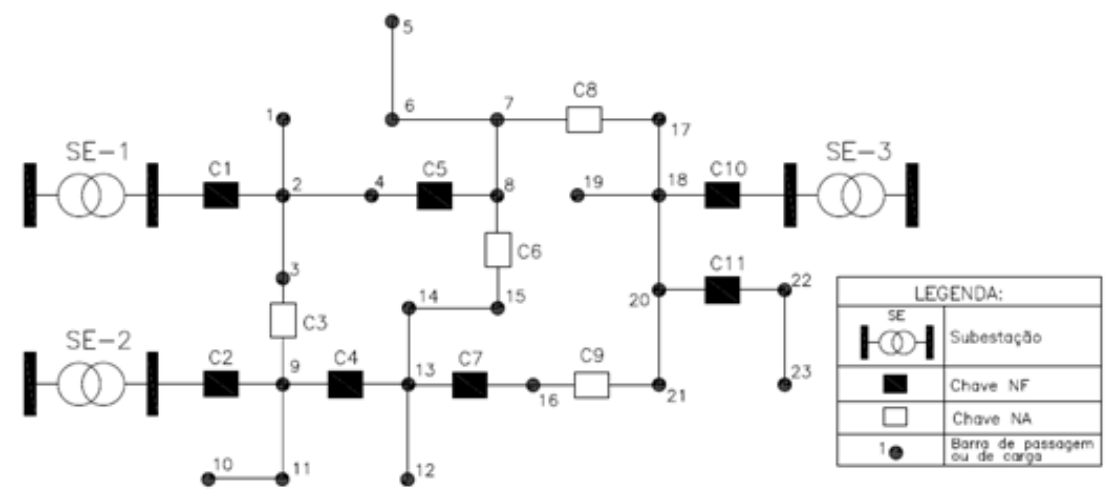

(a) Exemplo de um SD com três alimentadores.

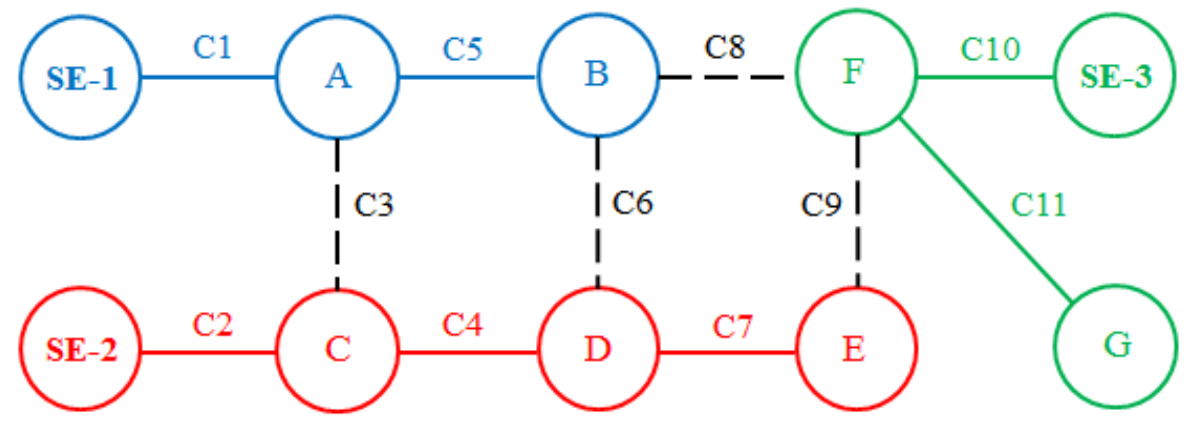

(b) Representação do SD por um grafo.

Na Figura 2.5(b) os três alimentadores, do SD exemplificado na Figura 2.5(a), são representados por três árvores de grafos, formados pelas linhas preenchidas e representados por cores diferentes na Figura 2.5(b). Uma árvore de grafo é definida como um subgrafo conexo (existe unicamente um caminho entre dois nós quaisquer), acíclico (não possui ciclos ou malhas) e com $n-1$ arestas (sendo $n$ o número de nós). Os nós $S E-1, S E-2$ e $S E$-3 são os nós raízes das árvores 1, 2 e 3, e correspondem às subestações 1, 2 e 3 respectivamente. $\mathrm{O}$ conjunto das três árvores de grafo formam uma floresta, que representa uma configuração radial do SD.

\subsubsection{Representação Nó-Profundidade}

A RNP (Delbem et al., 2004) é uma representação de árvores baseada nos conceitos de nó e profundidade e consiste basicamente de uma lista contendo os nós da árvore e suas respectivas profundidades, formando pares do tipo $(n x ; p x)$, onde $n x$ é o nó da árvore e $p x$ a profundidade desse nó. A ordem em que os pares $(n x ; p x)$ são dispostos é importante (Mansour, 2009). Uma busca em profundidade em uma árvore de grafo 
pode produzir uma ordenação adequada inserindo um par $(n x ; p x)$ na lista quando o nó $n x$ é visitado pela busca. Este processamento pode ser executado off-line. A Figura 2.6 representa uma árvore de grafo e a correspondente RNP, assumindo o nó 1 como o nó raiz da árvore.

Figura 2.6: Representação Nó-Profundidade (RNP)

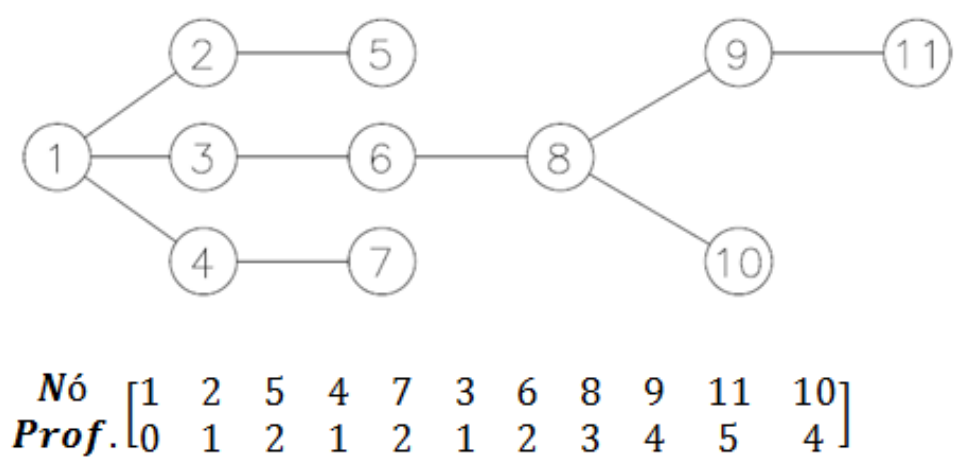

Fonte: Elaborado pelo autor.

Em analogia a um SD, cada RNP representa um alimentador (árvore de grafo) e o conjunto de RNPs representa uma configuração do SD completo (floresta).

Para facilitar a manipulação de uma floresta armazenada em RNPs, com baixo custo computacional, foram criados dois operadores: o PAO (do inglês, Preserve Ancestor Operator) e o CAO (do inglês, Change Ancestor Operator) (Delbem et al., 2004). Estes operadores produzem novas florestas geradoras $G$ quando aplicados a uma floresta $G^{x}$ qualquer, armazenada em RNPs. Assim, ambos transferem uma subárvore de uma árvore $T_{d e}$ (árvore origem) para uma árvore $T_{\text {para }}$ (árvore destino). Entretanto, no operador PAO a raiz da subárvore podada será a raiz da mesma subárvore na árvore $T_{\text {para }}$, enquanto que no operador $\mathrm{CAO}$ um novo nó, diferente da raiz da subárvore podada, é escolhido para ser a nova raiz da subárvore transferida para $T_{\text {para }}$.

O operador PAO requer a definição prévia de dois nós: o nó de poda $p$, que representa a raiz da subárvore que será podada, e o nó adjacente $a$, que indica onde a subárvore podada será inserida na árvore $T_{\text {para }}$. Já o operador CAO requer, além desses dois nós, um terceiro nó chamado de nó $r$, que será a nova raiz da subárvore que será transferida. 


\subsubsection{Formulação Matemática}

Apresenta-se, a seguir, a formulação matemática para tratar computacionalmente o problema de restabelecimento de energia. Esta seção foi desenvolvida com base nos seguintes trabalhos: (Sanches et. al., 2014), (Marques, 2013) e (Marques et al., 2014).

Como descrito na seção 2.4, o problema de restabelecimento de energia consiste em minimizar o número de operações de chaveamentos que resultam em uma configuração com o mínimo de setores "sãos" fora de serviço sem violar as restrições operacionais e de radialidade da rede. O problema pode ser modelado como apresentado na Equação 2.1:

$$
\begin{aligned}
& \text { Min. }\left[\phi(G), \psi_{C C M}\left(G, G^{0}\right) \text { e } \psi_{C C R}\left(G, G^{0}\right)\right] \\
& \text { s. } a: H(G)=0 \\
& X(G) \leq 1 \\
& B(G) \leq 1 \\
& V(G) \leq 1 \\
& G \text { ser uma floresta, }
\end{aligned}
$$

onde $G$ é uma floresta de grafo representando uma configuração radial do SD; $\phi(G)$ é o número de consumidores sem falta fora de serviço em $G ; \psi_{C C M}\left(G, G^{0}\right)$ é o número de operações de manobra em CCMs necessárias para se obter $G$ a partir da configuração $G^{0}$, após a localização e isolação da falta; $\psi_{C C R}\left(G, G^{0}\right)$ é o número de operações de manobra em CCRs necessárias para se obter $G$ a partir da configuração $G^{0} ; H(G)=0$ são as restrições de igualdade representando as equações de fluxo de carga; $X(G)$ é o máximo carregamento da rede em $G$, dado por $X(G)=M A X\left(x_{j} / \overline{x_{j}}\right)$, sendo $\overline{x_{j}}$ um limitante superior de corrente para cada magnitude de corrente $x_{j}$ em uma linha $j ; B(G)$ é o máximo carregamento de subestação em $G$, dado por $B(G)=M A X\left(b_{s} / \overline{b_{s}}\right)$, sendo $\overline{b_{s}}$ um limitante superior para cada magnitude de injeção de corrente $b_{s}$ provida por uma subestação $s ; V(G)$ é a máxima queda de tensão em $G$, dada por $V(G)=M A X\left(\mid v_{s}-\right.$ $v_{k} \mid / \delta$ ), sendo $v_{s}$ a magnitude de tensão na barra de uma subestação $s, v_{k}$ é a magnitude de tensão em uma barra $k$ da rede e $\delta$ é a máxima queda de tensão admissível (neste trabalho $10 \%$, isto é, $\delta=0,1)$.

As restrições de igualdade, que correspondem às equações de fluxo de carga, podem ser representadas como um sistema do tipo $A x=b$, sendo $A$ a matriz incidência de $G ; x$ o vetor de correntes de linha na configuração $G$; e $b$ um vetor contendo as correntes complexas nas barras de carga $\left(b_{i}<0\right)$, de passagem $\left(b_{i}=0\right)$ e as injeções de corrente nas barras das subestações $\left(b_{i}>0\right)$. 
$\mathrm{O}$ vetor das tensões complexas nodais $v$ é dado por $Y v=b$, onde $Y$ é a matriz de admitância nodal da rede que pode ser calculada por meio da expressão $Y=A Y_{x} A^{t}$, sendo $Y_{x}$ a matriz admitância diagonal.

A partir da formulação do problema de Restabelecimento de Energia apresentada na Equação 2.1, pode-se definir:

$\checkmark$ Configuração Factível: uma configuração radial do SD que re-conecta todos os setores "sãos" que foram desconectados em função da abertura de chaves para isolação dos setores em falta;

$\checkmark$ Solução Factível: uma configuração factível que satisfaz todas as restrições operacionais do problema $(X(G), B(G)$ e $V(G))$;

$\checkmark$ Solução Ótima do problema de Restabelecimento de Energia: a solução factível que requer o menor número de chaveamentos para ser implementada. Ou seja, é a configuração radial do SD que re-conecta todos os setores "sãos" que ficaram sem fornecimento, satisfazendo todas as restrições operacionais $(X(G), B(G)$ e $V(G))$ e que requer o menor número de chaveamentos para ser implementada.

A formulação matemática pode ainda ser reescrita por meio das seguintes considerações:

i) utilização da RNP e de seus operadores (Mansour et al., 2010; Delbem et al., 2004) que são capazes de armazenar e manipular de forma eficiente florestas de grafo e garantir que todas as modificações produzirão também uma floresta, ou seja, uma configuração factível;

ii) $\phi(G)=0$, uma vez que a RNP possui dois operadores (PAO e CAO) que, por meio de poda e transferência de subárvores, geram exclusivamente florestas capazes de fornecer energia para todas as partes de um SD possíveis de serem conectadas por meio de chaves (Santos et al., 2010);

iii) a RNP organiza naturalmente todas as barras de cada configuração gerada $G$ segundo uma relação conhecida como "Modelo Pai-Filho" (MPF) (Kagan et al., 2005), necessária à execução de FCs de varredura direta/inversa. Com isso evita-se o uso de um algoritmo de busca para obter tal modelo. Assim, o fluxo de carga pelo MPF com RNP é mais eficiente que fluxos de carga convencionais para SDs (Santos et al., 2008a). Além disso, o uso do MPF garante que as restrições de igualdade $(H(F)=0)$ em (2.1) sejam satisfeitas; 
iv) tratar as restrições relacionadas à $X(G), B(G)$ e $V(G)$ por meio da minimização do valor assumido por estes parâmetros.

Assim, a formulação matemática para o problema de restabelecimento de energia apresentada na Equação 2.1 pode ser simplificada e reescrita conforme mostrado na Equação 2.2.

$$
\begin{aligned}
& \text { Min. } \psi_{C C M}\left(G, G^{0}\right), \psi_{C C R}\left(G, G^{0}\right), X(G), B(G) \text { e } V(G) \\
& \text { s. a: Utilizar MPF com RNP para cálculo do Fluxo de Carga } \\
& \text { G ser uma floresta gerada pela RNP. }
\end{aligned}
$$

\subsection{Revisão Bibliográfica}

Esta seção revisa alguns dos principais trabalhos tratando do problema de restabelecimento de energia via reconfiguração de redes. Entretanto, vale destacar que, como citado no item 2.4, reconfiguração de redes pode ser utilizada, também, para tratamento de outros problemas no contexto da operação de SDs, dentre os quais se destacam: redução de perdas nas linhas (Baran e Wu, 1989; Mirhoseini et al., 2014; Oliveira et al., 2014); balanceamento de carga entre alimentadores (Kashem et al., 1999; Lin, 2003); e melhoria do perfil de tensão (Kashem et al., 2000; Chakravorty et al., 2009).

O trabalho de Aoki et. al. (1989) trata do problema de restabelecimento de energia através do método do gradiente dual efetivo. O restabelecimento ocorre transferindo as cargas à jusante da falta permanente que estão "sãs" e sem fornecimento de energia para alimentadores adjacentes. Posteriormente é analisado se os alimentadores adjacentes violaram as restrições de radialidade, queda de tensão, limite de fluxo nas linhas e de carregamento dos alimentadores. Se essas restrições não forem atendidas, cargas extras são transferidas para outros alimentadores, buscando eliminar as violações de restrições. A função objetivo busca restaurar o maior número de cargas fora de serviço. Os resultados demonstraram a eficiência da técnica em evitar chaveamentos desnecessários.

Outra abordagem foi apresentada em (Fukuyama; Chiang, 1995) que utiliza um algoritmo genético paralelo para tratar do problema de restabelecimento de energia. As restrições operacionais consideradas foram: queda de tensão, limite de fluxo nas linhas e limite de capacidade dos alimentadores. Essas restrições foram tratadas por fatores de penalidade na função de avaliação dos indivíduos. Em situações em que um indivíduo 
gerado não era radial, um operador de reparação foi proposto. Os resultados demonstraram eficiência no tempo computacional exigido em relação ao tamanho do SD.

Em Curcic et al. (1996) é apresentado um estudo detalhado sobre o problema de restabelecimento de energia em sistemas de distribuição. Nesse estudo realiza-se uma revisão bibliográfica abrangente sobre os principais trabalhos da época, bem como são apresentadas diretrizes para trabalhos futuros, como: a necessidade de considerar consumidores especiais, necessidade de priorizar a operação de CCRs, os tipos de falta que podem ser tratados, os níveis de tensão do problema, as restrições de carga, a necessidade de uma boa interface gráfica e da determinação da sequência de chaveamento.

Nos últimos anos as pesquisas em restabelecimento de energia continuam em desenvolvimento, devido principalmente ao aumento da velocidade de processamento dos computadores e do advento das chamadas Redes Inteligentes (Smart Grids).

O trabalho de (Kumar et al., 2008) propôs uma abordagem baseada no Algoritmo Evolutivo Multi-Objetivo (AEMO) denominado "Non-dominated Sorting Genetic Algorithm-II" (NSGA-II) (Deb et. al., 2002). O método possui a característica principal de manter a natureza multi-objetiva do problema sem a necessidade de fatores de penalidade. Também foram considerados aspectos práticos do problema, como: a presença de consumidores especiais, dando prioridade para seu restabelecimento e a priorização de chaves seccionadoras controladas remotamente. No trabalho foram utilizadas três técnicas diferentes (NSGA-II avançado, NSGA-II básico e um AG tradicional) em quatro SDs de pequeno porte. Os resultados mostraram que o NSGA-II avançado conseguiu obter os mesmos resultados encontrados pelas outras técnicas com um tempo de execução menor.

Para Moazami et al. (2013), o maior desafio do problema de restabelecimento de energia é reduzir o esforço computacional, buscando todas as respostas possíveis em tempo real. Em seu trabalho é proposta uma nova abordagem para tratar o problema utilizando um algoritmo genético híbrido com o objetivo de reduzir o espaço de busca. A eficácia do método é demonstrada em um sistema teste de 33 barras. A comparação com outra metodologia apresenta uma redução no número de iterações.

Em Romero et al. (2015) foi apresentado um modelo matemático clássico para solucionar o problema de restabelecimento de energia. A ideia principal que norteia esta metodologia é modificar a formulação usual do problema (modelado tradicionalmente 
como um problema de programação não linear inteira mista) para torná-lo um problema de programação cônica de segunda ordem inteira mista, que pode ser resolvido usando softwares comerciais eficientes baseados em técnicas de otimização da família branch and bound (Land \& Doig, 1960). Limitando o espaço de busca a partir de algumas restrições técnicas do problema (evitando manobras em alimentadores com consumidores especiais), os resultados obtidos são bem interessantes. Essa formulação não considera ainda algumas características práticas do problema e não foi validada para SDs reais de grande porte, mas representa um novo caminho a ser explorado para desenvolvimento de técnicas para solução exata do problema de restabelecimento de energia em SDs.

Com o intuito de tratar o problema de restabelecimento de energia da mesma forma que os trabalhos apresentados anteriormente, o grupo de pesquisa do Laboratório de Análise Computacional em Sistemas Elétricos de Potência (LACO-SEP) da USP desenvolveu diversos trabalhos na área com o objetivo de aprimorar as soluções dos PREs e considerar cada vez mais as particularidades de um SD real de grande porte.

Em Delbem et. al. (2004) foi desenvolvida uma estrutura de dados baseada nos conceitos de caminho e profundidade de um nó em uma árvore de grafo, denominada Representação Nó-Profundidade (RNP). Com essa codificação foram desenvolvidos operadores de reprodução que proporcionaram grandes melhoras no desempenho de AEs para tratar de problemas de projeto de redes.

A metodologia utilizando a RNP no problema de restabelecimento de energia foi apresentada inicialmente em Santos, Delbem, e Bretas (2008b). Nesta abordagem foi utilizada a RNP com um AE convencional mono-objetivo, denominada de AENP. Já Mansour et. al. (2009) fez uso da RNP com o NSGA-II (Deb et. al., 2002), um AEMO, denominado de NSNP. As duas metodologias foram comparadas em Mansour et. al. (2010), com o intuito de determinar qual tem melhor desempenho com essa nova estrutura de dados. Foram realizadas simulações no SD real da cidade de São Carlos/SP e os resultados apresentaram que ambas as metodologias restabeleceram todos os consumidores interrompidos, entretanto o NSNP resolveu o problema com um número menor de chaveamentos.

A metodologia proposta em Santos et. al. (2010), denominada AEMT, também faz uso de um AEMO, com a codificação RNP, que trabalha em paralelo com várias subpopulações armazenadas em tabelas (Benayon et. al., 1971). Assim, os melhores indivíduos para cada característica do problema (número de manobras, perdas resistivas, 
queda de tensão, carregamento da rede e carregamento da subestação), são armazenados em suas respectivas subpopulações.

Em Sanches et al. (2012) foi desenvolvida uma metodologia que também faz uso da RNP e que combinou os melhores aspectos das metodologias de Mansour et al. (2009) e Santos et al. (2010). Assim como em Santos et al. (2010), a metodologia de Sanches et al. (2012) também trabalha em paralelo com várias subpopulações em tabelas. Entretanto, este trabalho utiliza-se de tabelas adicionais, definidas como tabelas de subpopulações não dominadas, que utilizam o conceito de dominância de Pareto para comparar duas soluções factíveis, da mesma maneira que em Mansour et al. (2009).

Mais recentemente, Marques (2013) propôs uma metodologia que foi nomeada AEMT++, que também faz uso da RNP e do AEMT (Santos et al., 2010), onde sua abordagem considera e prioriza o restabelecimento de consumidores especiais, prioriza a utilização de chaves controladas remotamente e ainda determina a sequência de chaveamento necessária para a implantação do PRE obtido.

Em Sanches et al. (2014) foi desenvolvida uma metodologia denominada AEMT-H que combina as melhores características do NSNP, do AEMT e de uma nova heurística. Esta nova heurística basicamente foca a aplicação dos operadores da RNP (PAO e CAO) nas regiões do SD que demandam reconfigurações (alimentadores com altas taxas de queda de tensão e de carregamento). Foram realizadas simulações computacionais em pequenos SDs e também em SDs de grande porte (SD real da cidade de São Carlos), com única falta e múltiplas faltas, notou-se que a metodologia proposta (AEMT-H) apresenta resultados satisfatórios comparado com outras abordagens, principalmente com relação à minimização do número de chaveamento e a capacidade de encontrar soluções factíveis com o aumento da escala do SD.

\subsection{Considerações finais}

A busca por técnicas alternativas para solução do problema de restabelecimento de energia é motivada em função das dificuldades encontradas pelas abordagens tradicionais. Isto acontece em razão do problema apresentar funções objetivo difíceis de serem expressas de uma forma precisa e que são, em geral, não suaves, pois possuem muitas não linearidades e descontinuidades (Delbem, 2002). Além disso, o elevado número de variáveis do problema pode levar a uma explosão combinatória, dificultando ainda mais a utilização de programação matemática para SDs de grande porte. 
Assim, devido à natureza multi-objetiva do problema de restabelecimento de energia e a necessidade de se obter a solução em tempo real, conforme apresentado na revisão bibliográfica diversas metodologias foram desenvolvidas baseadas em: busca heurística, sistemas especialistas e meta-heurísticas. Dentre as meta-heurísticas já utilizadas destacam-se os AEs, isto em razão de serem flexíveis, de fácil implementação computacional e possuírem um suporte relevante da literatura (Deb, 2001; Mendoza et al., 2006).

O grupo de pesquisa do LACO-SEP desenvolveu diversos trabalhos para tratar o problema. A metodologia proposta utilizará como base um dos mais recentes trabalhos desse grupo de pesquisa, o AEMT++, que será apresentado detalhadamente no próximo capítulo. 


\section{Capítulo 3 - Metodologia Base: AEMT++}

\subsection{Introdução}

Como descrito anteriormente, este trabalho tem como metodologia base o AEMT++ apresentado em Marques (2013), que trata o problema de restabelecimento de energia através da utilização da RNP e de um Algoritmo Evolutivo Multi-objetivo em Tabelas (AEMT). A metodologia base considera a presença e a priorização de consumidores especiais e de CCRs, determinando, ainda, uma solução final para o problema e a sequência de chaveamento necessária para a implantação do PRE obtido.

\subsection{Características Gerais}

A metodologia AEMT++ foi desenvolvida com o intuito de determinar PREs, em SDs de grande porte, considerando a presença e a priorização de consumidores especiais e de CCRs, determinando ainda uma solução final para o problema e a sequência de chaveamento necessária para a implantação do PRE obtido.

Para a representação computacional dos SDs o AEMT++ faz uso da RNP (Mansour et al. 2010; Delbem et al., 2004) e, para avaliação de cada indivíduo (uma configuração radial da rede), o AEMT++ utiliza-se de um algoritmo de FC de varredura direta/inversa do tipo soma de correntes (Shirmohammadi et al., 1988) com RNP (Santos et al., 2010).

Baseado no método de tabelas (Benayoun et al., 1971) e no AEMT (Santos et al., 2010), o AEMT++ possui 13 tabelas de subpopulações que armazenam os indivíduos que possuem os menores valores para: carregamento da rede - $X(G)$, carregamento da subestação $-B(G)$, máxima queda de tensão - $V(G)$, número de manobras em CCMs - $\psi_{C C M}\left(G, G^{0}\right)$, número de manobras em CCRs - $\psi_{C C R}\left(G, G^{0}\right)$, perdas ôhmicas $\gamma(G)$ e função agregação - $f(G)$.

Vale ressaltar que apesar da minimização das perdas resistivas não ser um dos objetivos do problema de restabelecimento de energia, esta tabela de subpopulação foi incluída com o intuito de melhorar a diversidade entre os indivíduos gerados, característica que ajuda o algoritmo evolutivo a sair de ótimos locais e explorar melhor o espaço de busca. 
O valor da função agregação $f(G)$ é calculado para cada indivíduo $G$ segundo a Equação 3.1, que reuni os valores de $X(G), B(G), V(G)$ e das perdas resistivas $\gamma(G)$ :

$$
f(G)=w_{X} X(G)+w_{B} B(G)+w_{V} V(G)+\gamma(G)
$$

onde $w_{X}, w_{B}, w_{V}$ são pesos definidos em função da adequação de $G$ às restrições operacionais relacionados aos valores de $X(G), B(G), V(G)$, da seguinte forma:

$$
w_{I}=\left\{\begin{array}{l}
100, \text { se } I(G)>1, \text { para } I=X, B \text { eV } \\
0, \text { caso contrário. }
\end{array}\right.
$$

As primeiras 5 tabelas de subpopulações são as mesmas apresentadas em (Santos et al., 2010):

$\checkmark \quad P_{1}$ - soluções com os menores valores de função agregação, $f(G)$ (Equação 3.1);

$\checkmark \quad P_{2}$-soluções com os menores valores de perdas resistivas, $\gamma(G)$;

$\checkmark \quad P_{3}$-soluções com os menores valores de carregamento da rede, $X(G)$;

$\checkmark \quad P_{4}$ - soluções com os menores valores de carregamento de subestação, $B(G)$;

$\checkmark \quad P_{5}$-soluções com os menores valores de queda máxima de tensão, $V(G)$.

Em uma situação de contingência, após a localização e a isolação do setor sob falta, o AEMT++ inicia a sua execução pela obtenção de um primeiro indivíduo, isto é, de uma primeira configuração da rede na qual todos os setores sãos e sem fornecimento são reconectados a uma parte saudável do SD.

Após a geração do primeiro indivíduo gera-se a população inicial a fim de preencher todas as tabelas de subpopulação. Para isso utiliza-se exclusivamente o operador PAO da RNP, no primeiro indivíduo ou em um dos indivíduos gerados a partir dele, até que todas as subpopulações estejam completas.

Depois da geração da população inicial, a geração de novos indivíduos é realizada por meio da aplicação dos dois operadores genéticos da RNP (Santos et al., 2010). A seleção e a reprodução ocorrem de acordo com os seguintes passos:

i) escolha randômica de uma tabela de subpopulação $P *$;

ii) escolha randômica de um indivíduo $G^{*}$ armazenado em $P$; 
iii) aplicação de um dos operadores genéticos da RNP em $G^{*}$ para a geração do novo indivíduo $\left(G^{\text {novo }}\right)$.

Posteriormente, $G^{\text {novo }}$ é avaliado por meio de um FC de varredura direta/inversa com RNP, como explicado anteriormente. Em seguida, para cada uma das 13 tabelas, este novo indivíduo será inserido na tabela se esta não estiver cheia ou se $G^{\text {novo }}$ for melhor que o pior indivíduo já armazenado na mesma, substituindo-o. Esta competição garante a evolução da aptidão destas subpopulações. Assim, este procedimento que envolve seleção, reprodução e competição, é realizado até que seja atingido um número máximo de indivíduos gerados.

A fim de priorizar a operação de CCRs a estratégia utilizada foi de minimizar o número total de manobras em chaves e o número de manobras em CCMs. Assim, dados dois indivíduos $G_{i}$ e $G_{j}$ dir-se-á que $G_{i}$ é melhor que $G_{j}$ se $G_{i}$ exigir um número de manobras em CCMs menor que $G_{j}$. Caso ambos tenham o mesmo número de manobras em CCMs, então, dir-se-á que o melhor é aquele que exigir o menor número de manobras em CCRs. Assim, minimiza-se, simultânea e respectivamente, o número de manobras em CCM e o número total de manobras em chaves.

Dentre as tabelas de subpopulação existentes no AEMT++, são as tabelas $P_{6}, P_{7}$, $P_{8}, P_{9}, P_{10}$ e $P_{11}$ que possuem a função de priorizar a operação de CCRs. Deste modo, em $P_{i}$, com $6 \leq i \leq 10$, são armazenados subpopulações formadas exclusivamente por indivíduos que possuem, após a obtenção do primeiro indivíduo:

$\checkmark \quad P_{6}-0$ CCMs alteradas, isto é, que exigem manobras exclusivamente em CCRs;

$\checkmark \quad P_{7}-$ de 1 até 4 CCMs alteradas;

$\checkmark \quad P_{8}$ - de 5 até 8 CCMs alteradas;

$\checkmark \quad P_{9}-$ de 9 até 12 CCMs alteradas;

$\checkmark \quad P_{10}$ - de 13 até 16 CCMs alteradas.

Além disso, estas cinco tabelas também utilizam um novo conceito de tabelas de subpopulação que permite a otimização de mais de um objetivo em uma única tabela, obedecendo a uma ordem de prioridade entre eles, diferenciando-se de outras metodologias que também são baseadas no método de tabelas (Benayoun et al., 1971; Santos et al., 2010). Desta forma, em $P_{i}, \operatorname{com} 6 \leq i \leq 10$, são minimizados 
simultaneamente os seguintes parâmetros, cuja prioridade de otimização é a mesma na qual estes são apresentados a seguir:

$$
\begin{array}{ll}
\checkmark & P_{6}-\psi_{C C R}\left(G, G^{0}\right), V(G), X(G) e B(G) ; \\
\checkmark & P_{7}, P_{8}, P_{9}, P_{10}-\psi_{C C M}\left(G, G^{0}\right) \text { (dentro da faixa especificada para cada } \\
& \text { tabela e apresentada anteriormente), } \psi_{C C R}\left(G, G^{0}\right), V(G), X(G) e B(G) .
\end{array}
$$

Portanto, um novo indivíduo $G^{\text {novo }}$ será armazenado na tabela $P_{7}$, por exemplo, se o $\psi_{C C M}\left(G^{\text {novo }}, G^{0}\right)$ for maior ou igual a 1 e menor ou igual a 4 , e se, concomitantemente, possuir $\psi_{C C M}\left(G^{\text {novo }}, G^{0}\right)$ menor que o número de manobras em CCMs da pior solução em $P_{7}\left(G_{P_{C 2}}^{\text {pior }}\right)$. Se $\psi_{C C M}\left(G^{\text {novo }}, G^{0}\right)$ for igual a $\psi_{C C M}\left(G_{P_{C 2}}^{\text {pior }}, G^{0}\right)$, então $\quad G^{\text {novo }} \quad$ será $\quad$ inserido $\quad$ em $\quad P_{7}, \quad$ se $\psi_{C C R}\left(G^{\text {novo }}, G^{0}\right)<\psi_{C C R}\left(G_{P_{C 2}}^{\text {pior }}, G^{0}\right)$, e assim sucessivamente.

Na tabela $P_{11}$ são armazenados indivíduos que minimizam o número ponderado de manobras em chaves. Dado um indivíduo $G$ qualquer, o seu número ponderado de manobras em chaves $\left(\chi\left(G, G^{0}\right)\right)$ será dado pela soma do número de manobras em CCM de $G \psi_{C C M}\left(G, G^{0}\right)$ com o número de manobras em CCR de $G\left(\psi_{C C R}\left(G, G^{0}\right)\right)$, ponderada por meio de uma constante de ponderação $P$ maior do que 1, segundo a Equação 3.2.

$$
\chi\left(G, G^{0}\right)=\psi_{C C M}\left(G, G^{0}\right)+\frac{1}{P} \psi_{C C R}\left(G, G^{0}\right)
$$

A constante de ponderação $P$ representa o número de CCRs cuja operação tem o mesmo custo da operação de uma CCM, e por isso é um parâmetro que pode variar. Para ilustrar tomemos por base uma determinada concessionária de distribuição, que a operação de 10 CCRs tem o mesmo custo de operar 1 CCM, então $P$ assumirá o valor de 10 .

Assim, um novo indivíduo $G^{\text {novo }}$ será armazenado em $P_{11}$ :

i) se $P_{11}$ não estiver cheia, ou:

ii) se o número ponderado de manobras em chaves de $G^{\text {novo }}$ for menor que o número ponderado de manobras em chaves do pior indivíduo presente em $P_{11}$, substituindo-o. 
No AEMT++ existe ainda mais duas tabelas de subpopulações para consumidores especiais, com o objetivo de obter um PRE que não exija interrupção do fornecimento de energia para os consumidores especiais ou quando não for possível, obter uma solução com o mínimo possível destas transferências.

\subsection{Definição de uma Solução Final}

O AEMT++ possui a capacidade de selecionar e informar uma solução ao final de sua execução, ao contrário do AEMT (Santos et. al, 2010) que fornecia, não uma solução, mas, um conjunto de soluções que são os indivíduos que formam as subpopulações armazenadas nas tabelas. Além disso, essas soluções fornecidas pelo AEMT não são todas necessariamente factíveis, isto é, capazes de satisfazer todas as restrições do problema (ver definição de solução factível na seção 2.5.5).

Nesse sentido, o processo de escolha de uma solução final inicia-se pela verificação da factibilidade das soluções presentes nas tabelas ao final do processo evolutivo. Assim, após o AEMT++ atingir o seu critério de parada, as subpopulações armazenadas nas tabelas $P_{6}, P_{7}, P_{8}, P_{9}$ e $P_{10}$ são inicialmente verificadas e somente as soluções factíveis presentes nas mesmas são extraídas e salvas em um vetor auxiliar. Este vetor tem por finalidade reunir uma subpopulação formada exclusivamente por soluções factíveis que serão analisadas a fim de que seja extraída, desta subpopulação factível, a solução final a ser informada como o PRE. A verificação destas tabelas é interrompida quando esta subpopulação factível estiver completa.

Se ao término da verificação destas cinco tabelas este vetor ainda não estiver completo, então as demais tabelas serão também verificadas.

Em seguida, esta subpopulação formada exclusivamente por soluções factíveis é analisada para que seja determinado, dentre estas soluções, um subconjunto constituído pelas soluções com os menores valores das manobras ponderadas $\left(\chi\left(G^{y}, G^{i}\right)\right)$, ou seja, soluções que, além de serem factíveis, priorizam a operação de CCRs e exigirão menos manobras em chaves para serem implementadas. Finalmente, a solução final é definida como aquela que exige menos transferências de CEs.

Observe que esse procedimento de escolha de apenas uma solução demonstra que o AEMT++ trata o problema de restabelecimento como sendo um problema monoobjetivo. 


\subsection{Sequência de Chaveamento}

Um PRE deve conter a definição das chaves que precisam ser operadas para restaurar o fornecimento de energia. Conforme apresentado na seção anterior (3.3), esta definição é obtida após a determinação da solução final. Ou seja, o AEMT++ trata o problema de determinação da sequência de chaveamento de forma desacoplada. Isto é, primeiro resolve o problema de restabelecimento de energia minimizando o número de manobras e depois trata o problema de determinação da sequência de chaveamento para configuração obtida. Vale destacar que, mesmo com a solução final já encontrada, se a operação destas chaves for realizada de forma aleatória ou sem uma sequência correta, podem ocorrer diversos distúrbios no SD como, por exemplo, aqueles resultantes da formação de laços na rede e da conexão entre alimentadores e/ou subestações diferentes. Assim, além das chaves que devem ser operadas, o AEMT++ também informa uma sequência de chaveamento factível.

Primeiramente, a metodologia faz uso de matrizes que armazenam os pares de chaves que são alterados pelos operadores da RNP para gerar novos indivíduos. Assim, cada nova solução $G^{\text {novo }}$ possui uma matriz, chamada de $P M_{\text {novo }}$ ("Pares de Manobras da

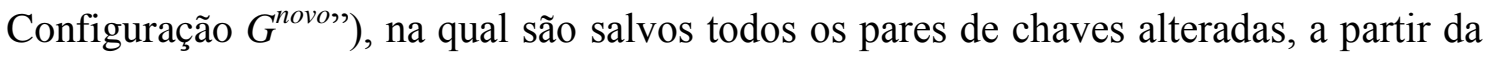
primeira configuração factível, para se obter $G^{\text {novo }}$. Sua dimensão é de $N_{P M n o v o} \mathrm{x} 2$, em que $N_{P M n o v o}$ é o número de pares de manobras em chaves de $G^{\text {novo }}$, parâmetro que varia em função do número de chaves alteradas de cada nova configuração. Na primeira coluna de $P M_{\text {novo }}$ são salvas as chaves a serem abertas e na segunda coluna as chaves a serem fechadas, após a reconexão das cargas sãs fora de serviço na primeira configuração factível obtida.

Assim, após o término do processo evolutivo, uma sequência de chaveamento será definida a partir dos pares de manobras das chaves alteradas apresentadas na solução final. De tal forma que a aplicação em sequência de cada um desses pares de manobras terminará com a implantação da solução final.

Porém, a cada par de manobras executado a rede passará temporariamente por outras configurações, chamadas de configurações intermediárias. Estas configurações intermediárias são testadas para analisar se as mesmas são configurações factíveis.

A verificação da factibilidade de uma configuração intermediária consiste em analisar se as modificações que serão produzidas pela aplicação do par de chaves, responsável pela sua obtenção, são correspondentes a aplicação de um dos operadores 
da RNP. Isto porque segundo Santos et al. (2010), a RNP e seus operadores geram exclusivamente configurações factíveis.

A análise de factibilidade de sequências de chaveamento está diretamente relacionada com a existência de chaves alteradas que retornaram ao seu estado na primeira configuração factível obtida, ou seja, na primeira configuração da rede após a reconexão dos setores sãos sem fornecimento reconectados. Estas chaves podem ser facilmente identificadas na matriz que armazena os pares de chaves alteradas de cada nova configuração, pois, quando uma chave retorna ao seu estado anterior, a mesma aparecerá duas vezes nessa matriz, em duas linhas distintas. Assim sendo, para que a sequência de chaveamento presente no plano de restabelecimento não exija duas operações em uma mesma chave, o que equivaleria a fechá-la e depois abri-la ou a abrila e depois fechá-la, esta deverá ser localizada e excluída da matriz que o armazena. O procedimento de verificação da factibilidade de uma sequência de chaveamento é diferente na ausência de chaves repetidas e na presença destas.

Para o caso onde a solução final, $G^{y}$, por exemplo, é definida e a sua matriz $P M_{y}$ não possui nenhuma chave repetida, a sequência de chaveamento final será a própria matriz $P M_{y}$ e nenhuma verificação adicional é necessária. Isto justifica-se pelo fato de que nesta matriz todos os pares de manobras foram gerados por meio de aplicações sucessivas dos operadores da RNP e, conforme citado anteriormente, estes operadores geram exclusivamente configurações factíveis. Desse modo, todas as configurações intermediárias que a rede possuirá com a execução de cada par de manobra serão factíveis. E se todas as configurações intermediárias são factíveis, logo o conjunto de pares de chaves alteradas, constituirão uma sequência de chaveamento factível.

Para o caso em que a solução final $\left(G^{y}\right)$ é definida e a sua matriz $P M_{y}$ possui uma chave que retornou ao seu estado anterior, na primeira configuração factível, então, esta chave aparecerá repetida em $P M_{y}$, isto é, em mais de uma linha. Neste caso, para que não haja manobras desnecessárias, esta chave que retornou ao seu estado anterior é localizada e excluída de $P M_{y}$. No entanto, sempre que uma chave é retirada, os dois pares de manobras aos quais ela pertencia ficarão incompletos e um novo arranjo de pares de chave deverá ser feito.

Segue abaixo um exemplo apresentado em Marques (2013) para um melhor entendimento do procedimento tomado quando existe uma chave repetida na lista de chaveamentos da solução final. 
Digamos que, após o processo evolutivo a configuração $5, G^{5}$, foi tomada como a solução final para o problema, sua matriz $P M_{5}$ é mostrada na Tabela 3.1.

Tabela 3.1: Conjunto de pares de chaves alteradas (Marques, 2013).

\begin{tabular}{c|c}
\hline \multicolumn{2}{c}{$\boldsymbol{P M}_{\mathbf{5}}$} \\
\hline $\mathbf{A}$ & $\mathbf{F}$ \\
$\underline{\mathbf{1 7}}$ & 20 \\
22 & 24 \\
23 & $\underline{\mathbf{1 7}}$ \\
\hline
\end{tabular}

Observe na primeira e na terceira linha de $P M_{5}$ que, após a reconexão dos setores sãos fora de serviço, a chave 17 inicialmente foi aberta e posteriormente fechada. Desse modo, para que estas alterações que se anulam não estejam presentes na sequência de chaveamento a ser apresentada no plano de restabelecimento, a chave 17 deve ser retirada do primeiro e do terceiro par de chaves e $P M_{5}$ atualizada, como mostrado na Tabela 3.2.

Tabela 3.2: Conjunto de chaves alteradas atualizado pela exclusão da chave 17 (Marques, 2013).

\begin{tabular}{c|c}
\hline \multicolumn{2}{|c}{$\boldsymbol{P M}_{5}$} \\
\hline $\mathbf{A}$ & $\mathbf{F}$ \\
& $\mathbf{2 0}$ \\
22 & 24 \\
$\mathbf{2 3}$ & \\
\hline
\end{tabular}

Pode-se analisar que esse conjunto de chaves alteradas de $G^{5}$, atualizado pela retirada da chave 17, não pode formar uma sequência de pares de manobras porque as chaves 20 e 23 encontram-se isoladas, e também porque, devido a radialidade da rede, se uma chave NA for fechada antes da abertura de uma NF, um laço ou uma conexão entre dois alimentadores poderá formar-se na rede.

Assim, as chaves 23 e 20 devem ser unidas, a fim de que um novo par seja formado com as mesmas. Este novo par é chamado de par rearranjado, pois não foi criado pela aplicação de um dos operadores da RNP, mas por uma combinação de duas chaves alteradas em configurações distintas. Após a formação do par rearranjado há duas combinações de chaveamento possíveis de se obter e que serão verificadas a fim de determinar uma que seja factível e que possa ser informada no PRE. A primeira combinação, $P M_{5}{ }^{1}$, é apresentada na Tabela 3.3, onde o par rearranjado foi inserido na primeira das duas linhas nas quais encontrava-se a chave repetida. 
Tabela 3.3: Sequência de chaveamento na qual o par rearranjado encontra-se na primeira das duas linhas (Marques, 2013).

\begin{tabular}{c|c}
\hline \multicolumn{2}{c}{$\boldsymbol{P M}_{5}{ }^{I}$} \\
\hline $\mathbf{A}$ & $\mathbf{F}$ \\
$\mathbf{2 3}$ & $\mathbf{2 0}$ \\
22 & 24 \\
& \\
\hline
\end{tabular}

A segunda combinação, $P M_{5}^{2}$, é mostrada na Tabela 3.4, onde o par rearranjado foi inserido na segunda das duas linhas na qual encontrava-se a chave repetida.

Tabela 3.4: Sequência de chaveamento na qual o par rearranjado encontra-se na segunda das duas linhas (Marques, 2013).

\begin{tabular}{c|c}
\hline \multicolumn{2}{c}{$\boldsymbol{P M}_{5}{ }^{2}$} \\
\hline $\mathbf{A}$ & $\mathbf{F}$ \\
& \\
22 & 24 \\
$\mathbf{2 3}$ & $\mathbf{2 0}$ \\
\hline
\end{tabular}

Contudo, como o par rearranjado e também estas duas sequências de chaveamento foram formados por meio de recombinações de chaves, e não através de aplicações sucessivas dos operadores da RNP, não é possível afirmar que ambas são factíveis. Assim, deve-se efetuar uma verificação da factibilidade destas sequências, antes de apresentar uma delas em PRE.

Começando pela primeira das combinações, $P M_{5}{ }^{1}$, apresentada na Tabela 3.3, devese simular a aplicação de cada par de manobras presente em $P M_{5}{ }^{1}$ e verificar se todas as configurações intermediárias que serão obtidas são factíveis. Ao aplicar o primeiro par de manobras ([23, 20]) obtêm-se a configuração intermediária 1. A verificação da configuração intermediária é realizada analisando se as mudanças ocorridas na rede pela aplicação do par de manobras correspondem à aplicação de um dos operadores da RNP.

Considerando que após o teste a configuração intermediária 1 é equivalente a aplicação de um dos operadores genéticos da RNP (PAO ou CAO), aplica-se assim o segundo e último par de manobras ([22, 24]) e obtêm-se a segunda e última configuração intermediária, que também deve ser testada. Assim se todas as configurações obtidas pela aplicação da sequência de pares de manobras presente em $P M_{5}{ }^{l}$ são factíveis, consequentemente, pode-se concluir que a sequência de chaveamento representada por $P M_{5}{ }^{l}$ é factível. 
Uma das limitações deste método para obter a sequência de chaveamento é que não é realizada a verificação das outras restrições do problema para as configurações intermediárias, como queda de tensão, carregamento da rede e carregamento da subestação. Esta metodologia limita-se a atender a restrição de radialidade da rede durante as configurações intermediárias, impedindo a criação de laços e de conexão entre alimentadores e/ou subestações distintos.

\subsection{Considerações Finais}

Este capítulo apresentou as características gerais da metodologia base, o AEMT++, a maneira como esta determina uma solução final para o problema, dentre todas as soluções armazenadas nas tabelas, e por fim, também foi apresentada a definição da sequência de chaveamento factível para um PRE.

A seguir será apresentado a metodologia proposta nesta dissertação, apresentando detalhadamente as diferenças e as contribuições desta metodologia para atender as proposições do trabalho (ver item 1.2). Haverá uma grande diferença, em especial, na função que trata a sequência de chaveamento para poder atender as características operacionais dos diferentes tipos de chaves seccionadoras presentes em um SD. 


\section{Capítulo 4 - Metodologia Proposta}

\subsection{Introdução}

Neste capítulo será apresentada a metodologia proposta desta dissertação para o tratamento do problema de restabelecimento de energia em SDs reais de grande porte. $\mathrm{O}$ diferencial desta metodologia, em relação à metodologia base (AEMT++) e às presentes na literatura, é a capacidade de considerar BCs, RTs com ajuste automático do tap e a consideração de diferentes tipos de chaves seccionadoras (existência de telecomando, possibilidade de manobra para chaves tipo seca, com carga e/ou em curto circuito).

Este capítulo inicia-se com o tratamento dos BCs e dos RTs. Estes são inseridos na metodologia proposta durante o cálculo do FC. O FC é parte essencial para as metodologias de restabelecimento de energia baseadas em AEs, onde o mesmo é utilizado para avaliar cada indivíduo gerado durante o processo evolutivo, ou seja, a execução do FC possibilita o cálculo da fitness das soluções candidatas e a inserção dos BCs e dos RTs trará ainda mais confiabilidade aos PREs.

Por fim, o capítulo apresenta a metodologia proposta de maneira geral, focando nos procedimentos adotados para a consideração dos diferentes tipos de chaves seccionadoras e apontando as principais diferenças desta metodologia para à metodologia adotada como base (AEMT++).

\subsection{Fluxo de Carga com BCs e RTs}

\subsubsection{Fluxo de Carga com RNP}

A RNP (Delbem et al, 2004) é uma estrutura de dados baseada nos conceitos de caminho e profundidade de um nó em uma árvore de grafo. A mesma foi explicada na seção 2.5.4. Nesta seção cada RNP representa um alimentador de um SD, logo esta RNP é denominada RNP de alimentador. Neste tipo de RNP cada nó, da árvore de grafo, representa um setor, e cada aresta representa uma chave seccionadora. Entretanto, para o cálculo do FC, além da RNP de alimentador é necessário outro tipo de RNP, que é denominada RNP de setor (Santos, 2009).

Para um melhor entendimento da RNP de setor e da distinção entre os dois tipos de RNPs, considere o exemplo abaixo. 
Observe a Figura 4.1, nela está representado um SD didático que possui dois alimentadores.

Figura 4.1: SD com dois alimentadores.

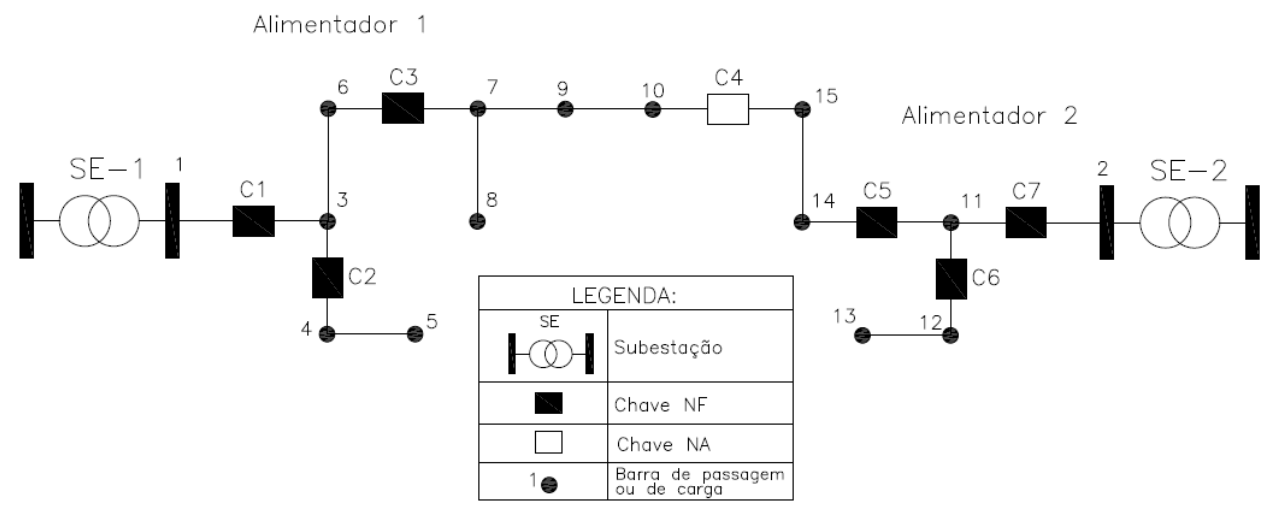

Fonte: Santos, 2009.

A Figura 4.2 agrupa as barras e linhas não separadas por chaves, estes grupos são denominados de setores e os mesmos são representados pelas letras: $A, B, C, D, E$, $F, G$ e $H$.

Figura 4.2: Junção das linhas e barras em setores.

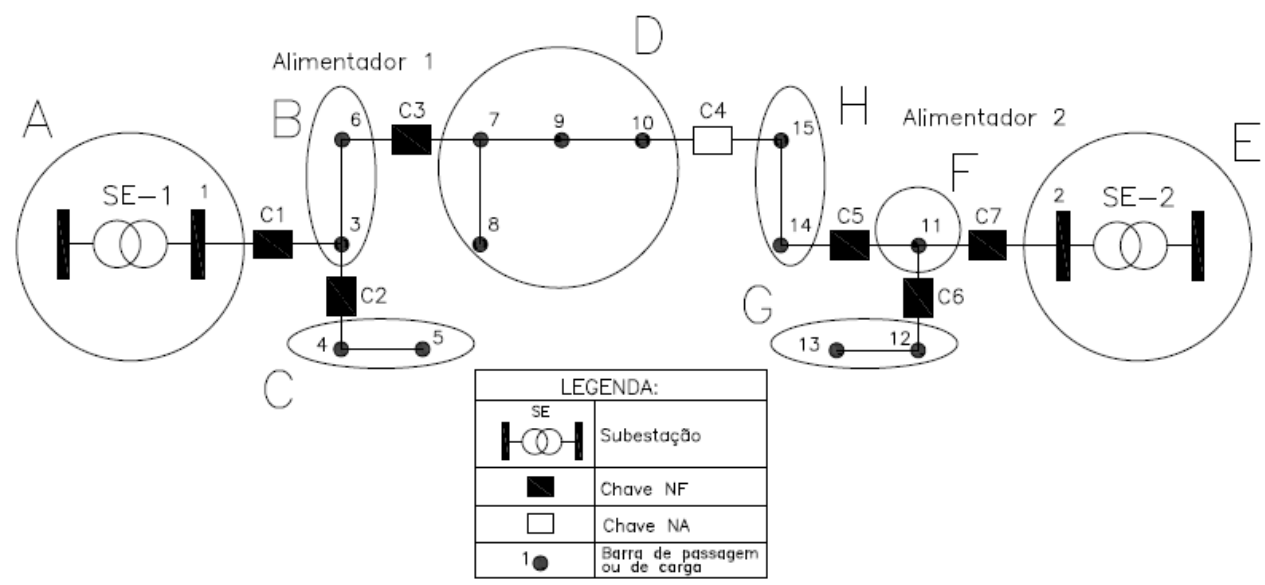

Fonte: Santos, 2009.

Assim, tem-se um grafo em que todas as arestas são chaves seccionadoras, onde as linhas contínuas representam chaves fechadas e as linhas tracejadas chaves abertas. $\mathrm{O}$ grafo é representado na Figura 4.3: 
Figura 4.3: Grafo representando setores do SD da Figura 4.2.

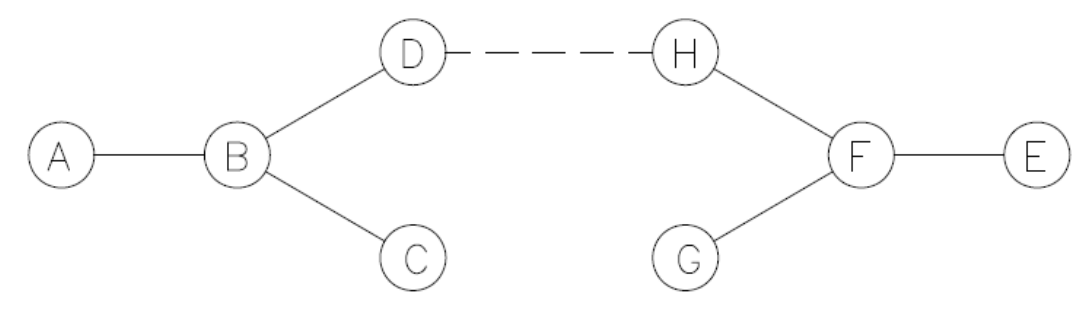

Fonte: Santos, 2009.

Logo a Figura 4.3 possui duas RNPs, uma para o Alimentador 1 e outra para o Alimentador 2. Assim, temos uma estrutura $T_{1}$ que armazena o endereço de memória da RNP do Alimentador 1 e a estrutura $T_{2}$ que armazena o endereço de memória da RNP do Alimentador 2. Estas duas RNPs são denominadas de RNPs de alimentadores.

$$
\begin{aligned}
& T_{1}=\underset{\text { Prof. }}{\text { Nó }}=\left[\begin{array}{llll}
A & B & C & D \\
0 & 1 & 2 & 2
\end{array}\right] \\
& T_{2}=\underset{\text { Prof. }}{\text { Nó }}=\left[\begin{array}{cccc}
E & F & G & H \\
0 & 1 & 2 & 2
\end{array}\right]
\end{aligned}
$$

A RNP de setor pode ser representada computacionalmente de forma semelhante a RNP do alimentador, e suas árvores são armazenadas em matrizes denominadas $B_{s r}$, onde o sub-índice $s$ representa o setor em análise e o sub-índice $r$ refere-se ao setor pelo qual a energia chega ao setor $s$.

Segundo Santos (2009), para utilizar a RNP de um setor $n$ no cálculo do FC, deve-se acrescentar um nó adjacente ao nó raiz da árvore do setor. Este nó adicional pertence a um setor $m$, e é por meio dele que a energia elétrica chega ao setor $n$. Tal procedimento é aplicado porque garante que as barras do sistema permaneçam ordenadas segundo uma relação conhecida como Terminal-Substation Order (Kagan et al., 2005). Nesta modelagem, as barras são ordenadas de acordo com o sentido do FC, de tal maneira que uma barra pai sempre está a montante de suas barras filhos.

A Figura 4.4 ilustra que o fluxo de potência pode chegar ao setor D (Barras: 7, 8, 9 e 10) por dois caminhos diferentes, pelo setor $B$ (à esquerda - barra 6) ou pelo setor $H$ (à direita - barra 15). Assim, pelo setor $B$, tem-se $B_{s r}=B_{D B}$ e para o setor $H$, tem-se que $B_{s r}=B_{D H}$ 
Figura 4.4: Árvore do setor D, com os nós adjacentes dos setores: B (à esquerda) e H (à direita).

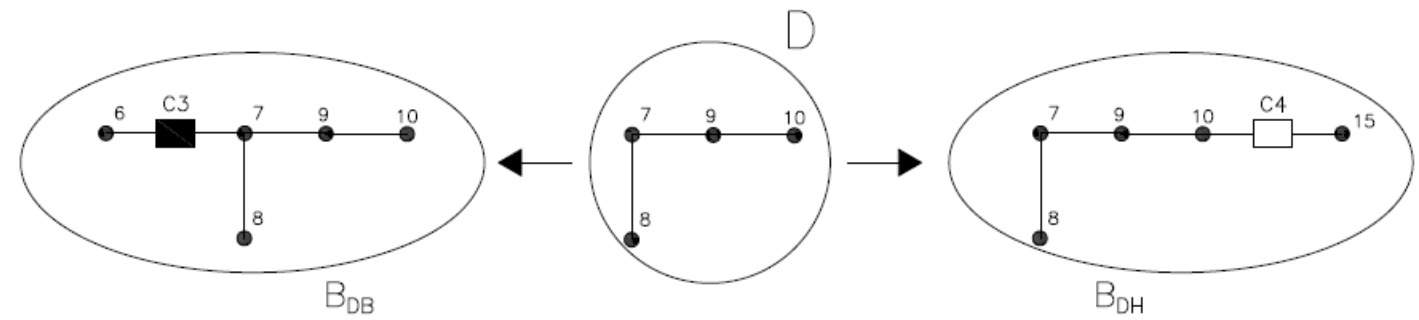

Fonte: Santos, 2009.

As estruturas das RNPs possíveis para o setor $D$ são apresentadas abaixo:

$$
\begin{aligned}
B_{D B} & =\left[\begin{array}{ccccc}
6 & 7 & 8 & 9 & 10 \\
0 & 1 & 2 & 2 & 3
\end{array}\right] \\
B_{D H} & =\left[\begin{array}{ccccc}
15 & 10 & 9 & 7 & 8 \\
0 & 1 & 2 & 3 & 4
\end{array}\right]
\end{aligned}
$$

Observa-se que a RNP do alimentador apresenta qual das configurações acima utilizar. A RNP do Alimentador 1 indica que o setor $D$ está conectado ao setor $B$. Assim, a estrutura da RNP do setor $D$ no exemplo acima é $B_{D B}$, conforme apresentado anteriormente em $T_{1}$.

$$
T_{1}=\underset{\text { Prof }}{\text { Nó }}=\left[\begin{array}{cccc}
A & \boldsymbol{B} & C & \boldsymbol{D} \\
0 & \mathbf{1} & 2 & \mathbf{2}
\end{array}\right]
$$

Portanto, o cálculo do FC de varredura direta/inversa pode ser executado corretamente, uma vez que a RNP do sistema garante que as barras estejam sempre ordenadas de acordo com a relação Terminal-Substation Order. Além disso, os operadores genéticos da RNP sempre geram configurações radiais, assim, a RNP elimina a necessidade de ordenação das barras e de verificação da radialidade da rede, características estas que permitem que o tempo computacional do FC seja reduzido.

\subsubsection{FC de varredura direta/inversa-Método soma das correntes}

O cálculo do FC é responsável pela obtenção do estado operacional de um sistema elétrico, isto é, das tensões complexas (módulo e ângulo) de todas as barras. Assim, obtendo-se os valores precisos das tensões complexas consegue-se obter as demais grandezas de interesse no SD. Contudo, para a execução do cálculo do FC é 
necessário que se conheça as potências das cargas, os parâmetros das linhas e a topologia da rede (Santos, 2009).

O FC de varredura direta/inversa é uma abordagem específica para SDs, pois atende suas características especiais, como: alta relação R/X e a topologia radial da rede. Além disso, também se destaca pela sua robustez e simplicidade de implementação (Santos, 2009).

O FC de varredura direta/inversa possui duas etapas distintas. Primeiramente inicia-se com a etapa inversa (Backward), nessa etapa calcula-se todas as correntes nos trechos do SD, começando das barras mais afastadas das subestações e terminando na subestação, por essa razão, denominada inversa (inversa ao fluxo de potência). Posteriormente, inicia-se a etapa direta (Forward), que representa o cálculo da tensão em todas as barras do SD no sentido da subestação para as barras mais distantes. Nesse cálculo da tensão utilizam-se as correntes calculadas na etapa anterior e as impedâncias de cada trecho. Assim, este processo continua iterativamente até que um critério de convergência seja devidamente atendido.

A seguir será apresentado, de maneira mais detalhada, o equacionamento e o procedimento do FC de varredura direta/inversa pelo método soma das correntes.

Vale destacar que o FC, aqui adotado, trata o SD como um sistema trifásico equilibrado, ou seja, os cálculos dentro do FC são realizados considerando uma fase do sistema trifásico. Outro ponto a ser lembrado é que a modelagem da carga adotada é de potência constante com a tensão.

Primeiramente, assume-se que a tensão complexa em todas as barras seja igual à tensão na barra da subestação. Os passos do processo iterativo são apresentados abaixo (considerando o modelo de carga de potência constante):

Calculam-se as correntes de carga de cada barra $i$ do sistema, conforme a Equação 4.1:

$$
\begin{gathered}
\dot{I}_{i}^{(k)}=\left(\frac{S_{i}}{\dot{V}_{i}^{(k-1)}}\right)^{*}-Y_{i}^{s h} \dot{V}_{i}^{(k-1)} \\
i=1,2, \ldots, N B
\end{gathered}
$$

onde:

NB é o número total de barras do sistema (sem considerar as barras das subestações); $\dot{I}_{i}^{(k)}$ é a corrente demandada pela barra $i$ na iteração $k$; 
$\dot{V}_{i}^{(k-1)}$ é a tensão da barra $i$ na iteração $k-1$. Se $k=1$ (primeira iteração do algoritmo), assume-se que a tensão complexa em todas as barras seja igual à tensão na barra da subestação;

$Y_{i}^{s h}$ é a soma de todos os elementos shunt conectados à barra $i$;

$S_{i}$ é a potência complexa da barra $i$.

Etapa Backward: Começando das barras extremas do alimentador em direção as barras da subestação, calcula-se o fluxo de corrente $\left(\dot{j}_{x}^{(k)}\right)$ que circula em cada trecho $x$ que conecta uma barra $m$ (barra à montante) a barra $n$ (barra à jusante):

$$
\begin{gathered}
\dot{j}_{x}^{(k)}=\sum(\text { correntes dos trechos que saem da barra } \boldsymbol{n}) \\
x=1,2, \ldots, N T
\end{gathered}
$$

onde:

NT é o número de trechos do sistema.

Etapa Forward: Começando das barras das subestações e terminando nas barras mais extremas do alimentador, calcula-se a tensão complexa de cada barra $i$ do sistema, conectada a barra $m$ (barra a montante da barra $i$ ), através da seguinte equação:

$$
\dot{V}_{i}^{(k)}=\dot{V}_{m}^{(k)}-Z_{x} \cdot \dot{J}_{x}^{k}
$$

onde:

$x$ é o trecho de ligação entre a barra $i$ e a barra a sua montante $m$;

$Z_{x}$ é a impedância complexa no trecho $x$;

Por fim, verifica-se se a convergência foi alcançada. Para cada barra do sistema analisa-se a diferença da tensão complexa, módulo e ângulo, da iteração atual com a iteração anterior. Se a diferença (erro) for maior que o critério de convergência, então $k=k+1$ e volta-se ao passo 1 (Equação 4.1). Caso contrário, o cálculo do FC chega ao fim e têm-se os valores das tensões complexas em todas as barras e as correntes complexas em todos os trechos do sistema. 


\subsubsection{Modelagem dos Bancos de Capacitores}

Os BCs são equipamentos elétricos utilizados principalmente para correção do fator de potência de determinada carga ou conjunto de cargas. Além dessa função principal, eles também ajudam na regulação da tensão do sistema e na redução das perdas elétricas. Isto em razão de os BCs fornecerem potência reativa contribuindo com a demanda de potência reativa dos elementos indutivos (característica predominante na maioria das cargas elétricas), fazendo com que sejam reduzidas a potência aparente total do sistema, a corrente complexa fornecida pela subestação e as quedas de tensão nas redes.

Os dados de entrada do programa de FC para cada BC são: a barra onde o BC está conectado e a potência reativa trifásica em $\mathrm{kVAr}$.

A modelagem dos BCs adotada se resume a cargas de potência puramente reativa. Assim a metodologia trata os BCs como se fossem cargas do SD.

\subsubsection{Modelagem dos Reguladores de Tensão e do ajuste automático dos taps}

Para implementar o RT no FC que será utilizado na metodologia proposta, foi necessário incluir algumas particularidades para incorporar os padrões da Copel (projeto $\mathrm{P} \& D)$ :

$\checkmark$ Os RTs possuem capacidade máxima de regulação igual a $10 \%$ para elevação ou abaixamento da tensão;

$\checkmark$ Possuem 33 taps igualmente divididos com: 16 taps para elevação de tensão, 16 para o abaixamento e o tap 0. Assim, as posições máximas de tap do equipamento são, respectivamente: +16 e -16 .

Assim, com essas particularidades a regulação para cada tap (passo) é uma constante e calculada da seguinte forma:

$$
\text { passo }=\frac{R}{\text { Número de posições de tap }},
$$

onde $R$ é a capacidade máxima de regulação e neste trabalho igual a $0,1(10 \%)$.

Inserindo os valores na equação (4.4), tem-se: 


$$
\text { passo }=\frac{0,1}{16}=0,00625
$$

Ou seja, cada tap possui uma capacidade de $0,625 \%$ de regulação. Assim os 16 taps totalizam os $10 \%$ de regulação máxima.

Os dados de entrada do programa referentes ao RT são: as barras nas quais ele está conectado (denominadas barra primária e barra secundária, respectivamente) e a corrente nominal do equipamento.

Tendo em vista que o passo é uma constante para todos os RTs do projeto $(0,00625)$, a posição do tap torna-se a principal variável para a implementação do RT no FC.

O tap será utilizado para calcular (atualizar) o valor da tensão na barra secundária $V_{2}$ do RT durante a etapa forward (cálculo das tensões), através da equação:

$$
V_{2}=V_{1}(1+\text { passo } * \operatorname{tap})
$$

onde:

$V_{1}$ é a tensão na barra primária do RT;

$V_{2}$ é a tensão na barra secundária do RT;

O tap também é utilizado para calcular (atualizar) a corrente no ramo do RT durante a etapa backward (soma das correntes), através da equação:

$$
I_{1}=I_{2}(1+\text { passo } * \text { tap })
$$

onde:

$I_{1}$ é a corrente no enrolamento primário do RT;

$I_{2}$ é a corrente no enrolamento secundário do RT;

Observe que a determinação das tensões e das correntes é influenciada diretamente pela posição do tap, como apresentado nas equações (4.6) e (4.7). Verificando as particularidades dos SDs da Copel, foi adotado que a posição do tap é uma variável estimada durante as iterações do próprio $\mathrm{FC}$, mais precisamente durante a etapa forward (cálculo das tensões). A metodologia para a estimação do tap é descrita a seguir. 
Como no início do FC de varredura direta/inversa o procedimento é considerar a tensão base para todas as barras (ou a tensão na barra da SE de cada alimentador), logo não há necessidade de se ter um ajuste na posição do tap e, portanto, inicialmente todos os taps dos RTs estarão na posição "zero" (não há regulação).

Com o decorrer do processo iterativo, é natural à alteração dos valores das tensões nas barras (geralmente uma queda nos valores). Assim, seguindo as informações da Copel sobre ajuste de tap, deve-se primeiramente estabelecer uma faixa de tensão de linha para identificar se o tap será ou não ajustado, que para Copel é a seguinte:

$$
\begin{aligned}
& \text { Limite Inferior }=0,9776 p u \\
& \text { Limite Superior }=0,9973 p u
\end{aligned}
$$

Durante a etapa forward, se a tensão na barra secundária do RT $\left(V_{2}\right)$ estiver fora da faixa de tensão, então o tap será ajustado, caso contrário não será.

A equação para o ajuste do tap é:

$$
\text { tap }=\frac{1}{\text { passo }} \cdot\left(\frac{V_{2 e s p}}{V_{1}}-1\right)
$$

onde:

$V_{2 e s p}$ é a tensão que se deseja na barra secundária, ou seja, se a tensão $V_{2}$ for menor que o limite inferior $(0,97776 \mathrm{pu})$, então $V_{2 e s p}$ é $0,97776 \mathrm{pu}$, caso contrário, se $V_{2}$ for maior que o limite superior $(0,9973 \mathrm{pu})$, então $V_{2 e s p}$ será $0,9973 \mathrm{pu}$.

Como as posições do tap de um RT variam de forma discreta e não contínua (variáveis discretas), deve-se garantir que o valor resultante de (4.10) seja um número inteiro. Assim, se a tensão $V_{2}$ atualizada pela equação (4.6), for maior que o limite superior, o resultado de (4.10) é arredondado para um valor inteiro abaixo, caso $V_{2}$ seja menor que o limite inferior, o resultado é arredondado para um valor inteiro acima. Estas ações foram implantadas com o objetivo de que na próxima iteração (próxima etapa forward) a tensão em $V_{2}$ do RT esteja dentro da faixa de tensão desejada.

Analisando a equação (4.10) pode-se observar que a mesma não aponta qualquer restrição, porém a posição do tap é limitada pelos valores máximos do equipamento (no nosso caso, +16 e -16), e também pelo carregamento do RT, ou seja, se a corrente que passa pelo RT ultrapassa seu valor nominal, a regulação máxima de tensão diminui o 
que também implica na redução do valor máximo da posição do tap. Os limites das posições dos taps em função de seu carregamento são apresentados na tabela a seguir:

Tabela 4.1: Limites das posições dos taps em função do carregamento do RT

\begin{tabular}{c|c}
\hline Carregamento do RT $(\mathrm{y})$ & Máximas posições do tap \\
\hline$y \leq 100 \%$ & $+16 \mathrm{e}-16$ \\
$100 \% \leq y \leq 110 \%$ & $+14 \mathrm{e}-14$ \\
$110 \% \leq y \leq 120 \%$ & $+12 \mathrm{e}-12$ \\
$120 \% \leq y \leq 135 \%$ & $+10 \mathrm{e}-10$ \\
$135 \% \leq y \leq 160 \%$ & $+8 \mathrm{e}-8$ \\
$y>160 \%$ & 0 \\
\hline
\end{tabular}

$\mathrm{Na}$ última condição de limitação do tap, isto é, quando o carregamento do RT for maior que $160 \%$, a posição do tap deve ser 0 (não há regulação de tensão), isto na prática representa a necessidade de se fazer um by-pass do equipamento para que o mesmo não se danifique por extrapolar seu limite de ampacidade. Interessante destacar que, se houver a necessidade de se fazer um by-pass do equipamento, então deve-se considerar esta ação como uma manobra de chave manual para o problema de restabelecimento de energia.

Assim, após o processo do ajuste do tap é feita uma análise que verifica se a posição do tap foi alterada, se a resposta for afirmativa, então deve-se necessariamente fazer mais uma iteração do FC (1 - atualização das correntes nos nós, 2 - Etapa Backward e 3 - Etapa Forward) para atualizar as correntes e as tensões do alimentador com essa nova posição do tap. Quando não houver mudança de tap o teste de convergência que indicará a necessidade de uma nova iteração.

Para um melhor entendimento do processo do FC considerando a presença de BCs e de RTs, no Apêndice B desta dissertação apresenta-se um exemplo didático com base em um sistema teste de 4 barras. Neste exemplo é descrito numericamente todos os procedimentos, passo a passo, para o cálculo do FC com BCs e RTs até a sua convergência. 


\subsubsection{Validação do Fluxo de Carga no SD de Marília/SP}

Com o intuito de validar o FC com RNP desenvolvido, foi realizado um teste no SD de grande porte da cidade de Marília/SP, ilustrado na Figura 4.5, considerando todas as suas barras, linhas, chaves, BCs e RTs. A Figura 4.5 apresenta o SD de Marília/SP como um todo, cada alimentador do SD é representado por uma cor diferente, e a figura também destaca o alimentador (roxo) que possui o setor em falta.

Os dados utilizados foram obtidos de Pereira (2014), que obteve as informações diretamente com a concessionária de distribuição de energia elétrica local, Companhia Paulista de Força e Luz (CPFL), com o consentimento desta.

Figura 4.5: Diagrama unifilar do SD-Marília - Setor Analisado (em destaque).

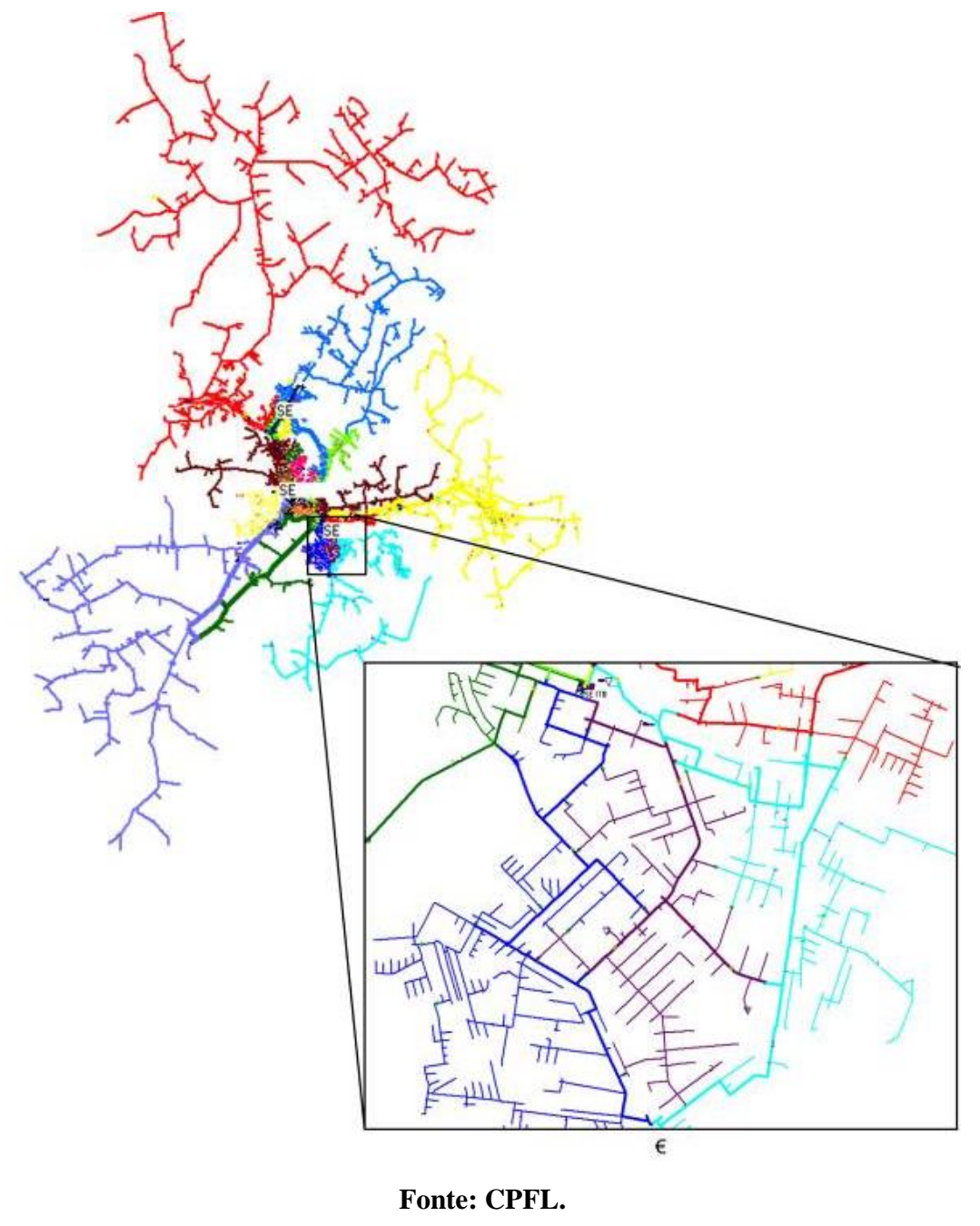

Com referência aos dados reais do SD de Marília/SP, verificou-se que o SD é composto por: 3 subestações, 20 alimentadores, 15.648 barras, 2.112 setores e 1.905 chaves no total (1.730 NF e 175 NA), dentre estas 51 são CCRs (2,67\% do total). Estes 
dados são referentes à configuração em operação no ano de 2012. Destaca-se que foram considerados a modelagem de todos os 33 BCs e 5 RTs presentes no sistema real. Destaca-se ainda que todos os 5 RTs possuem operação automática de tap, característica considerada no FC desenvolvido.

A modelagem de carga utilizada foi de potência constante com a tensão e o limiar para a convergência do FC foi de $10^{-3}$. O programa computacional foi implementado em linguagem $\mathrm{C}$, e foram executados em um computador portátil (laptop) com processador Core i7-4510U, 2,0GHz, 8Gbytes de memória RAM, Sistema Operacional Linux, distribuição Ubuntu 14.04.2.

Os resultados deste teste foram comparados e validados com os dados do FC fornecido pela CPFL.

A comparação dos resultados obtidos pelo FC desenvolvido, e os valores fornecidos pela concessionária de energia, considerando o carregamento máximo da rede, são apresentados na Tabela 4.2.

Tabela 4.2: Parâmetros elétricos gerais do FC desenvolvido

\begin{tabular}{l|ccc}
\hline & Resultados CPFL & FC desenvolvido & Erros (\%) \\
\hline Máxima Queda de & 5,06 & 5,066 & 0,12 \\
Tensão do SD (\%) & & & \\
Perdas Totais (kW) & $2.037,00$ & $2.043,55$ & 0,32 \\
Máximo Carregamento & 79,00 & 79,50 & 0,63 \\
da Rede (\%) & & & \\
Tempo (s) & --- & 0,08 & --- \\
\hline
\end{tabular}

Analisando os dados da Tabela 4.2 observa-se que os resultados obtidos pelo FC desenvolvido são muito próximos dos resultados apresentados pela concessionária. Comparando-se os valores, nota-se que o pior caso é para o carregamento máximo da rede onde o erro encontrado foi de $0,63 \%$. Outro ponto a ser destacado é que o número de iterações para convergência do FC da CPFL é igual ao do FC proposto. 


\subsection{Metodologia Proposta para o problema de Restabelecimento de Energia}

4.3.1 Tabelas consideradas na metodologia proposta e priorização entre os diferentes tipos de chaves seccionadoras.

Recentemente foi realizado um estudo da eficiência de cada uma das tabelas de subpopulação do AEMT++, conforme apresentado em Marques (2015). As conclusões deste estudo foram utilizadas para determinar a escolha das tabelas a serem consideradas pela metodologia proposta nesta pesquisa.

A metodologia proposta possui então 11 tabelas de subpopulações, as 5 primeiras tabelas são as mesmas apresentadas na metodologia base (AEMT++):

$\checkmark \quad P_{1}$ - soluções com os menores valores de função agregação, $f(G)$;

$\checkmark \quad P_{2}$-soluções com os menores valores de perdas resistivas, $\gamma(G)$;

$\checkmark \quad P_{3}$-soluções com os menores valores de carregamento da rede, $X(G)$;

$\checkmark \quad P_{4}$ - soluções com os menores valores de carregamento da subestação, $B(G)$;

$\checkmark \quad P_{5}$ - soluções com os menores valores de queda máxima de tensão, $V(G)$;

Contudo, devido ao estudo realizado observou-se que há uma melhora no processo evolutivo do AEMO quando a função agregação (ver equação 3.1) da tabela $P_{1}$ é normalizada. Assim, foi realizada esta alteração conforme apresentado na Equação 4.11 .

$$
f(G)=w_{X} \frac{X(G)}{X\left(G^{p}\right)}+w_{B} \frac{B(G)}{B\left(G^{p}\right)}+w_{V} \frac{V(G)}{V\left(G^{p}\right)}+\frac{\gamma(G)}{\gamma\left(G^{p}\right)}
$$

Onde:

$f(G)$ - Função agregação normalizada relativa à configuração $G$;

$G$ - Configuração qualquer da rede, gerada pelo processo evolutivo;

$G^{p}$ - Configuração da rede antes da ocorrência da falta (configuração pré-falta);

Já os pesos definidos por: $w_{X}, w_{B}$ e $w_{V}$ mantiveram a mesma ideia da equação 3.1, trocando-se apenas o valor do peso de 100 para 1, caso as restrições sejam violadas, assim: 


$$
w_{I}=\left\{\begin{array}{l}
1, \text { se } I>1, \text { para } I=X, B \text { eV } \\
0, \text { caso contrário. }
\end{array}\right.
$$

Logo, a metodologia proposta adotou esta alteração na função agregação para a consideração da primeira tabela de subpopulação.

As tabelas de 6 a 10 também foram mantidas as mesmas da metodologia base $(\mathrm{AEMT}++)$ :

$\checkmark \quad P_{6}-0$ CCMs alteradas, isto é, que exigem manobras exclusivamente em CCRs;

$\checkmark \quad P_{7}$ - de 1 até 4 CCMs alteradas;

$\checkmark \quad P_{8}$ - de 5 até 8 CCMs alteradas;

$\checkmark \quad P_{9}-$ de 9 até 12 CCMs alteradas;

$\checkmark \quad P_{10}-$ de 13 até 16 CCMs alteradas.

Entretando, a ideia de otimização destas tabelas foi modificada na metodologia proposta com o intuito de considerar a priorização dos diferentes tipos de chaves seccionadoras. Assim, além de respeitar as restrições do intervalo de manobras em CCMs, em caso de empate, são minimizados simultaneamente os seguintes tipos de chaves para as tabelas de 7 a 10, cuja prioridade de otimização segue a sequência apresentada abaixo:
$\checkmark$ Manobras em chaves tipo seca (chaves faca e fúsivel);
$\checkmark$ Manobras em CCMs que podem ser operadas com carga;
$\checkmark$ Manobras em CCMs que posem ser operadas com curto;

Logo, um novo indivíduo $G^{\text {novo }}$ será armazenado na tabela $P_{8}$, por exemplo, se o número de manobras em CCMs estiver dentro da faixa determinada, e se, simultaneamente, possuir manobras em CCMs menor que o da pior solução armazenado em $P_{8}$. Se houver um empate no número de manobras em CCMs entre $G^{\text {novo }}$ e a pior solução de $P_{8}$, então $G^{\text {novo }}$ será inserido em $P_{8}$, se o número de manobras em chaves do tipo seca for menor que o da pior solução. Caso aconteça novos empates, tenta-se minimizar os demais tipos de chaves manuais (CCMs que podem operar com carga e por último $\mathrm{CCMs}$ com curto). Se em último caso, houver empate até em relação às 
manobras de CCMs do tipo que podem operar com curto circuito, então será mantida a pior solução da tabela $P_{8}$.

Este procedimento foi adotado para que seja prirorizado primeiramente as CCRs do $\mathrm{SD}$, e posteriormente, os demais tipos de chaves que são operados manualmente seguindo a ordem de priorização descrita acima.

Devido ao estudo realizado em Marques (2015), observou-se que a tabela referente ao número ponderado de manobras da metodologia base (AEMT++) não apresenta um ganho para o processo evolutivo e, assim, a mesma foi excluída da metodologia proposta. Da mesma forma as tabelas referentes aos consumidores especiais foram excluídas por não se tratar de uma das proposições principais desta pesquisa.

A última tabela considerada na metodologia proposta desta dissertação é a tabela $P_{11}$, que armazena apenas soluções factíveis, ou seja, configurações factíveis e que atendam as restrições operacionais do problema. Um novo indivíduo $G^{\text {novo }}$ será armazenado em $P_{11}$, se esta não estiver cheia, ou se estiver, se $G^{\text {novo }}$ for melhor que a pior solução $G^{\text {pior }}$. O criterio para determinar se um individuo é melhor, atende os seguintes conceitos, cuja prioridade de otimização segue esta ordem: $i$ ) menor número ponderado de manobras; ii) menor carregamento da rede; iii) melhor perfil de tensão; e iv) menor carregamento da SE.

\subsubsection{Características gerais da metodologia proposta.}

Nesta seção será descrito o funcionamento geral da metodologia proposta e por fim será apresentado o seu algoritmo. Entretanto, inicialmente, será apresentado uma heurística também considerada neste trabalho e que foi desenvolvida recentemente pelo grupo de pesquisa LACO-SEP.

Basicamente esta heurística, desenvolvida em Sanches et al. (2014), age durante o processo evolutivo da metodologia. A mesma focaliza a aplicação dos operadores de reprodução da RNP (PAO e CAO) nas regiões do SD que realmente necessitam de reconfigurações, isto é, nos alimentadores que possuem um grande carregamento e altas taxas de queda de tensão. O objetivo da heurística é restringir o espaço de busca do problema. 


\section{$\checkmark$ Obtenção da Primeira Configuração Factível}

Descrevendo o tratamento geral, a metodologia proposta inicia-se com a obtenção da primeira configuração factível, a partir da configuração original (pré-falta) do SD. Como descrito na seção 2.5.5, uma configuração é considerada factível quando a mesma é radial e garante o fornecimento de energia a todos os setores (exceto os setores sob falta).

Primeiramente, em uma situação de contingência, o setor sob falta é isolado através da abertura das chaves adjacentes à ele. Em seguida, os setores sãos fora de serviço (setores à jusante do setor sob falta) são reconectados a setores adjacentes a estes que possuem fornecimento de energia. Estes setores adjacentes são escolhidos aleatoriamente. Assim, a reconecção é realizada através do fechamento de chaves NAs e quando fornecido energia a todos os setores sãos obtem-se a primeira configuração factível.

\section{$\checkmark$ Primeira População de Indivíduos}

Após a determinação da primeira configuração factível, gera-se 5 novos indivíduos através da aplicação exclusiva do operador genético PAO. O operador genético age na primeira configuração factível ou em uma das configurações já geradas a partir do operador. Essa geração inicial de indivíduos tem o intuito de preencher todas as tabelas de subpopulação (cada tabela contém espaço para 5 indivíduos), formando, assim, a primeira população de indivíduos.

Cada um dos indivíduos gerados será avaliado (fitness) através da aplicação do FC desenvolvido (descrito na seção 4.2). Além disso, os indivíduos também são avaliados em relação ao número de operações de manobras para cada tipo de chave seccionadora.

Logo que os indivíduos são avaliados, os mesmos serão inseridos nas 11 tabelas de subpopulação, respeitando, entretanto, as restrições específicas de cada tabela.

\section{$\checkmark$ Processo Evolutivo}

Uma vez que foi criada a primeira população de indivíduos, a metodologia proposta iniciará o processo evolutivo. A geração de um novo indivíduo inicia-se pela escolha aleatória de uma tabela $P^{*}$, dentre as 11 tabelas existentes na metodologia proposta. Posteriormente, um indivíduo $G^{*}$, pertencente a tabela $P^{*}$, é também 
selecionado aleatoriamente. Por fim, uma nova solução $G^{\text {novo }}$ será criada através da aplicação de um dos operadores genéticos da RNP (PAO ou CAO) em $G^{*}$.

A escolha do operador (PAO ou CAO), para gerar uma nova configuração $G^{\text {novo }}$, é feita seguindo um ajuste dinâmico, que funciona da seguinte forma: no início do processo de busca, o algoritmo utiliza a mesma taxa de probabilidade de escolha para ambos operadores (50\% para cada). Considere que o operador CAO tenha sido escolhido para a geração de um novo indivíduo. Se o indivíduo gerado entrar em uma ou mais tabelas, aumenta-se a probabilidade de CAO para $51 \%$ e, consequentemente, a probabilidade de PAO cai para 49\%, e assim sucessivamente. Esse ajuste dinâmico do processo de escolha dos operadores melhora consideravelmente o desempenho do algoritmo, conforme apresentado em (Santos et al., 2010). Vale lembrar, que em alguns casos para esse ajuste dinâmico, ocorre a saturação da escolha de um operador genético, ou seja, este acaba sendo escolhido $100 \%$ dos casos.

Com a geração do novo indivíduo, $G^{\text {novo }}$, este será avaliado também pela execução do $\mathrm{FC}$ obtendo os valores das perdas resistivas totais $\gamma\left(G^{\text {novo }}\right)$, do maior carregamento da rede $X\left(G^{\text {novo }}\right)$, da maior taxa de queda de tensão $V\left(G^{\text {novo }}\right)$ e do maior carregamento de subestação $B\left(G^{\text {novo }}\right)$. Além da obtenção dos parâmetros elétricos, nesta etapa também é determinado o número de manobras em cada tipo de chave seccionadora para se obter $G^{\text {novo }}$.

Por fim, determinadas as características do novo indivíduo, $G^{\text {novo }}$ será inserido em cada uma das tabelas, se elas não estiverem totalmente preenchidas, ou se estas já estiverem preenchidas, através da comparação com o pior indivíduo de cada tabela. Nesta comparação, se $G^{\text {novo }}$ for melhor que a pior solução, este será inserido na tabela e a pior solução será descartada.

Este processo evolutivo que inclui seleção, reprodução e evolução da população de indivíduos continua até que um critério de parada seja atendido. O critério de parada adotado é um número máximo de avaliações da função.

\section{$\checkmark$ Melhor Solução após o Processo Evolutivo}

Após o processo evolutivo, analogamente a definição da solução final no AEMT++ (seção 3.3), a metodologia proposta determina a melhor solução, seguindo um critério de decisão, entre todas as soluções armazenadas nas 11 tabelas. Basicamente se faz uma varredura em todos os indivíduos armazenados nas 11 tabelas e verifica-se: i) quais deles são soluções factíveis; e ii) após esta primeira verificação busca-se a 
solução com o menor número de manobras ponderadas (ver equação 3.2). A partir daí em caso de empate, analisa-se a seguinte ordem de prioridades: iii) a solução com o menor carregamento da rede; iv) menor queda de tensão; v) menor carregamento da subestação; e, por último, se ainda houver empate em todos os critérios anteriores, escolhe-se o indivíduo que foi encontrado primeiro.

Caso nenhuma das soluções armazenadas nas 11 tabelas for factível, a metodologia sinaliza que não foi encontrada nenhuma solução factível e busca a melhor solução infactível entre elas. Nesta busca pela melhor solução infactível, atendende-se os mesmos critérios, de ii) à v), criados para a busca das soluções factíveis.

Neste caso de infactibilidade, o processo evolutivo não conseguiu encontrar nenhuma solução que atenda aos limites operacionais da rede. Para essa situação, uma sugestão para trabalhos futuros seria inserir procedimentos para cortes de carga, isto é, como última alternativa, desconectam-se cargas dos alimentadores sobrecarregados para que a solução possa respeitar às restrições elétricas.

\section{$\checkmark$ Definição de sequência de chaveamento factível.}

Nota-se que mesmo com a analogia entre a metodologia proposta e o AEMT++, tomou-se o cuidado, acima, de não denominar definição da solução final, mas sim, a melhor solução após o processo evolutivo. Isto porque na metodologia proposta foram alterados os procedimentos para a definição de uma sequência de chaveamento factível. Esta etapa pode modificar a melhor solução encontrada após o processo evolutivo. Assim, só após a definição da sequência de chaveamento é que se tem uma solução final, $G^{\text {final }}$, que pode ou não ser igual a melhor solução após o processo evolutivo.

Basicamente, além de eliminar operações repetidas da melhor solução, como a desenvolvida na metodologia base (AEMT++), busca-se também, na sequência de chaveamento, várias combinações com o objetivo de minimizar o número de manobras da melhor solução após o processo evolutivo mantendo sua factibilidade. Além disso, esta etapa considera e trata o problema das restrições de chaveamento dos diferentes tipos de chaves seccionadoras (uma das proposições desta dissertação).

Assim, devido a importância e complexidade desta etapa, a próxima seção descreverá detalhadamente a definição da sequência de chaveamento, bem como apresentará um exemplo didático para uma melhor compreensão da mesma. 


\section{$\checkmark$ Algoritmo da metodologia proposta.}

Conforme descrito inicialmente nesta seção, apresenta-se abaixo o algoritmo que resume as características gerais da metodologia proposta para o problema de restabelecimento de energia.

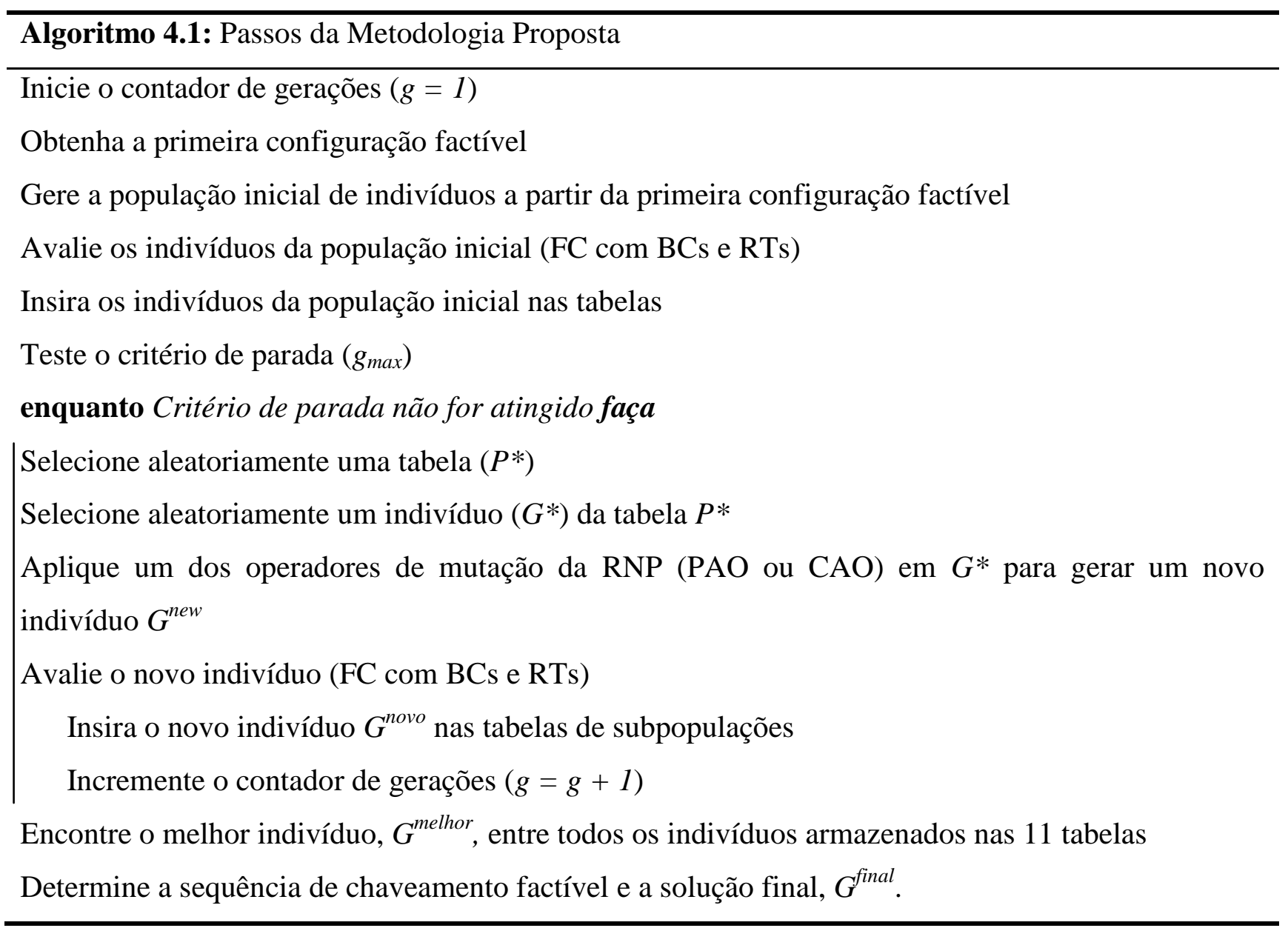

\subsubsection{Definição de Sequência de Chaveamento}

Após o término do processo evolutivo encontra-se a melhor solução, $G^{\text {melhor }}$, entre todos os indivíduos armazenados nas 11 tabelas de subpopulação. Este indivíduo apresenta uma lista de chaves que devem ser operadas para se obter a configuração final desta solução. Entretanto, apenas esta lista de chaves a serem manobradas não é o suficiente para a implantação prática do PRE, deve-se apresentar também, a ordem em que serão manobradas cada chave desta lista.

Outro ponto importante é que cada chaveamento realizado desta lista cria uma configuração intermediária no SD. Estas configurações intermediárias devem ser avaliadas e devem atender as restrições operacionais relaxadas até que se chegue à 
configuração final $\left(G^{f i n a l}\right)$. Abaixo é definido o conceito de restrições relaxadas adotado no trabalho:

Nota 1: Nas restrições relaxadas é aceitável um carregamento do transformador de até $150 \%$, e até $20 \%$ de queda de tensão máxima, porém não são aceitos carregamentos da rede superiores a $100 \%$. Estas restrições relaxadas são consideradas durante as configurações intermediárias, isto é, durante o processo das operações de chaveamento para se obter a configuração final.

Assim, a função de sequência de chaveamento tem como objetivo ordenar as chaves que serão manobradas pelos operadores do sistema, além disso, a mesma também busca minimizar o número de manobras apresentados por $G^{\text {melhor }}$.

Esta etapa da metodologia proposta adota métodos que consideram as restrições de operação dos diferentes tipos de chaves seccionadoras durante cada chaveamento, este tratamento, atende a uma das proposições desta pesquisa.

\section{Procedimento}

Com a lista de manobras da melhor configuração após o término do processo evolutivo, o procedimento para se obter a sequência de chaveamento pode ser dividido em três etapas: i) Abertura das chaves para isolar o setor com falta; ii) Fechamento das chaves adjacentes para restabelecer os setores à jusante da falta, e, iii) Operação dos pares de manobras. Assim, para um melhor entendimento do procedimento, será descrito um algoritmo detalhando cada uma das três etapas:

Etapa 1: Abertura das chaves para isolar o setor com falta.

Passo 1: Primeiramente são operadas as chaves para isolar o setor em falta. Assim, são indicadas, na lista de sequência de chaveamento, as aberturas das chaves à montante e à jusante do setor que está em falta.

Etapa 2: Fechamento das chaves para restabelecer os setores à jusante da falta.

Passo 2: Faz-se a tentativa de fechamento das chaves adjacentes dos grupos de setores que estão sem fornecimento. Durante o restabelecimento de cada grupo, verifica se as restrições relaxadas são violadas. Após a tentativa de reconecção de todos os grupos, se as restrições relaxadas não forem violadas, indica-se o fechamento das chaves seccionadoras na lista de sequência de chaveamento e vá para o próximo passo. Caso contrário, se nem todos os grupos, ou se nenhum dos 
grupos restabelecidos, atenderam as restrições relaxadas, então, desfaz-se as manobras das restrições violadas e siga para o passo 5.

Passo 3: Analisa as restrições gerais (10\% queda de tensão, $100 \%$ carregamento da rede e $100 \%$ carregamento da SE). Se não forem violadas, encerra-se o processo. Caso contrário, vá para o próximo passo.

Etapa 3: Operação dos pares de manobras.

Passo 4: Acrescenta-se a configuração, a operação dos pares de manobras ainda não executados, um par de cada vez. Para cada nova configuração intermediária, verifica se as restrições gerais são atendidas. Continua neste passo até que as restrições gerais sejam atendidas, quando estas forem atendidas, encerra-se o processo.

Passo 5: Faz-se combinações nas operações da lista de pares de manobras. Para cada nova combinação, volte para o passo 2 .

Para melhor entendimento das combinações do passo 5, observe a explicação a seguir: a primeira combinação fará com que a execução do chaveamento seja feita apenas para o primeiro par de manobras da lista, a segunda combinação fará a operação apenas para o segundo par de manobras, e assim, sucessivamente. Quando as opções de um único par de manobras acabarem, fará então, combinações com dois pares de manobras simultaneamente e assim por diante. Vale repetir que, para cada nova combinação, volta-se para o passo 2.

Estes procedimentos realizados buscam minimizar o número de manobras encontrados em $G^{\text {melhor }}$, assegurando porém a factibilidade elétrica relaxada das configurações intermediárias e a factibilidade elétrica geral para a configuração final, $G^{\text {final }}$, determinando assim a ordem de cada chaveamento a ser implantado na prática pelos operadores do sistema.

Vale lembrar também que, em todas as etapas, em cada tentativa de chaveamento (abertura ou fechamento de chaves seccionadoras), sempre é verificado se as restrições de operação das CCMs tipo seca são violadas.

Deve-se primeiramente calcular a carga à jusante da CCM seca que será operada, ou seja, verificar se a carga extrapola o valor de 720kVA (manobra de fechamento) e 120kVA (manobra de abertura). Se estes limites são violados, então se faz uma busca inversa até encontrar uma CCR à montante da chave seca e que possa ser manobrada com carga. Encontrada a CCR, executa-se o seguinte procedimento: abre-se a CCR à montante, opera-se a chave seca selecionada e por último fecha-se novamente 
a CCR. Esta ordem é gravada na sequência de chaveamento, ao invés de ser gravado apenas a operação da CCM tipo seca. Este processo elimina a restrição de chaveamento.

\section{Exemplo}

Para facilitar o entendimento da definição de sequência de chaveamento factível será apresentado a seguir um exemplo ilustrativo de um sistema de distribuição radial com as seguintes características: 9 alimentadores, 24 setores e 35 chaves, sendo que destas 9 são CCRs (representadas em vermelho), 11 são CCMs tipo seca (representadas em verde) e 15 são CCMs que podem ser operadas sob carga (representadas em preto). A ilustração do SD é apresentada na Figura 4.6:

Figura 4.6: Exemplo de um SD pré-falta.

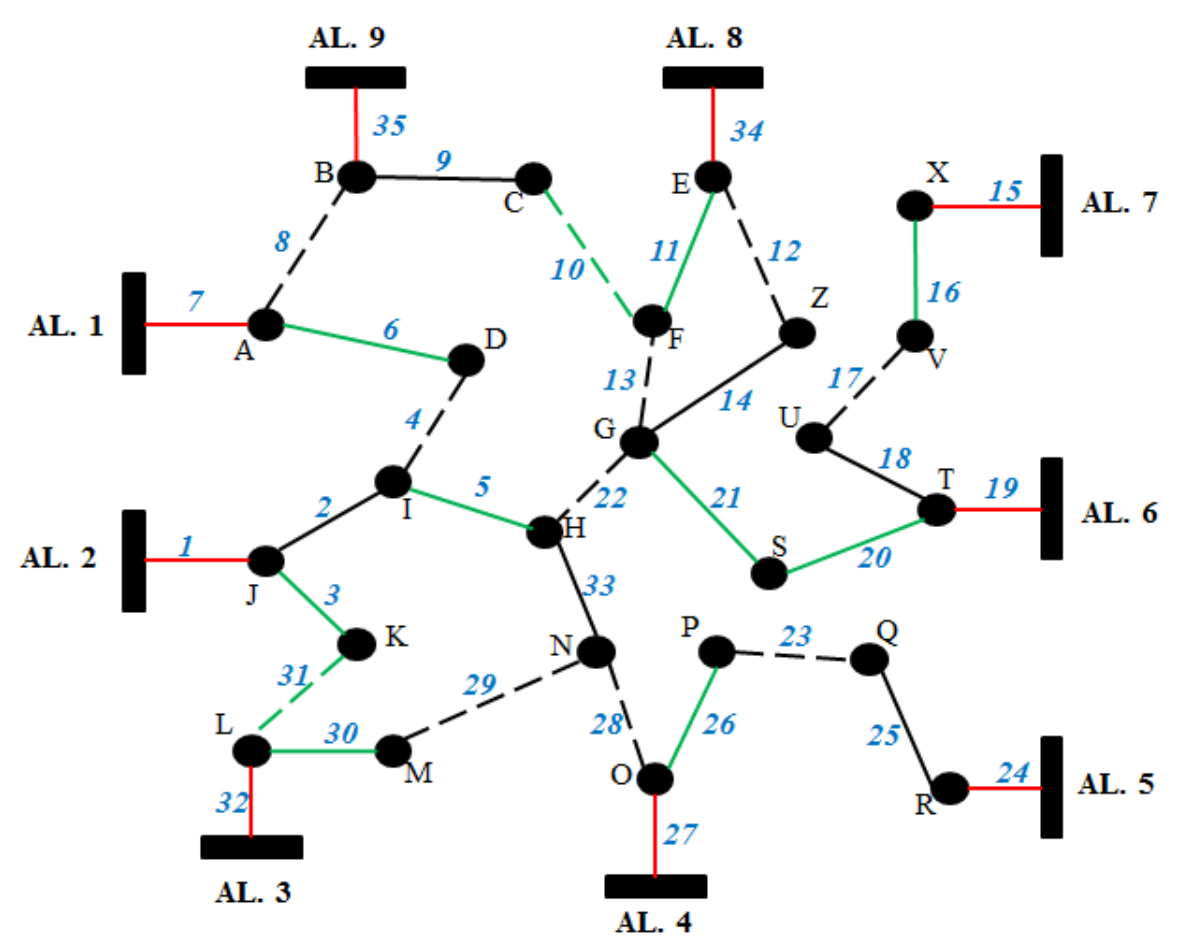

Fonte: Elaborado pelo autor.

As arestas, identificadas por números, representam as chaves, arestas preenchidas são chaves fechadas e arestas tracejadas são chaves abertas. Já as circunferências representam os setores, estes são identificados por letras.

A lista de chaveamentos do melhor indivíduo após o processo evolutivo, $G^{\text {melhor }}$, é apresentada na Tabela 4.3: 
Tabela 4.3: Lista de manobras do melhor indivíduo após o processo evolutivo.

\begin{tabular}{c|c}
\hline \multicolumn{2}{c|}{ Lista de Manobras } \\
\hline Abre & Fecha \\
1 & \\
2 & \\
3 & \\
& 31 \\
14 & 22 \\
18 & 12 \\
\hline
\end{tabular}

Considerando uma falta no setor $\mathbf{J}$ pertencente ao alimentador 2 , a primeira etapa da função da sequência de chaveamento é a abertura das chaves à montante e à jusante da falta, ou seja, será isolado o setor $\mathbf{J}$ através da abertura das chaves 1, 2 e 3, como apresentado nas três primeiras linhas da Tabela 4.3. Esta ação faz com que os setores sãos a jusante (I, H, N e K) fiquem sem fornecimento de energia. A Figura 4.7 representa o estado da rede após a execução deste procedimento. Nota-se que os setores sem fornecimento são representados por circunferências não preenchidas.

Assim, nesta primeira etapa é gravada a seguinte sequência de chaveamento: Indica-se a abertura da chave $\mathbf{1}$ e posteriormente as chaves $\mathbf{2}$ e $\mathbf{3}$.

Figura 4.7: Setor $\mathrm{J}$ em falta isolado pela abertura das chaves 1,2 e 3.

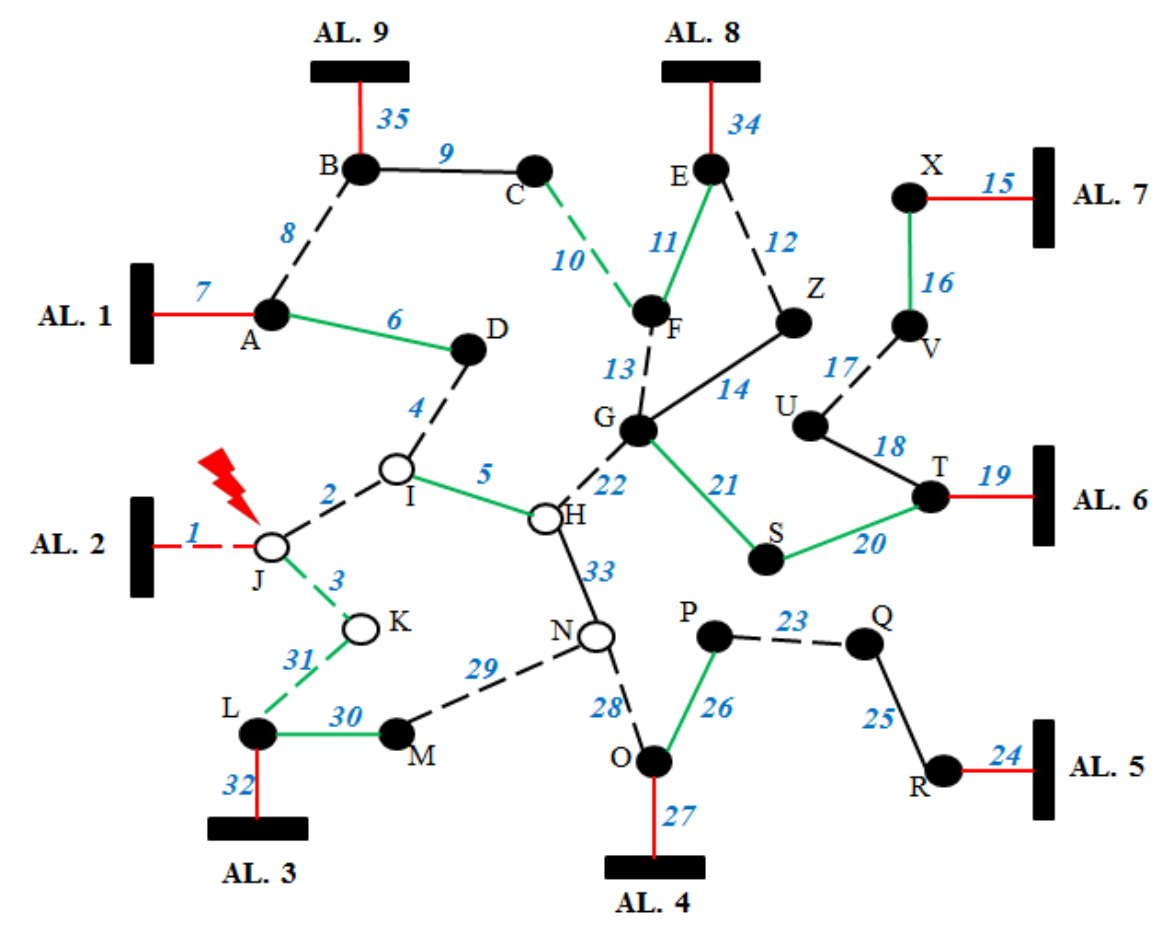

Fonte: Elaborado pelo autor. 
A segunda etapa da função de sequência de chaveamento é responsável pela tentativa do fechamento das chaves que podem restabelecer os setores à jusante da falta e que estão "sãos", ou seja, setores sem fornecimento de energia e que não necessitam permanecerem neste estado.

Observa-se que os setores $\mathbf{I}, \mathbf{H}, \mathbf{K}$ e $\mathbf{N}$ são os setores que estão sem fornecimento e os mesmos formam dois grupos. Grupo 1, formado apenas pelo setor $\mathbf{K}$ e grupo 2, formado pelos setores $\mathbf{I}, \mathbf{H}$ e $\mathbf{N}$. Estes são restabelecidos através do fechamento de uma chave adjacente para cada grupo.

A ordem para a tentativa de fechamento de cada grupo é aleatória. Assim, considere inicialmente o grupo 1, analisando a Figura 4.7, a lista de manobras (linha 4 Tabela 4.3) indica que o setor $\mathbf{K}$ pode ser restabelecido através do fechamento da chave 31, que por sua vez é uma CCM do tipo seca (em verde). O procedimento para este tipo de chave é inicialmente calcular a carga à jusante da mesma, ou seja, verificar se a carga do setor K é menor ou maior que 720kVA (limite de carga para o fechamento da chave tipo seca).

Em seguida, verifica-se se o fechamento desta chave e consequentemente a agregação do setor $\mathbf{K}$ ao alimentador 3 não viola as restrições relaxadas. Considerando que essas não sejam violadas e supondo que a carga no setor $\mathbf{K}$ é superior a 720kVA, a chave seca 31 não pode ser operada. Então, deve-se primeiramente abrir uma CCR que pode ser manobrada sob carga e que esteja à montante desta CCM tipo seca. A chave à montante com estas características é a chave 32. Portanto, abre-se a chave 32, fecha-se a CCM tipo seca 31 e finalmente, volta-se a fechar a CCR 32. Esta sequência de chaveamento é então gravada. O estado final destas operações é uma configuração intermediária apresentada na Figura 4.8. 
Figura 4.8: Setor K restabelecido.

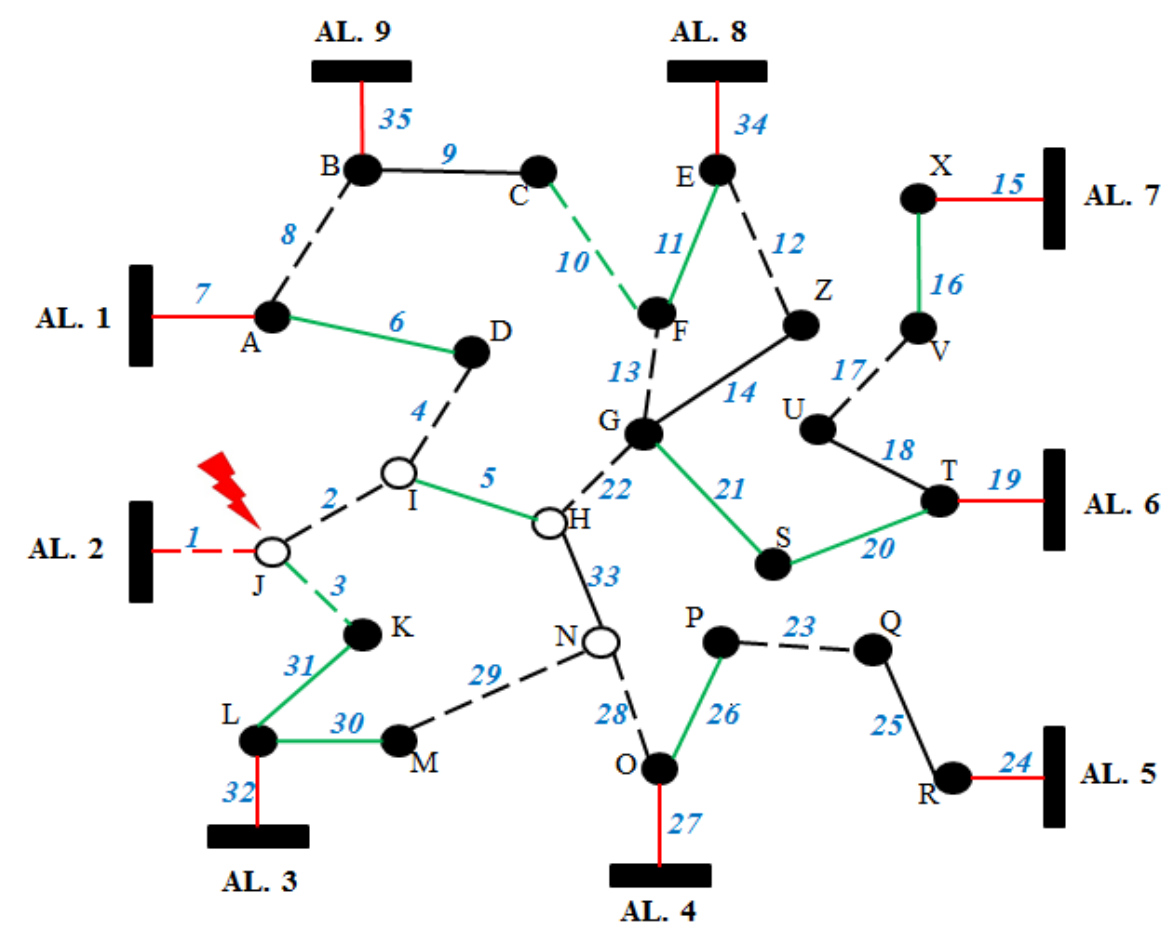

Fonte: Elaborado pelo autor.

Ainda na etapa 2, tenta-se restabelecer agora o grupo 2, formado pelos setores I, H e N. Para isso tenta-se o fechamento da chave 22 (linha 5 - Tabela 4.3). A chave 22 é uma chave que pode ser operada sob carga. Avalia-se então, somente a factibilidade elétrica em relação às restrições relaxadas. Suponha-se que o fechamento viole estas restrições relaxadas, logo não será executada a manobra de fechamento da chave 22 e portanto, segue-se para a etapa 3 (passo 5).

$\mathrm{Na}$ etapa 3, os pares de manobras a serem considerados são apresentados abaixo (linha 6 e 7 - Tabela 4.3):

Par de manobras 1: abertura da chave 14 e fechamento da chave 12.

Par de manobras 2: abertura da chave 18 e fechamento da chave 17.

A primeira combinação executará apenas a operação do par de manobras 1 (abertura chave 14 e fechamento chave 12). Verifica-se que o par não é do tipo chave seca, assim não há necessidade de verificar a factibilidade do chaveamento. Logo depois, verifica-se se a operação não extrapola as restrições relaxadas. Suponha-se que as restrições relaxadas deste par de manobras não sejam extrapoladas.

Após a operação do par de manobras o próximo passo é voltar a etapa 2 (passo 2), e tentar realizar o fechamento da chave 22 para restabelecer o grupo 2 (ainda sem 
fornecimento), verificando novamente a factibilidade elétrica em relação as restrições relaxadas.

Considere que as restrições relaxadas foram violadas, logo, esta configuração (Figura 4.9) é desfeita. Portanto, volta-se ao estado da Figura 4.8, ou seja, desfaz-se a tentativa de fechamento da chave 22 e a operação do primeiro par de manobras.

O estado final da tentativa para a primeira combinação é apresentado na Figura 4.9 .

Figura 4.9: Estado final da rede após a tentativa da primeira combinação (restrições relaxadas violadas).

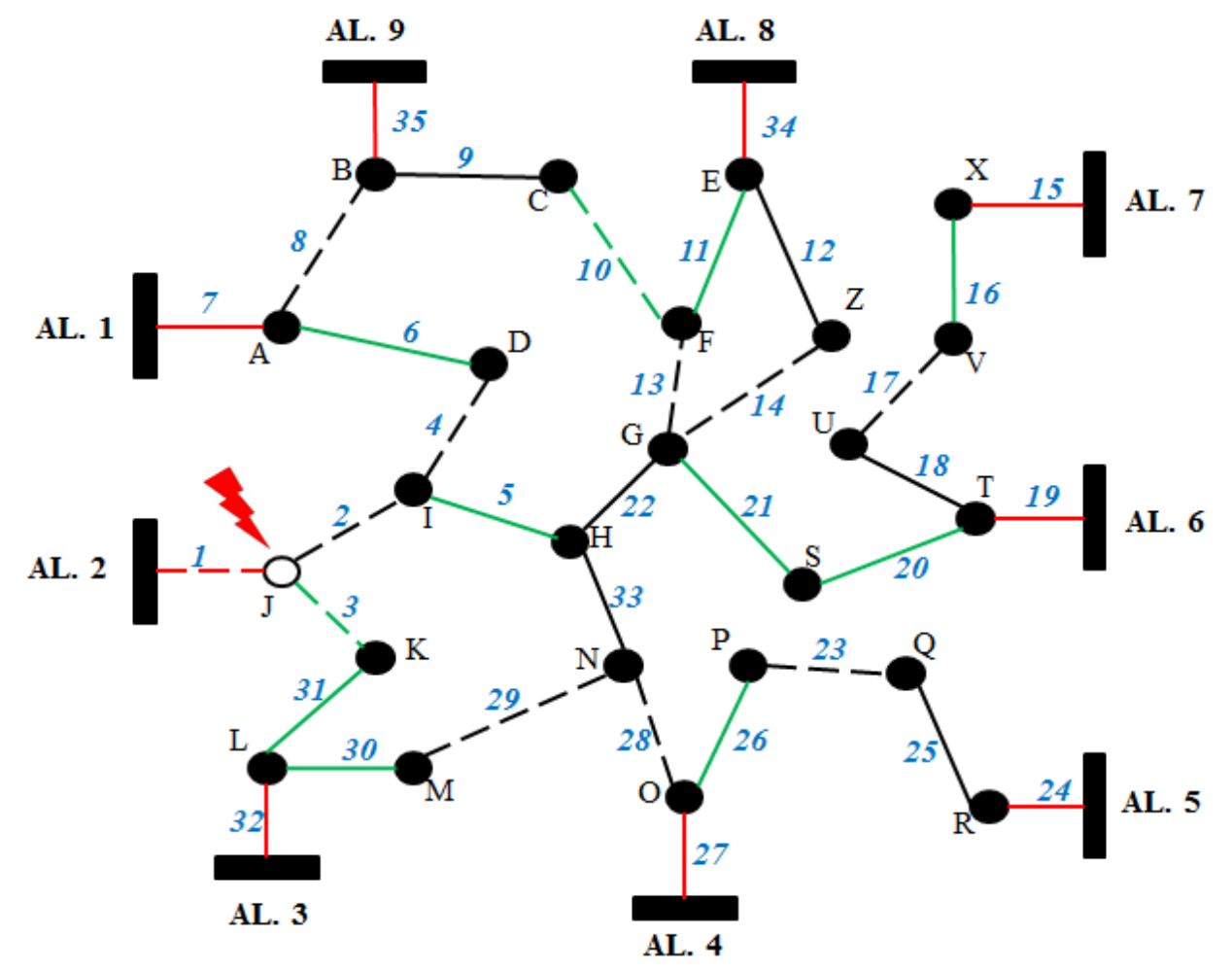

Fonte: Elaborado pelo autor.

Como houve violação das restrições relaxadas durante a tentativa de restabelecer os setores sãos que estavam sem fornecimento, vá para o passo 5 e tenta-se obter uma nova combinação.

Assim, a partir da configuração da Figura 4.8, tenta-se a segunda combinação que será a operação única do par de manobras 2 (abertura da chave $\mathbf{1 8}$ e fechamento da chave 17). As duas chaves são CCMs que podem ser operadas sob carga, e então faz-se necessário verificar apenas a factibilidade elétrica das restrições relaxadas ao operar o par de manobras. 
Suponha que a operação do par de manobras satisfaz as restrições relaxadas. $\mathrm{O}$ próximo passo é voltar a etapa 2, passo 2 , e tentar realizar o fechamento dos setores que não foram ainda restabelecidos. Este procedimento, novamente, é realizado através da tentativa do fechamento da chave 22. Com a operação do segundo par de manobras e o fechamento da chave 22, analisa-se se esta configuração intermediária (Figura 4.10) atende as restrições relaxadas.

Caso as restrições relaxadas da configuração intermediária (Figura 4.10) fossem respeitadas, o próximo passo (passo 3) seria testar as restrições elétricas gerais desta mesma configuração, e caso estas também sejam atendidas, tem-se o fim do processo. Entretanto, se as restrições relaxadas fossem atendidas e as restrições gerais não, iria-se para o passo 4, ou seja, manteria-se esta configuração (Figura 4.10), encerraria a busca por novas combinações e acrescentaria-se as operações dos demais pares de manobras até que as restrições elétricas gerais fossem atendidas.

Figura 4.10: Estado final da rede após a tentativa da segunda combinação (restrições relaxadas violadas).

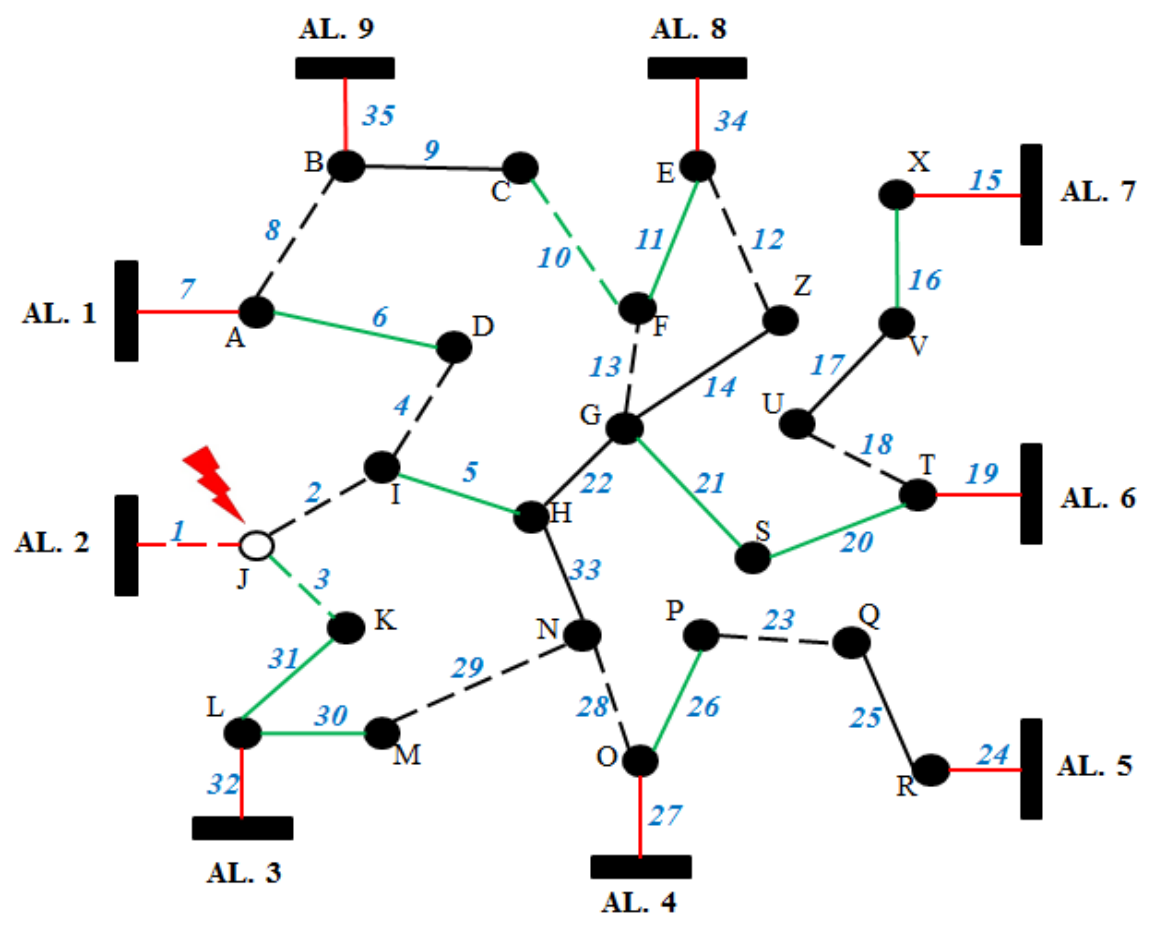

Fonte: Elaborado pelo autor.

Porém, para este exemplo, as restrições relaxadas no momento do fechamento da chave 22 (Figura 4.10) não foram atendidas, assim, faz-se necessário a busca por mais uma combinação (passo 5) dos pares de manobras para a tentativa de restabelecer os setores ainda não energizados. 
Assim, a terceira combinação será realizada através da operação dos dois pares de manobras 1 e 2, respectivamente: $i$ ) abertura da chave 14 e fechamento da chave $12 \mathrm{e}$ ii) abertura da chave 18 e fechamento da chave 17. Verificando as operações de cada par, obtem-se que as operações não extrapolam as restrições relaxadas.

Após a operação dos dois pares de manobras ocorre uma nova tentativa em fechar a chave $\mathbf{2 2}$ para restabelecer os setores $\mathbf{I}, \mathbf{H}$ e $\mathbf{N}$. O próximo passo é verificar se o fechamento atende as restrições elétricas relaxadas. Neste caso, atende e a chave pode ser fechada (Figura 4.11).

Por fim, com as restrições relaxadas atendidas, testa-se, nesta mesma configuração (Figura 4.11), se as restrições elétricas gerais são atendidas. Neste caso a factibilidade elétrica geral é também atingida, obtendo-se assim, o fim do procedimento de sequência de chaveamento

Figura 4.11: Estado final da rede após a tentativa da terceira combinação (resposta para o problema).

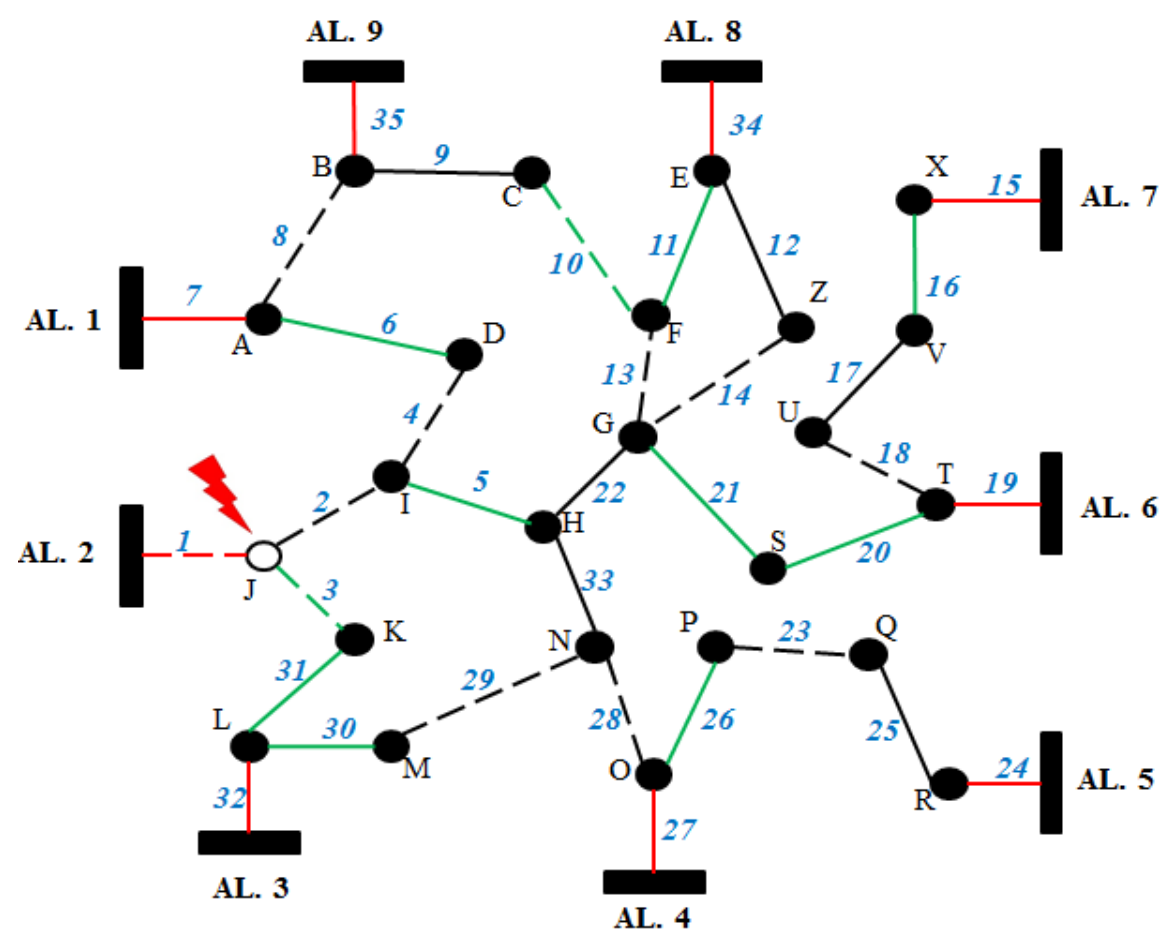

Fonte: Elaborado pelo autor.

Portanto, a sequência de chaveamento factível para a configuração final, $G^{\text {final }}$ (Figura 4.11), é:

$\left.\begin{array}{ll}\text { i) } & \text { Abertura da Chave 1; } \\ \text { ii) } & \text { Abertura da Chave 2; } \\ \text { iii) } & \text { Abertura da Chave 3; }\end{array}\right\}$ Etapa 1 


$\left.\begin{array}{ll}\text { iv) } & \text { Abertura da Chave 32; } \\ \text { v) } & \text { Fechamento da Chave 31; } \\ \text { vi) } & \text { Fechamento da Chave 32; }\end{array}\right\}$ Etapa 2

Observa-se que a sequência factível foi alcançada apenas com a realização de todas as operações dos pares de manobras, porém primeiramente foram realizadas várias combinações com a tentativa de minimizar o número de manobras.

Além disso, analisa-se que apareceram mais duas manobras com o objetivo de respeitar as restrições de chaveamento dos diferentes tipos de chaves (operações de chaveamento $i v$ e vi).

\subsection{Considerações Finais}

Neste capítulo foi apresentada a metodologia proposta nesta dissertação para o tratamento do problema de restabelecimento de energia. Foi apresentado também que a modelagem dos BCs e dos RTs, com ajuste automático de taps, foi inserida no FC de varredura direta/inversa com RNP. Vale ressaltar que esse FC é de suma importância para a metodologia proposta, pois é ele quem avalia os parâmetros elétricos de cada uma das configurações geradas durante o processo evolutivo do AEMO.

Posteriormente, o capítulo abordou a metodologia para o problema de restabelecimento de energia de maneira geral, explicando cada etapa e apresentando um algoritmo que resume seu funcionamento.

Por fim, foi detalhada a etapa da metodologia proposta que trata da definição da sequência de chaveamento. Esta etapa abordou as características dos diferentes tipos de chaves seccionadoras, respeitando as restrições operacionais exclusivas das chaves seccionadoras tipo seca (maioria em um SD).

O próximo capítulo abordará os resultados da metodologia proposta em SDs reais e de grande porte. Foram criados vários casos para apontar os resultados específicos de cada proposição desta dissertação. 



\section{Capítulo 5 - Testes e Análises dos Resultados}

\subsection{Introdução}

Neste capítulo serão apresentados os resultados experimentais obtidos a partir da aplicação da metodologia proposta em SDs reais de grande porte. Foram realizadas diversas simulações computacionais e estas foram divididas em quatro testes diferentes.

No primeiro teste a metodologia proposta foi aplicada no SD da cidade de Marília/SP, que contém dados de BCs e de RTs. O objetivo deste teste é validar a metodologia proposta para SDs possuindo esses equipamentos. Foi avaliado, também, o efeito desses equipamentos na obtenção de PREs. Os demais testes foram realizados no SD de Londrina/PR, dados obtidos juntamente com a equipe do projeto de P\&D ao qual esta dissertação está vinculada. Vale destacar que esse SD não possui RTs.

Para execução de todos os testes o programa computacional da metodologia proposta foi implementado em linguagem $\mathrm{C}$, e foram executados em um computador portátil (laptop) com processador Core i7-4510U, 2,0GHz, 8Gbytes de memória RAM, Sistema Operacional Linux, distribuição Ubuntu 14.04.2.

\subsection{Teste 1 - Metodologia Proposta considerando a existência de BCs e RTs (SD Marília/SP)}

Com o objetivo de analisar o impacto da consideração dos BCs e RTs para tratar o problema de restabelecimento de energia, foram realizadas duas análises distintas: Caso 1) sem considerar os BCs e RTs existentes no SD da cidade de Marília/SP e Caso 2) considerando a presença desses equipamentos.

Conforme apresentado na seção 4.2.1 o SD da cidade de Marília/SP possui 15.471 barras, 2.112 setores, 1.905 chaves, 20 alimentadores, 3 subestações, 33 BCs e 5 RTs com ajuste automático de tap.

Em ambos os testes foi considerada uma falta permanente no setor 1.762, que se localiza no começo do alimentador 05, em roxo na Figura 5.1, provocando assim a abertura do disjuntor deste alimentador e a interrupção do fornecimento de energia a todos os consumidores conectados a ele, conforme Figura 5.2, alimentador em rosa. 
Figura 5.1: SD de Marília - Alimentador Pré-Falta.

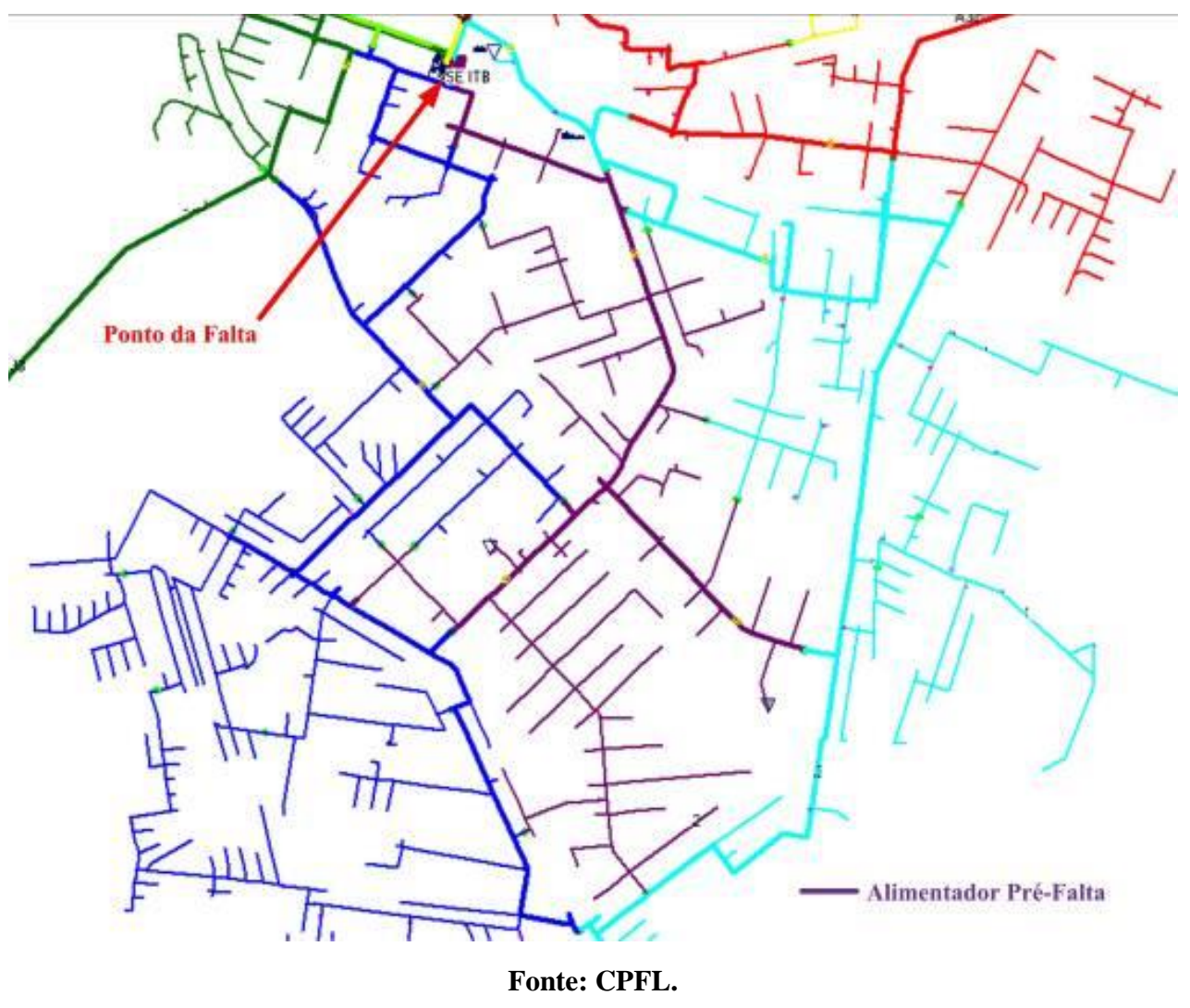

Figura 5.2: SD de Marília - Alimentador Isolado.

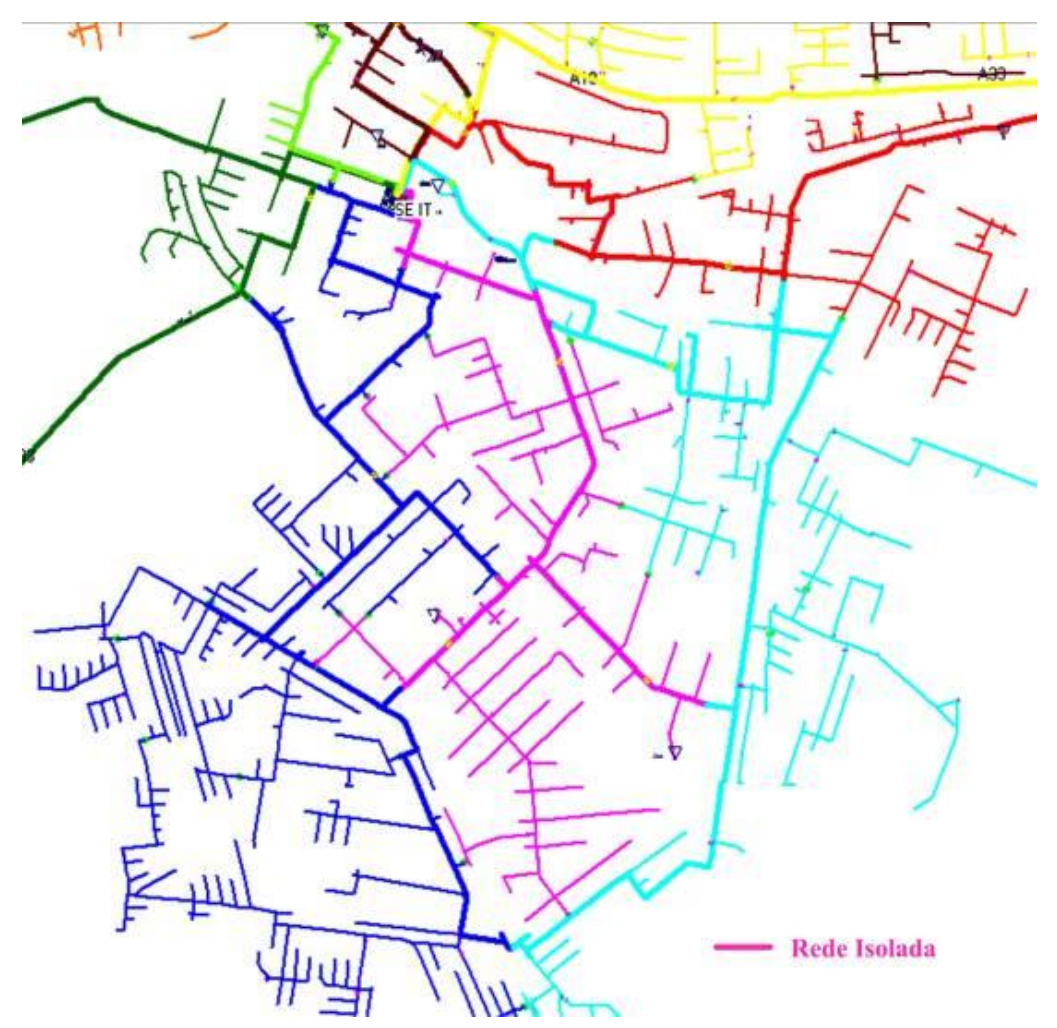

Fonte: CPFL. 
Nestes testes foram realizadas 200 execuções da metodologia proposta, ou seja, 100 execuções para cada um dos casos considerados. Nestas simulações foram utilizados os seguintes valores para os parâmetros de entrada da metodologia proposta:

$\checkmark$ Número máximo de indivíduos gerados $=10.000$;

$\checkmark$ Tamanho das subpopulações em cada tabela $=5$.

Vale destacar que todos os resultados experimentais apresentados nestes casos são relativos a um único indivíduo, selecionado e fornecido pela metodologia proposta para ser a solução final do problema. Esta solução é aquela que corresponderá ao plano de restabelecimento fornecido ao operador do SD.

\subsubsection{Caso 1: Sem considerar BCs e RTs}

A Tabela 5.1 apresenta os valores mínimo, médio, máximo e desvio padrão dos parâmetros (características elétricas e operacionais) dos 100 PREs obtidos nas 100 execuções da metodologia proposta, sem considerar os BCs e os RTs.

Tabela 5.1:Valores das manobras, das restrições operacionais e das perdas ativas para as soluções finais do

Caso 1.

\begin{tabular}{c|cccc}
\hline & Mínimo & Médio & Máximo & DP* \\
\hline Manobras em CCMs & 0,00 & 0,00 & 0,00 & 0,00 \\
Manobras em CCRs & 1,00 & 1,00 & 1,00 & 0,00 \\
Manobras totais & 1,00 & 1,00 & 1,00 & 0,00 \\
Queda de tensão (\%) & 8,65 & 11,08 & 11,16 & 0,41 \\
Carreg. da Rede (\%) & 90,17 & 90,17 & 90,17 & 0,00 \\
Carreg. da SE (\%) & 101,24 & 101,69 & 118,30 & 2,60 \\
Perdas (kW) & $1.817,73$ & $2.315,71$ & $2.326,57$ & 63,39 \\
\hline
\end{tabular}

*Desvio Padrão

Analisando os resultados da Tabela 5.1 verifica-se que todos os PREs apresentados pela metodologia são soluções não factíveis, pois o valor mínimo de carregamento da SE é 101,24\%, valor este que extrapola o limite máximo de $100 \%$. Analisando os valores médios verifica-se também que os valores de queda de tensão e de carregamento da SE são respectivamente 11,08\% e 101,69\%, valores que também extrapolam os limites de $10 \%$ e $100 \%$, respectivamente. 


\subsubsection{Caso 2: Considerando BCs e RTs}

Da mesma maneira que no teste anterior, mas agora considerando os BCs e RTs, concluídas as 100 execuções da metodologia proposta, são obtidos 100 PREs, onde os valores das manobras, das restrições operacionais e das perdas ativas são apresentados na Tabela 5.2.

Tabela 5.2: Valores das manobras, das restrições operacionais e das perdas ativas para as soluções finais do Caso 2.

\begin{tabular}{c|cccc}
\hline & Mínimo & Médio & Máximo & DP* \\
\hline Manobras em CCMs & 0,00 & 0,00 & 0,00 & 0,00 \\
Manobras em CCRs & 1,00 & 1,00 & 1,00 & 0,00 \\
Manobras totais & 1,00 & 1,00 & 1,00 & 0,00 \\
Queda de tensão (\%) & 4,75 & 5,13 & 5,14 & 0,06 \\
Carreg. da Rede (\%) & 81,64 & 81,64 & 81,64 & 0,00 \\
Carreg. da SE (\%) & 96,14 & 96,15 & 97,00 & 0,09 \\
Perdas (kW) & $2.046,66$ & $2.068,99$ & $2.069,45$ & 3,22 \\
\hline
\end{tabular}

*Desvio Padrão

Analisando a Tabela 5.2 nota-se que todas as soluções obtidas foram factíveis, pois nenhuma delas desrespeitou os limites das restrições operacionais. Analisando a pior situação, verifica-se que todos os valores máximos estão dentro dos limites (queda de tensão inferior a 7\% e carregamentos da rede e da SE inferiores a 100\%).

Comparando os resultados obtidos para os dois casos testados constata-se a importância de a metodologia possibilitar a consideração de BCs e RTs, pois sem considerar esses equipamentos não foi possível encontrar solução factível alguma. Por outro lado, considerando a existência desses equipamentos, a metodologia proposta conseguiu encontrar soluções factíveis. Vale ressaltar que se a metodologia não permitisse a consideração de tais equipamentos ela indicaria, para o operador do sistema, que a saída seria realizar corte de cargas para obtenção de uma solução factível.

Os valores da queda de tensão máxima na rede, carregamento máximo dos componentes da rede e as perdas obtidas pela metodologia proposta nos dois casos são comparados com os valores obtidos pelo software da CPFL (concessionária responsável pelo SD de Marília/SP), conforme Tabela 5.3 e Tabela 5.4. Nota-se que os erros apresentados são menores que 1,38\%, o que mostra aderência da metodologia proposta. 
Tabela 5.3:Parâmetros gerais do FC proposto versus CPFL para o Caso 1.

\begin{tabular}{c|ccc}
\hline & \multicolumn{3}{|c}{ Caso 1 } \\
\cline { 2 - 4 } & Proposta & CPFL & Erro (\%) \\
Queda de tensão (\%) & 11,08 & 11,22 & 1,25 \\
Carreg. da Rede (\%) & 90,17 & 90,00 & $-0,19$ \\
Perdas (kW) & $2.315,71$ & $2.335,7$ & 0,86 \\
\hline
\end{tabular}

Tabela 5.4:Parâmetros gerais do FC proposto versus CPFL para o Caso 2.

\begin{tabular}{c|ccc}
\hline & \multicolumn{3}{|c}{ Caso 2 } \\
\cline { 2 - 4 } & Proposta & CPFL & Erro (\%) \\
Queda de tensão (\%) & 5,13 & 5,06 & $-1,38$ \\
Carreg. da Rede (\%) & 81,64 & 82,00 & 0,44 \\
Perdas (kW) & $2.068,99$ & $2.060,60$ & $-0,41$ \\
\hline
\end{tabular}

Por fim, são apresentados na Tabela 5.5 os valores médios das restrições operacionais nos dois casos, para uma comparação entre os mesmos.

Tabela 5.5: Valores médios das restrições operacionais para os Casos 1 e 2.

\begin{tabular}{c|ccc}
\hline & Caso 1 & Caso 2 & Diferença (\%) \\
\hline Queda de tensão (\%) & 11,08 & 5,13 & 115,98 \\
Carreg. da Rede (\%) & 90,17 & 81,64 & 10,45 \\
Perdas (kW) & 101,69 & 96,15 & 5,76 \\
\hline
\end{tabular}

Percebe-se, pela análise da Tabela 5.5, uma grande diferença entre os valores médios das restrições operacionais do SD quando se desconsidera equipamentos reais da rede (BCs e RTs), com diferenças da ordem de $115,98 \%$ no tocante a queda de tensão. Pode-se inferir também que, a modelagem dos BCs e RTs dos SDs influenciam diretamente na obtenção de planos de restabelecimento, visto que, quando não considerados no sistema, não foram obtidas soluções factíveis, como demonstrado no caso 1 . 


\subsection{Teste 2 - Restrições dos Chaveamentos (SD Londrina /PR)}

Nesta seção (teste 2) serão apresentados os resultados experimentais obtidos pela metodologia proposta considerando a ocorrência de 3 faltas simples no SD de Londrina/PR, com o intuito de comprovar o tratamento das restrições de chaveamento dos diferentes tipos de chaves seccionadoras na etapa de sequência de chaveamento (ver seção 4.3.3).

Os dados do Sistema de Londrina/PR são: 36.833 barras, 3.333 setores, 3.680 chaves, onde destas 159 são CCRs (82 que podem operar sob carga e 77 sob curto circuito) e 3.521 são CCMs (3.345 chaves tipo seca, 159 chaves que podem operar sob carga e 17 sob curto circuito). O sistema possui ainda 73 alimentadores e 13 transformadores de potência alocados em 7 subestações e mais de 235.000 consumidores.

Com o intuito de avaliar a metodologia proposta foram realizadas 100 simulações computacionais para cada setor em falta. Em todas as simulações foram utilizados os seguintes parâmetros de entrada:

$\checkmark \quad$ Número máximo de indivíduos gerados $\left(g_{\max }\right)=100.000$;

$\checkmark$ Tamanho das subpopulações armazenadas nas 11 tabelas $=5$.

No entanto, para este teste, foi analisado apenas 1 PRE dos 100 obtidos para cada setor em falta. Em virtude de a análise específica da sequência de chaveamento ser feita para cada PRE. Os PREs escolhidos são aqueles que apresentam como resposta da sequência de chaveamento o tratamento das restrições das CCMs secas.

\subsubsection{Setor em falta: 430}

Das 100 execuções realizadas considerando uma falta simples no setor 430 o melhor PRE obtido (semente de aleatoriedade $\mathrm{n}^{\circ} 48$ ) após o processo evolutivo tem seus parâmetros apresentados na Tabela 5.6.

Tabela 5.6:Valores das manobras, das restrições operacionais e das perdas ativas para a melhor solução após o processo evolutivo.

\begin{tabular}{c|c}
\hline & Valores \\
\hline Manobras Totais & 7,00 \\
(continua) \\
\hline
\end{tabular}




\begin{tabular}{c|c|}
\hline \multicolumn{2}{c|}{ (continuação) } \\
Número Ponderado de Manobras & 2,50 \\
Manobras em CCR & 5,00 \\
Manobras em CCM & 2,00 \\
Carreg. da Rede (\%) & 90,98 \\
Carreg. do Transformador (\%) & 96,62 \\
Queda de Tensão (\%) & 7,64 \\
Perdas (kW) & $3.951,73$ \\
Tempo de execução (s) & 35,801 \\
\hline
\end{tabular}

Observa-se, pelos parâmetros apresentados na Tabela 5.6, que a melhor solução obtida após o processo evolutivo, ou seja, a melhor solução entre os 100.000 indivíduos gerados no processo evolutivo, é factível, pois a mesma atende a todas as restrições operacionais da rede.

Como descrito no capítulo sobre a metodologia proposta (Capítulo 4), após a execução do processo evolutivo, a melhor solução encontrada (Tabela 5.6) será analisada para definição da sequência de chaveamento. Após essa etapa será determinada a solução final (PRE), com a respectiva lista contendo a ordem e as manobras que devem ser realizadas pelos operadores do sistema.

Os parâmetros da solução final (após a etapa de sequência de chaveamento) são apresentados na Tabela 5.7. Observe que nessa tabela são apresentados os números de chaveamentos para todos os tipos diferentes de chaves seccionadoras.

Tabela 5.7: Valores das manobras, das restrições operacionais e das perdas ativas para a solução final.

\begin{tabular}{c|c}
\hline & Valores \\
\hline Manobras Totais & 4,00 \\
Número Ponderado de Manobras & 1,30 \\
Manobras em CCR & 3,00 \\
Manobras em CCR com Carga & 2,00 \\
Manobras em CCR com Curto & 1,00 \\
Manobras em CCM & 1,00 \\
& (continua) \\
\hline
\end{tabular}




\begin{tabular}{c|c|}
\hline \multicolumn{2}{c|}{ (continuação) } \\
Manobras em CCM Seca & 1,00 \\
Manobras em CCM com Carga & 0,00 \\
Manobras em CCM com Curto & 0,00 \\
Carreg. da Rede (\%) & 84,57 \\
Carreg. do Transformador (\%) & 96,62 \\
Queda de Tensão (\%) & 7,12 \\
Perdas (kW) & $3.677,53$ \\
& (conclusão) \\
\hline
\end{tabular}

Os valores apresentados na Tabela 5.7 indicam que a solução final também é factível, pois a mesma atende às restrições operacionais da rede e, ainda, observa-se que a etapa de sequência de chaveamento conseguiu minimizar o número de manobras totais (4 manobras) em relação à melhor solução após o processo evolutivo indicado na Tabela 5.6 (7 manobras). Isto comprova a capacidade de a etapa de determinação de sequência, em certas situações, possibilitar a minimização do número de manobras (conforme apresentado na seção 4.3.3).

A sequência de chaveamento, ou seja, a ordem com que as chaves devem ser manobradas para implementar o PRE obtido (cujos parâmetros são apresentados na Tabela 5.7) é encontrada na Tabela 5.8.

Tabela 5.8:Ordem da sequência de chaveamento que deve ser realizada pelos Operadores do Sistema.

\begin{tabular}{c|ccc}
\hline Ordem & Operação & ID da Chave & Tipo de Chave \\
\hline $1^{\circ}$ & Abrir & 8480005694 & CCR \\
$2^{\circ}$ & Abrir & 8480003949 & CCR \\
$3^{\circ}$ & Fechar & 8480004893 & CCM Seca \\
$4^{\circ}$ & Fechar & 8480003949 & CCR \\
\hline
\end{tabular}

De acordo com a Tabela 5.8 verifica-se que as manobras destacadas em vermelho indicam o tratamento para a restrição de chaveamento da CCM tipo seca $\left(3^{\circ}\right.$ chaveamento).

É possível notar também, que não foi possível operar a chave seca (8480004893) sob carga. Isto ocorre, em virtude de a carga à jusante desta chave extrapolar o limite de 
720kVA para o seu fechamento. Sendo assim, foi necessário realizar uma busca inversa, à montante desta chave. Encontrada a primeira CCR que pode ser operada sob carga (chave 8480003949$)$, a chave é aberta ( $2^{\circ}$ chaveamento). Com isso, todos os setores a sua jusante ficam sem fornecimento de energia. Com o estado desenergizado a CCM tipo seca pode ser fechada ( $3^{\circ}$ chaveamento). Por fim, fecha-se novamente a CCR para reenergizar os setores à sua jusante.

\subsubsection{Setor em falta: 431}

Das 100 execuções realizadas considerando uma falta simples no setor 431, o melhor PRE obtido (semente de aleatoriedade $\mathrm{n}^{\circ} 45$ ) após o processo evolutivo tem seus parâmetros apresentados na Tabela 5.9.

Tabela 5.9: Valores das manobras, das restrições operacionais e das perdas ativas para a melhor solução após o processo evolutivo.

\begin{tabular}{c|c}
\hline & Valores \\
\hline Manobras Totais & 9,00 \\
Número Ponderado de Manobras & 2,70 \\
Manobras em CCR & 7,00 \\
Manobras em CCM & 2,00 \\
Carreg. da Rede (\%) & 90,98 \\
Carreg. do Transformador (\%) & 96,62 \\
Queda de Tensão (\%) & 7,64 \\
Perdas (kW) & $3.974,79$ \\
Tempo (s) & 24,498 \\
\hline
\end{tabular}

Os parâmetros da solução final (após a função de sequência de chaveamento) são apresentados na Tabela 5.10:

Tabela 5.10: Valores das manobras, das restrições operacionais e das perdas ativas para a solução final.

\begin{tabular}{c|c}
\hline Manobras Totais & Valores \\
\hline Número Ponderado de Manobras & 6,00 \\
1,50 \\
(continua) \\
\hline
\end{tabular}




\begin{tabular}{c|c|}
\hline \multicolumn{2}{c}{ (continuação) } \\
Manobras em CCR & 5,00 \\
Manobras em CCR com Carga & 4,00 \\
Manobras em CCR com Curto & 1,00 \\
Manobras em CCM & 1,00 \\
Manobras em CCM Seca & 1,00 \\
Manobras em CCM com Carga & 0,00 \\
Manobras em CCM com Curto & 0,00 \\
Carreg. da Rede (\%) & 88,94 \\
Carreg. do Transformador (\%) & 96,62 \\
Queda de Tensão (\%) & 7,12 \\
Perdas (kW) & $3.700,59$ \\
\hline
\end{tabular}

A sequência de chaveamento, ou seja, a ordem com que as chaves devem ser manobradas para implementar o PRE obtido (cujos parâmetros são apresentados na Tabela 5.10) é encontrada na Tabela 5.11.

\begin{tabular}{c|ccc}
\multicolumn{4}{c}{ Tabela 5.11: Ordem da sequência de chaveamento que deve ser realizada pelos Operadores do Sistem } \\
\hline Ordem & Operação & ID da Chave & Tipo de Chave \\
\hline $1^{\circ}$ & Abrir & 8480000188 & CCR \\
$2^{\circ}$ & Fechar & 8480000311 & CCR \\
$3^{\circ}$ & Abrir & 8480005694 & CCR \\
$4^{\circ}$ & Abrir & $\mathbf{8 4 8 0 0 0 3 9 4 9}$ & CCR \\
$5^{\circ}$ & Fechar & $\mathbf{8 4 8 0 0 0 4 8 9 3}$ & CCM Seca \\
$6^{\circ}$ & Fechar & $\mathbf{8 4 8 0 0 0 3 9 4 9}$ & CCR \\
\hline
\end{tabular}

\subsubsection{Setor em falta: 2269}

Das 100 execuções realizadas considerando uma falta simples no setor 2269 , o melhor PRE obtido (semente de aleatoriedade $\mathrm{n}^{\circ} 13$ ) após o processo evolutivo tem seus parâmetros apresentados na Tabela 5.12. 
Tabela 5.12: Valores das manobras, das restrições operacionais e das perdas ativas para a melhor solução após o processo evolutivo.

\begin{tabular}{c|c}
\hline & Valores \\
\hline Manobras Totais & 5,00 \\
Número Ponderado de Manobras & 5,00 \\
Manobras em CCR & 0,00 \\
Manobras em CCM & 5,00 \\
Carreg. da Rede (\%) & 84,75 \\
Carreg. do Transformador (\%) & 96,62 \\
Queda de Tensão (\%) & 3,93 \\
Perdas (kW) & $3.817,02$ \\
Tempo (s) & 17,984 \\
\hline
\end{tabular}

Os parâmetros da solução final (após a função de sequência de chaveamento) são apresentados na Tabela 5.13.

Tabela 5.13: Valores das manobras, das restrições operacionais e das perdas ativas para a solução final.

\begin{tabular}{c|c}
\hline & Valores \\
\hline Manobras Totais & 7,00 \\
Número Ponderado de Manobras & 5,20 \\
Manobras em CCR & 2,00 \\
Manobras em CCR com Carga & 2,00 \\
Manobras em CCR com Curto & 0,00 \\
Manobras em CCM & 5,00 \\
Manobras em CCM Seca & 3,00 \\
Manobras em CCM com Carga & 2,00 \\
Manobras em CCM com Curto & 0,00 \\
Carreg. da Rede $(\%)$ & 84,75 \\
Carreg. do Transformador $(\%)$ & 96,62 \\
Queda de Tensão (\%) & 7,12 \\
Perdas (kW) & $3.817,02$ \\
\hline
\end{tabular}


A sequência de chaveamento, ou seja, a ordem com que as chaves devem ser manobradas para implementar o PRE obtido (cujos parâmetros são apresentados na Tabela 5.13) é encontrada na Tabela 5.14.

\begin{tabular}{c|ccc}
\multicolumn{4}{c}{ Tabela 5.14: Ordem da sequência de chaveamento que deve ser realizada pelos Operadores do Siste } \\
\hline Ordem & Operação & ID da Chave & Tipo de Chave \\
\hline $1^{\mathbf{0}}$ & Abrir & 8480000285 & CCM Seca \\
$2^{\mathbf{o}}$ & Abrir & 8480000256 & CCM Seca \\
$\mathbf{3}^{\mathbf{0}}$ & Abrir & $\mathbf{8 4 8 0 0 0 5 4 0 6}$ & CCR \\
$\mathbf{4}^{\mathbf{0}}$ & Abrir & $\mathbf{8 4 8 0 0 0 0 0 9 5}$ & CCM Seca \\
$\mathbf{5}^{\mathbf{0}}$ & Fechar & $\mathbf{8 4 8 0 0 0 5 4 0 6}$ & CCR \\
$6^{\mathbf{0}}$ & Fechar & 8480000251 & CCM com Carga \\
$7^{\mathbf{0}}$ & Fechar & 8480000174 & CCM com Carga \\
\hline
\end{tabular}

\subsection{Teste 3: Faltas Simples (SD Londrina/PR)}

Nesta seção serão apresentados os resultados experimentais obtidos através da metodologia proposta considerando faltas simples em diversos setores do SD da cidade de Londrina/PR. Os setores escolhidos para simular essas faltas representam os casos testes que não podem ser solucionados pelo procedimento de Busca Exaustiva (BE) proposto em (Camillo et al., 2015). Essa BE testa todas as possibilidades de solução envolvendo apenas as chaves abertas incidentes aos setores sãos que foram desligados em função do isolamento dos setores em falta. Se a solução ótima do problema de restabelecimento envolve manobras apenas nesse tipo de chave, essa $\mathrm{BE}$ garante a obtenção dessa solução. Entretanto, se a solução ótima envolve manobras em outros tipos de chave essa BE não encontra essa solução.

Face ao exposto, os 18 setores que serão considerados nesta dissertação para simulação de faltas simples serão denominados de setores críticos. Esses setores são os seguintes: 2, 388, 389, 430, 431, 642, 1662, 1663, 2172, 2269, 2607, 2684, 2832, 2834, 2835, 2907, 3017 e 3036. Nesta seção serão discutidos apenas os resultados obtidos para simulação de falta simples em apenas dois desses setores, que correspondem aos setores que proporcionaram os melhores e os piores resultados. Os resultados para os demais setores são apresentados no Apêndice C. O critério adotado para definir o setor em falta que proporcionou os melhores e os piores resultados abrange os seguintes conceitos: $i$ ) 
determinação de soluções factíveis; ii) quantas vezes, entre as 100 simulações, foi encontrada o melhor PRE; iii) menor número ponderado de manobras; iv) menor carregamento da rede; $v$ ) melhor perfil da queda de tensão; vi) menor carregamento de SE.

Com o intuito de avaliar a metodologia proposta foram realizadas 100 simulações computacionais para cada setor crítico em falta, em todas as simulações foram utilizados os seguintes parâmetros de entrada:

$\checkmark$ Número máximo de indivíduos gerados $\left(g_{\max }\right)=100.000$;

$\checkmark$ Tamanho das subpopulações armazenadas em tabelas $\left(S_{P 1, \ldots, P 11}\right)=5$.

5.4.1 Setor crítico em falta: 2684 (teste que proporcionou os melhores resultados)

A Tabela 5.15 apresenta os valores mínimo, máximo, médio e desvio padrão, dos parâmetros das 100 primeiras configurações factíveis obtidas nas 100 execuções da metodologia proposta considerando uma falta simples no setor 2684 .

Tabela 5.15: Valores das manobras, das restrições operacionais e das perdas ativas para a primeira configuração factível.

\begin{tabular}{c|cccc}
\hline & Mínimo & Médio & Máximo & DP* \\
\hline Manobras Totais & 7,00 & 8,98 & 9,00 & 0,20 \\
Número Ponderado de Manobras & 5,20 & 7,14 & 7,20 & 0,26 \\
Manobras em CCR & 2,00 & 2,04 & 3,00 & 0,20 \\
Manobras em CCM & 5,00 & 6,94 & 7,00 & 0,28 \\
Carreg. da Rede (\%) & 104,52 & 108,20 & 255,50 & 21,32 \\
Carreg. do Transformador (\%) & 96,62 & 96,72 & 101,48 & 0,68 \\
Queda de Tensão (\%) & 7,26 & 7,66 & 13,46 & 0,83 \\
Perdas (kW) & $3.802,71$ & $3.828,74$ & $4.346,38$ & 75,43 \\
\hline
\end{tabular}

* Desvio Padrão

Analisando a Tabela 5.15, nota-se que em todas as 100 simulações as primeiras configurações factíveis obtidas são soluções que não obedecem todas as restrições operacionais (carregamento da rede superior a 100\%). Assim, comprova-se a necessidade de essas configurações passarem pelo processo evolutivo, em busca de soluções factíveis. 
A Tabela 5.16 apresenta os valores mínimo, máximo, médio e desvio padrão, dos parâmetros das soluções obtidas após o processo evolutivo nas 100 execuções da metodologia proposta.

Tabela 5.16: Valores das manobras, das restrições operacionais e das perdas ativas para a melhor solução após o processo evolutivo.

\begin{tabular}{c|cccc}
\hline & Mínimo & Médio & Máximo & DP* \\
\hline Manobras Totais & 9,00 & 9,28 & 13,00 & 0,75 \\
Número Ponderado de Manobras & 5,40 & 5,43 & 5,80 & 0,08 \\
Manobras em CCR & 4,00 & 4,28 & 8,00 & 0,75 \\
Manobras em CCM & 5,00 & 5,00 & 5,00 & 0,00 \\
Carreg. da Rede (\%) & 97,14 & 97,15 & 98,05 & 0,09 \\
Carreg. do Transformador (\%) & 96,62 & 96,62 & 96,62 & 0,00 \\
Queda de Tensão (\%) & 9,52 & 9,52 & 9,52 & 0,00 \\
Perdas (kW) & $3.900,99$ & $3.904,05$ & $4.031,52$ & 14,51 \\
Tempo Processo Evolutivo (s) & 37,577 & 44,897 & 54,348 & 3,691 \\
\hline
\end{tabular}

* Desvio Padrão

Percebe-se, pela análise da Tabela 5.16, que todas as melhores soluções após o processo evolutivo são soluções factíveis. Analisando a pior situação, nota-se que todos os valores máximos estão dentro dos limites (queda de tensão inferior a $10 \%$ e carregamentos da rede e da SE inferior a 100\%). Porém, para se obter a sequência de chaveamento, obedecendo as restrições de chaveamento das CCMs tipo seca e ainda tentar minimizar o número de manobras, as melhores soluções, obtidas após o processo evolutivo, passam pela etapa de definição da sequência de chaveamento.

A Tabela 5.17 apresenta os valores mínimo, máximo, médio e desvio padrão, dos parâmetros das soluções finais obtidas, após a etapa de definição da sequência de chaveamento, nas 100 execuções da metodologia proposta.

Tabela 5.17: Valores das manobras, das restrições operacionais e das perdas ativas para a solução final.

\begin{tabular}{c|cccc}
\hline & Mínimo & Médio & Máximo & DP* $^{*}$ \\
\hline Manobras Totais & 9,00 & 9,00 & 9,00 & 0,00 \\
Número Ponderado de Manobras & 5,40 & 5,40 & 5,40 & 0,00 \\
& & & & (continua) \\
\hline
\end{tabular}




\begin{tabular}{c|cccc|}
\hline Manobras em CCR & \multicolumn{3}{c}{ (continuação) } \\
Manobras em CCR com Carga & 4,00 & 4,00 & 4,00 & 0,00 \\
Manobras em CCR com Curto & 0,00 & 4,00 & 4,00 & 0,00 \\
Manobras em CCM & 5,00 & 5,00 & 5,00 & 0,00 \\
Manobras em CCM Seca & 3,00 & 3,00 & 3,00 & 0,00 \\
Manobras em CCM com Carga & 2,00 & 2,00 & 2,00 & 0,00 \\
Manobras em CCM com Curto & 0,00 & 0,00 & 0,00 & 0,00 \\
Carreg. da Rede (\%) & 97,14 & 97,14 & 97,14 & 0,00 \\
Carreg. do Transformador (\%) & 96,62 & 96,62 & 96,62 & 0,00 \\
Queda de Tensão (\%) & 9,52 & 9,52 & 9,52 & 0,00 \\
Perdas (kW) & $3.900,99$ & $3.900,99$ & $3.900,99$ & 0,00 \\
Tempo Sequência de Chaveamento (s) & 0,132 & 0,144 & 0,365 & 0,026 \\
Tempo Total (s) & 37,718 & 45,041 & 54,486 & 3,692 \\
& & & & $($ conclusão) \\
\hline
\end{tabular}

* Desvio Padrão

Os resultados da Tabela 5.17 demonstram que todos os PREs obtidos (soluções finais obtidas pela metodologia proposta) são soluções factíveis e que o tempo total médio para obter as respostas finais é de 45,041s, um tempo aceitável se levar em conta a dimensão do SD considerado.

Outro ponto a se destacar é que, em média, das 9 manobras totais realizadas para se obter os PREs, 4 manobras são realizadas em CCRs, o que demonstra a capacidade de priorização das chaves automáticas, mesmo estas sendo minoria com relação ao número total de chaves, apenas 4,32\%. De maneira análoga, analisando os valores médios observa-se que apenas 33,33\% das manobras (3 manobras) são realizadas em CCMs tipo seca, o que também demonstra a minimização de manobras neste tipo de chave proporcionada pela metodologia proposta, já que este tipo representa cerca de $90,90 \%$ de todas as chaves do SD.

Os parâmetros da melhor solução encontrada nas 100 execuções do programa são apresentados na Tabela 5.18. Essa solução foi encontrada em 99 das 100 execuções da metodologia proposta para este caso de falta. 
Tabela 5.18: Valores das manobras, das restrições operacionais e das perdas ativas para a melhor resposta entre as 100 execuções.

\begin{tabular}{c|c}
\hline & Valores \\
\hline Manobras Totais & 9,00 \\
Número Ponderado de Manobras & 5,40 \\
Manobras em CCR & 4,00 \\
Manobras em CCR com Carga & 4,00 \\
Manobras em CCR com Curto & 0,00 \\
Manobras em CCM & 5,00 \\
Manobras em CCM Seca & 3,00 \\
Manobras em CCM com Carga & 2,00 \\
Manobras em CCM com Curto & 0,00 \\
Carreg. da Rede (\%) & 97,14 \\
Carreg. do Transformador (\%) & 96,62 \\
Queda de Tensão (\%) & 9,52 \\
Perdas (kW) & $3.900,99$ \\
\hline
\end{tabular}

5.4.2 Setor crítico em falta: 3036 (teste que proporcionou os piores resultados)

A Tabela 5.19 apresenta os valores mínimo, máximo, médio e desvio padrão, dos parâmetros das 100 primeiras configurações factíveis obtidas nas 100 execuções da metodologia proposta considerando uma falta simples no setor 3036 .

Tabela 5.19: Valores das manobras, das restrições operacionais e das perdas ativas para a primeira configuração factível.

\begin{tabular}{c|cccc}
\hline & Mínimo & Médio & Máximo & DP* \\
\hline Manobras Totais & 7,00 & 7,00 & 7,00 & 0,00 \\
Número Ponderado de Manobras & 5,20 & 6,80 & 7,00 & 0,40 \\
Manobras em CCR & 0,00 & 0,22 & 2,00 & 0,44 \\
Manobras em CCM & 5,00 & 6,78 & 7,00 & 0,44 \\
Carreg. da Rede (\%) & 54,80 & 66,23 & 171,06 & 15,66 \\
Carreg. do Transformador (\%) & 96,62 & 96,62 & 96,62 & 0,00 \\
Queda de Tensão (\%) & 16,66 & 19,82 & 26,91 & 2,02 \\
Perdas (kW) & $3.938,28$ & $3.994,44$ & $4.344,28$ & 53,41 \\
\hline
\end{tabular}


Analisando a Tabela 5.19, nota-se que em todas as 100 simulações as primeiras configurações factíveis obtidas são soluções que não obedecem todas as restrições operacionais (valor mínimo para queda de tensão extrapola o limite de 10\%). Assim, comprova-se a necessidade de essas configurações passarem pelo processo evolutivo, em busca de soluções factíveis.

A Tabela 5.20 apresenta os valores mínimo, máximo, médio e desvio padrão, dos parâmetros das soluções obtidas após o processo evolutivo nas 100 execuções da metodologia.

Tabela 5.20: Valores das manobras, das restrições operacionais e das perdas ativas para a melhor solução após o processo evolutivo.

\begin{tabular}{c|cccc}
\hline & Mínimo & Médio & Máximo & DP* $^{*}$ \\
\hline Manobras Totais & 5,00 & 5,00 & 5,00 & 0,00 \\
Número Ponderado de Manobras & 5,00 & 5,00 & 5,00 & 0,00 \\
Manobras em CCR & 0,00 & 0,00 & 0,00 & 0,00 \\
Manobras em CCM & 5,00 & 5,00 & 5,00 & 0,00 \\
Carreg. da Rede (\%) & 55,73 & 68,98 & 69,75 & 3,07 \\
Carreg. do Transformador $(\%)$ & 96,62 & 96,62 & 96,62 & 0,00 \\
Queda de Tensão $(\%)$ & 17,13 & 17,52 & 21,84 & 1,20 \\
Perdas (kW) & $3.938,28$ & $3.944,83$ & $4.020,44$ & 20,44 \\
Tempo Processo Evolutivo (s) & 52,484 & 65,259 & 75,885 & 4,722 \\
\hline
\end{tabular}

* Desvio Padrão

Observa-se, na Tabela 5.20, que todas as melhores soluções encontradas após o processo evolutivo continuam soluções infactíveis. Analisando o melhor cenário, verifica-se que o valor mínimo para queda de tensão, 17,13\%, está fora do limite aceitável (valor superior a 10\%). Estes resultados indicam que mesmo ao término do processo evolutivo não foi encontrada uma solução que seja factível para o problema de restabelecimento de energia.

Uma ideia para trabalhos futuros seria criar uma metodologia para cortes de carga, ou seja, deixaria sem energia alguns setores para que as soluções finais obedecessem as restrições operacionais (queda de tensão, carregamento da rede e carregamento da SE). Outra possibilidade seria verificar a possibilidade de relaxar 
algumas das restrições operacionais possibilitando a obtenção de soluções factíveis sem corte de carga.

Outro ponto a destacar, é que, como após o processo evolutivo não foram encontradas soluções factíveis, não há necessidade de entrar na etapa de sequência de chaveamento. Já que estas respostas não podem ser executadas na prática.

\subsection{Teste 4: Múltiplas Faltas (SD Londrina/PR)}

Nesta seção serão apresentados os resultados experimentais obtidos pela metodologia proposta para três casos distintos de múltiplas faltas no $\mathrm{SD}$ de Londrina/PR. Múltiplas faltas consistem em faltas simultâneas localizadas em mais de um setor.

Foram realizadas, também, 100 simulações computacionais para avaliar a metodologia proposta para cada um dos três casos de múltiplas faltas. Em todas as simulações foram considerados os seguintes parâmetros de entrada:

$\checkmark$ Número máximo de indivíduos gerados $\left(g_{\max }\right)=100.000$;

$\checkmark$ Tamanho das subpopulações armazenadas em tabelas $\left(S_{P 1, \ldots, P 11}\right)=5$.

\subsubsection{Falta Dupla: Setores 431 e 460:}

A Tabela 5.21 apresenta os valores mínimo, máximo, médio e desvio padrão, dos parâmetros das 100 primeiras configurações factíveis obtidas nas 100 execuções da metodologia proposta considerando falta dupla nos setores 431 e 460 .

Tabela 5.21: Valores das manobras, das restrições operacionais e das perdas ativas para a primeira configuração factível.

\begin{tabular}{c|cccc}
\hline & Mínimo & Médio & Máximo & DP* \\
\hline Manobras Totais & 4,00 & 4,00 & 4,00 & 0,00 \\
Número Ponderado de Manobras & 2,20 & 2,91 & 3,10 & 0,37 \\
Manobras em CCR & 1,00 & 1,21 & 2,00 & 0,41 \\
Manobras em CCM & 2,00 & 2,79 & 3,00 & 0,41 \\
Carreg. da Rede (\%) & 93,97 & 113,93 & 133,87 & 13,75 \\
Carreg. do Transformador (\%) & 96,62 & 96,62 & 96,62 & 0,00 \\
Queda de Tensão (\%) & 3,44 & 8,11 & 10,25 & 2,70 \\
Perdas (kW) & $3.793,89$ & $3.968,51$ & $4.047,08$ & 100,46 \\
\hline
\end{tabular}

* Desvio Padrão 
A Tabela 5.22 apresenta os valores mínimo, máximo, médio e desvio padrão, dos parâmetros das soluções obtidas após o processo evolutivo nas 100 execuções da metodologia.

Tabela 5.22: Valores das manobras, das restrições operacionais e das perdas ativas para a melhor solução após o processo evolutivo.

\begin{tabular}{c|cccc}
\hline & Mínimo & Médio & Máximo & DP* \\
\hline Manobras Totais & 6,00 & 6,52 & 8,00 & 0,88 \\
Número Ponderado de Manobras & 3,30 & 3,58 & 5,10 & 0,55 \\
Manobras em CCR & 1,00 & 3,27 & 5,00 & 1,20 \\
Manobras em CCM & 3,00 & 3,25 & 5,00 & 0,63 \\
Carreg. da Rede (\%) & 79,67 & 89,91 & 99,65 & 3,42 \\
Carreg. do Transformador (\%) & 96,62 & 96,62 & 96,62 & 0,00 \\
Queda de Tensão (\%) & 4,04 & 7,51 & 8,40 & 0,70 \\
Perdas (kW) & $3.789,40$ & $3.945,21$ & $4.062,56$ & 39,57 \\
Tempo Processo Evolutivo (s) & 32,138 & 43,295 & 55,975 & 5,443 \\
\hline
\end{tabular}

* Desvio Padrão

Analisando os valores máximos da Tabela 5.22, nota-se que todas as soluções após o processo evolutivo são factíveis, ou seja, atendem as restrições operacionais da rede. Entretanto, estes indivíduos ainda precisam passar pela etapa de definição de sequência de chaveamento.

A Tabela 5.23 apresenta os valores mínimo, máximo, médio e desvio padrão, dos parâmetros das soluções finais obtidas, após a etapa de definição da sequência de chaveamento, nas 100 execuções da metodologia proposta.

Tabela 5.23: Valores das manobras, das restrições operacionais e das perdas ativas para a solução final.

\begin{tabular}{c|cccc}
\hline & Mínimo & Médio & Máximo & DP* \\
\hline Manobras Totais & 3,00 & 7,61 & 10,00 & 1,41 \\
Número Ponderado de Manobras & 1,50 & 3,92 & 9,10 & 2,13 \\
Manobras em CCR & 1,00 & 4,10 & 5,00 & 1,31 \\
Manobras em CCR com Carga & 0,00 & 2,58 & 4,00 & 1,02 \\
Manobras em CCR com Curto & 1,00 & 1,52 & 2,00 & 0,50 \\
& & & & (continua) \\
\hline
\end{tabular}




\begin{tabular}{|c|c|c|c|c|}
\hline & & & \multicolumn{2}{|c|}{ (continuação) } \\
\hline Manobras em CCM & 1,00 & 3,51 & 9,00 & 2,24 \\
\hline Manobras em CCM Seca & 1,00 & 3,51 & 9,00 & 2,24 \\
\hline Manobras em CCM com Carga & 0,00 & 0,00 & 0,00 & 0,00 \\
\hline Manobras em CCM com Curto & 0,00 & 0,00 & 0,00 & 0,00 \\
\hline Carreg. da Rede (\%) & 84,57 & 90,08 & 90,89 & 2,06 \\
\hline Carreg. do Transformador (\%) & 96,62 & 96,62 & 96,62 & 0,00 \\
\hline Queda de Tensão (\%) & 7,12 & 7,63 & 8,40 & 0,20 \\
\hline Perdas $(\mathbf{k W})$ & $3.700,59$ & $3.937,33$ & $3.978,56$ & 42,09 \\
\hline Tempo Sequência de Chaveamento (s) & 0,080 & 0,107 & 0,172 & 0,015 \\
\hline Tempo Total (s) & 32,250 & 43,401 & 56,079 & 5,444 \\
\hline
\end{tabular}

* Desvio Padrão

Percebe-se na Tabela 5.23 que todos as soluções finais (PREs), para este caso de múltiplas faltas, são factíveis. Os valores máximos de carregamento da rede, 90,89\%, carregamento do transformador de SE, 96,62\%, e queda de tensão, 8,40\%, estão dentro dos limites das restrições operacionais $(100 \%, 100 \%$ e $10 \%$, respectivamente).

Vale ressaltar também que, em valores médios, as chaves tipo seca representam 46,12\% das manobras realizadas nos PREs obtidos, o que demonstra a minimização de chaveamento deste tipo de chave, já que as mesmas representam cerca de 90,90\% das chaves de todo o SD. Nota-se, também, que o tempo médio para obtenção das soluções finais foi de 43,401s.

Os parâmetros da melhor solução encontrada nas 100 execuções do programa são apresentados na Tabela 5.24. Essa solução foi encontrada em 1 das 100 execuções da metodologia proposta para essa caso de múltipla falta.

Tabela 5.24: Valores das manobras, das restrições operacionais e das perdas ativas para a melhor resposta entre as 100 execuções.

\begin{tabular}{c|c}
\hline & Valores \\
\hline Manobras Totais & 6,00 \\
Número Ponderado de Manobras & 1,50 \\
Manobras em CCR & 5,00 \\
& (continua) \\
\hline
\end{tabular}




\begin{tabular}{c|c|}
\hline \multicolumn{2}{c}{ (continuação) } \\
Manobras em CCR com Carga & 4,00 \\
Manobras em CCR com Curto & 1,00 \\
Manobras em CCM & 1,00 \\
Manobras em CCM Seca & 1,00 \\
Manobras em CCM com Carga & 0,00 \\
Manobras em CCM com Curto & 0,00 \\
Carreg. da Rede (\%) & 88,84 \\
Carreg. do Transformador (\%) & 96,62 \\
Queda de Tensão (\%) & 7,12 \\
Perdas (kW) & $3.700,59$ \\
\multicolumn{2}{c}{ (conclusão) } \\
\hline
\end{tabular}

Observa-se na Tabela 5.24, que são apresentados os valores das manobras para todos os diferentes tipos de chaves seccionadoras. É interessante destacar que dentre as 6 manobras realizadas para determinar o PRE, 5 delas $(83,33 \%)$ são CCRs, o que destaca a priorização deste tipo de chave, mesmo sendo minoria com relação ao número total de chaves seccionadoras, apenas $4,32 \%$.

Os outros dois casos de múltiplas faltas seguem a mesma ordem de apresentação dos resultados apresentados nesta subseção.

5.5.2 Falta Dupla: Setores 2269 e 789 :

A Tabela 5.25 apresenta os valores mínimo, máximo, médio e desvio padrão, dos parâmetros das 100 primeiras configurações factíveis obtidas nas 100 execuções da metodologia proposta considerando falta dupla nos setores 2269 e 789 .

Tabela 5.25: Valores das manobras, das restrições operacionais e das perdas ativas para a primeira configuração factível.

\begin{tabular}{c|cccc}
\hline & Mínimo & Médio & Máximo & DP* \\
\hline Manobras Totais & 4,00 & 4,00 & 4,00 & 0,00 \\
Número Ponderado de Manobras & 4,00 & 4,00 & 4,00 & 0,00 \\
Manobras em CCR & 0,00 & 0,00 & 0,00 & 0,00 \\
& & & & (continua) \\
\hline
\end{tabular}




\begin{tabular}{c|cccc|}
\hline \multicolumn{1}{c}{} & & \multicolumn{3}{c}{ (continuação) } \\
Manobras em CCM & 4,00 & 4,00 & 4,00 & 0,00 \\
Carreg. da Rede (\%) & 102,25 & 124,94 & 140,08 & 15,80 \\
Carreg. do Transformador (\%) & 96,62 & 96,62 & 96,62 & 0,00 \\
Queda de Tensão (\%) & 3,77 & 4,67 & 6,31 & 1,01 \\
Perdas (kW) & $3.801,76$ & $3.868,71$ & $3.944,74$ & 50,31 \\
& & & \multicolumn{3}{c}{ (conclusão) } \\
\hline
\end{tabular}

* Desvio Padrão

A Tabela 5.26 apresenta os valores mínimo, máximo, médio e desvio padrão, dos parâmetros das soluções obtidas após o processo evolutivo nas 100 execuções da metodologia.

Tabela 5.26: Valores das manobras, das restrições operacionais e das perdas ativas para a melhor solução após o processo evolutivo.

\begin{tabular}{c|cccc}
\hline & Mínimo & Médio & Máximo & DP* \\
\hline Manobras Totais & 6,00 & 6,26 & 10,00 & 0,73 \\
Número Ponderado de Manobras & 5,10 & 5,74 & 6,20 & 0,40 \\
Manobras em CCR & 0,00 & 0,58 & 5,00 & 1,00 \\
Manobras em CCM & 5,00 & 5,68 & 6,00 & 0,47 \\
Carreg. da Rede (\%) & 84,75 & 89,38 & 99,65 & 4,06 \\
Carreg. do Transformador (\%) & 96,62 & 96,62 & 96,62 & 0,00 \\
Queda de Tensão (\%) & 3,77 & 4,09 & 6,27 & 0,38 \\
Perdas (kW) & $3.780,67$ & $3.825,10$ & $3.942,26$ & 35,47 \\
Tempo Processo Evolutivo (s) & 45,159 & 55,378 & 67,550 & 4,114 \\
\hline
\end{tabular}

* Desvio Padrão

A Tabela 5.27 apresenta os valores mínimo, máximo, médio e desvio padrão, dos parâmetros das soluções finais obtidas, após a etapa de definição da sequência de chaveamento, nas 100 execuções da metodologia proposta. 
Tabela 5.27: Valores das manobras, das restrições operacionais e das perdas ativas para a solução final.

\begin{tabular}{c|cccc}
\hline & Mínimo & Médio & Máximo & DP* \\
\hline Manobras Totais & 6,00 & 6,56 & 8,00 & 0,90 \\
Número Ponderado de Manobras & 5,10 & 5,77 & 6,20 & 0,47 \\
Manobras em CCR & 0,00 & 0,88 & 2,00 & 0,82 \\
Manobras em CCR com Carga & 0,00 & 0,88 & 2,00 & 0,82 \\
Manobras em CCR com Curto & 0,00 & 0,00 & 0,00 & 0,00 \\
Manobras em CCM & 5,00 & 5,68 & 6,00 & 0,47 \\
Manobras em CCM Seca & 3,00 & 3,30 & 5,00 & 0,48 \\
Manobras em CCM com Carga & 1,00 & 2,38 & 3,00 & 0,51 \\
Manobras em CCM com Curto & 0,00 & 0,00 & 0,00 & 0,00 \\
Carreg. da Rede (\%) & 84,75 & 89,14 & 99,56 & 3,14 \\
Carreg. do Transformador $(\%)$ & 96,62 & 96,62 & 96,62 & 0,00 \\
Queda de Tensão (\%) & 7,12 & 7,12 & 7,12 & 0,00 \\
Perdas (kW) & $3.780,67$ & $3.816,38$ & $3.942,26$ & 28,97 \\
Tempo Sequência de Chaveamento (s) & 0,100 & 0,114 & 0,162 & 0,010 \\
Tempo Total (s) & 45,260 & 55,492 & 67,660 & 4,116 \\
\hline
\end{tabular}

* Desvio Padrão

Os parâmetros da melhor solução encontrada nas 100 execuções do programa são apresentados na Tabela 5.28. Essa solução foi encontrada em 32 das 100 execuções da metodologia proposta para essa caso de múltipla falta.

Tabela 5.28: Valores das manobras, das restrições operacionais e das perdas ativas para a melhor resposta entre as 100 execuções.

\begin{tabular}{c|c}
\hline & Valores \\
\hline Manobras Totais & 6,00 \\
Número Ponderado de Manobras & 5,10 \\
Manobras em CCR & 1,00 \\
Manobras em CCR com Carga & 1,00 \\
Manobras em CCR com Curto & 0,00 \\
Manobras em CCM & 5,00 \\
Manobras em CCM Seca & 3,00 \\
& (continua) \\
\hline
\end{tabular}




\begin{tabular}{c|c|}
\hline \multicolumn{2}{c}{ (continuação) } \\
Manobras em CCM com Carga & 2,00 \\
Manobras em CCM com Curto & 0,00 \\
Carreg. da Rede (\%) & 87,78 \\
Carreg. do Transformador (\%) & 96,62 \\
Queda de Tensão (\%) & 7,12 \\
Perdas (kW) & $3.780,67$ \\
& (conclusão) \\
\hline
\end{tabular}

\subsubsection{Falta Tripla: Setores 2607, 379 e 537:}

A Tabela 5.29 apresenta os valores mínimo, máximo, médio e desvio padrão, dos parâmetros das 100 primeiras configurações factíveis obtidas nas 100 execuções da metodologia proposta considerando falta tripla nos setores 2607, 379 e 537 .

Tabela 5.29: Valores das manobras, das restrições operacionais e das perdas ativas para a primeira configuração factível.

\begin{tabular}{c|cccc}
\hline & Mínimo & Médio & Máximo & DP* \\
\hline Manobras Totais & 5,00 & 5,00 & 5,00 & 0,00 \\
Número Ponderado de Manobras & 4,10 & 4,89 & 5,00 & 0,29 \\
Manobras em CCR & 0,00 & 0,12 & 1,00 & 0,33 \\
Manobras em CCM & 4,00 & 4,88 & 5,00 & 0,33 \\
Carreg. da Rede (\%) & 103,96 & 129,11 & 181,54 & 23,95 \\
Carreg. do Transformador (\%) & 96,62 & 96,62 & 96,62 & 0,00 \\
Queda de Tensão (\%) & 5,20 & 8,40 & 12,22 & 2,11 \\
Perdas (kW) & $3.756,16$ & $3.969,19$ & $4.205,35$ & 140,50 \\
\hline
\end{tabular}

A Tabela 5.30 apresenta os valores mínimo, máximo, médio e desvio padrão, dos parâmetros das soluções obtidas após o processo evolutivo nas 100 execuções da metodologia. 
Tabela 5.30: Valores das manobras, das restrições operacionais e das perdas ativas para a melhor solução após o processo evolutivo.

\begin{tabular}{c|cccc}
\hline & Mínimo & Médio & Máximo & DP* \\
\hline Manobras Totais & 7,00 & 7,94 & 11,00 & 1,08 \\
Número Ponderado de Manobras & 5,20 & 5,29 & 5,60 & 0,11 \\
Manobras em CCR & 2,00 & 2,94 & 6,00 & 1,08 \\
Manobras em CCM & 5,00 & 5,00 & 5,00 & 0,00 \\
Carreg. da Rede (\%) & 83,51 & 95,68 & 98,69 & 4,45 \\
Carreg. do Transformador $(\boldsymbol{\%})$ & 96,62 & 96,62 & 96,62 & 0,00 \\
Queda de Tensão $(\%)$ & 5,48 & 7,60 & 8,50 & 1,14 \\
Perdas (kW) & $3.845,65$ & $3.919,83$ & $4.044,50$ & 42,97 \\
Tempo Processo Evolutivo (s) & 52,391 & 65,541 & 82,208 & 6,128 \\
\hline
\end{tabular}

* Desvio Padrão

A Tabela 5.31 apresenta os valores mínimo, máximo, médio e desvio padrão, dos parâmetros das soluções finais obtidas, após a etapa de definição da sequência de chaveamento, nas 100 execuções da metodologia proposta.

Tabela 5.31: Valores das manobras, das restrições operacionais e das perdas ativas para a solução final.

\begin{tabular}{c|cccc}
\hline & Mínimo & Médio & Máximo & DP* \\
\hline Manobras Totais & 4,00 & 7,00 & 9,00 & 1,21 \\
Número Ponderado de Manobras & 0,40 & 5,03 & 7,20 & 1,33 \\
Manobras em CCR & 1,00 & 2,19 & 4,00 & 0,61 \\
Manobras em CCR com Carga & 1,00 & 2,08 & 4,00 & 0,39 \\
Manobras em CCR com Curto & 0,00 & 0,11 & 1,00 & 0,31 \\
Manobras em CCM & 0,00 & 4,81 & 7,00 & 1,35 \\
Manobras em CCM Seca & 0,00 & 4,12 & 7,00 & 1,48 \\
Manobras em CCM com Carga & 0,00 & 0,69 & 2,00 & 0,49 \\
Manobras em CCM com Curto & 0,00 & 0,00 & 0,00 & 0,00 \\
Carreg. da Rede (\%) & 84,57 & 95,68 & 99,38 & 4,37 \\
Carreg. do Transformador (\%) & 96,62 & 96,62 & 96,62 & 0,00 \\
Queda de Tensão (\%) & 7,12 & 7,95 & 8,50 & 0,65 \\
Perdas (kW) & $3.587,90$ & $3.910,09$ & $3.957,09$ & 48,05 \\
& & & & $($ continua) \\
\hline
\end{tabular}




\begin{tabular}{c|ccccc|}
\hline \multicolumn{1}{|c}{$\begin{array}{c}\text { (continuação) } \\
\text { Tempo Sequência de Chaveamento (s) } \\
\text { Tempo Total (s) }\end{array}$} & 0,098 & 0,122 & 0,175 & 0,021 \\
& 52,491 & 65,663 & 82,321 & 6,128 \\
& & & & \multicolumn{2}{c}{ (conclusão) } \\
\hline
\end{tabular}

\footnotetext{
* Desvio Padrão
}

Os parâmetros, da melhor solução encontrada nas 100 execuções do programa, são apresentados na Tabela 5.32. Essa solução foi encontrada em 1 das 100 execuções da metodologia proposta para essa caso de múltiplas falta.

Tabela 5.32: Valores das manobras, das restrições operacionais e das perdas ativas para a melhor resposta entre as 100 execuções.

\begin{tabular}{c|c}
\hline & Valores \\
\hline Manobras Totais & 4,00 \\
Número Ponderado de Manobras & 0,40 \\
Manobras em CCR & 4,00 \\
Manobras em CCR com Carga & 4,00 \\
Manobras em CCR com Curto & 0,00 \\
Manobras em CCM & 0,00 \\
Manobras em CCM Seca & 0,00 \\
Manobras em CCM com Carga & 0,00 \\
Manobras em CCM com Curto & 0,00 \\
Carreg. da Rede (\%) & 84,57 \\
Carreg. do Transformador $(\%)$ & 96,62 \\
Queda de Tensão (\%) & 7,12 \\
Perdas (kW) & $3.587,90$ \\
\hline
\end{tabular}

\subsection{Considerações Finais}

Os testes realizados apresentados neste capítulo comprovaram a capacidade de a metodologia proposta fornecer adequados PREs para SDs reais e de grande porte, tendo em vista as respostas coerentes a que todos chegaram, para casos de faltas simples e múltiplas, exigindo um tempo de execução sempre inferior a $135 \mathrm{~s}$.

Os primeiros testes, realizados com o SD da cidade de Marília/SP, comprovaram a importância de se considerar os BCs e os RTs para obtenção de adequados PREs. 
Destaca-se, também, que foi possível validar a capacidade de a metodologia proposta definir uma sequência de chaveamento levando em consideração as características operacionais das chaves seccionadoras. 



\section{Capítulo 6 - Conclusões}

\subsection{Conclusões}

Este Capítulo sintetiza os principais resultados obtidos nesta pesquisa e algumas considerações sobre perspectivas futuras.

Nesta dissertação foi proposta uma metodologia para tratar o problema de restabelecimento de energia em SDs reais de grande porte, e assim auxiliar as atividades dos operadores da rede. Da mesma maneira que as metodologias desenvolvidas pelo grupo de pesquisa do LACO-SEP, a metodologia proposta possibilita o tratamento de SDs de grande porte considerando todas as barras e chaves seccionadoras da rede (diferencial em relação às metodologias presentes na literatura). O diferencial da metodologia proposta, em relação às metodologias desenvolvidas pelo grupo de pesquisa LACO-SEP, é a capacidade de considerar a presença de BCs, RTs e as características operacionais dos diferentes tipos de chaves seccionadoras.

Conforme descrito anteriormente, restabelecimento de energia é um problema de otimização multi-objetivo, sujeito a várias restrições operacionais e que exige respostas em tempo real. Logo, para lidar com o problema, diversas abordagens foram desenvolvidas na literatura, com destaque para as baseadas em AEs que, quando comparadas com outras técnicas, têm se mostrado mais flexíveis, mais simples de serem compreendidas, implementadas e apresentado resultados satisfatórios.

Assim, foram apresentados os aspectos básicos dos AEs bem como seu contexto no problema de restabelecimento de energia. Dentre os AEs, foi dado maior destaque ao AEMT++, tomado como base para desenvolvimento da metodologia proposta. Devido a sua importância para esta pesquisa, foi reservado um capítulo para a explicação em detalhes dessa metodologia, apontando suas principais características: representação computacional utilizando uma estrutura de dados para os alimentadores e os setores do SD (RNP), operadores genéticos que geram exclusivamente configurações factíveis (PAO e CAO), priorização de CCRs, determinação de uma solução final e definição da sequência de chaveamento sem manobras repetidas e sem formação de laços.

É bom enfatizar que a metodologia base e a metodologia proposta utilizam da RNP e dos seus operadores genéticos (Delbem et al., 2004) o que permite tratar o problema minimizando apenas o número de manobras. Isto em razão de a RNP e seus 
operadores genéticos garantirem a obtenção de configurações radiais capazes de fornecer energia para todas as partes de um SD possíveis de serem conectadas por meio de chaves (Santos et al., 2010).

Logo em seguida, foi apresentada a metodologia proposta. Assim como o AEMT++, a metodologia proposta faz uso da RNP, utiliza os operadores genéticos PAO e CAO e também prioriza a operação das CCRs. Para considerar os BCs e os RTs, primeira proposição desta pesquisa, o método para cálculo de FC de varredura direta/inversa através da RNP desenvolvido em Santos et al. (2008) foi estendido para considerar a existência de BCs e RTs com tap variável. Esse FC é de fundamental importância para avaliação (fitness) de cada indivíduo gerado pelos operadores genéticos da RNP.

Já a consideração dos diferentes tipos de chaves seccionadoras, segunda proposição desta dissertação, foi abordada em duas etapas: i) primeiramente, nas 5 tabelas de subpopulação que tratam da priorização de CCRs, foram inseridos, como objetivos secundários, a priorização das CCMs que podem operar sob carga e sob curto, com o intuito de minimizar as operações das CCMs tipo seca; e ii) durante o processo de definição de sequência de chaveamento foi desenvolvido um procedimento que trata as restrições de chaveamento das CCMs tipo seca, onde, caso seja violada sua restrição, busca-se uma CCR à montante para possibilitar a sua operação.

Por último, com o objetivo de avaliar a metodologia proposta, foram realizadas diversas simulações computacionais em dois SDs reais de grande porte, que correspondem ao SD de Marília/SP e o SD de Londrina/PR. O primeiro, devido à existência e a obtenção dos dados de BCs e RTs, validou a consideração destes equipamentos na metodologia proposta. Já no SD de Londrina/PR foram realizados outros testes que validaram o tratamento das características operacionais dos diferentes tipos de chaves seccionadoras. Vale ressaltar que neste último SD foram simulados casos de faltas simples e de múltiplas faltas. De maneira geral, em todos os testes foi possível analisar a capacidade de otimização dos objetivos do problema e a obtenção de adequados PREs.

Entretanto, pôde-se verificar algumas limitações da metodologia proposta. Estas serão retratadas nas perspectivas futuras.

\subsection{Perspectivas Futuras}

Como perspectivas de trabalhos futuros é possível citar: 
i) Considerar a possibilidade de corte de carga, em alimentadores sobrecarregados, na ausência de chaves que possibilitem a transferência das mesmas. Esta ação trataria o problema de soluções infactíveis como indicado no segundo caso da seção 5.4;

ii) Acrescentar, na metodologia proposta, um laço entre a etapa de sequência de chaveamento e o processo evolutivo. Nesta ideia mais de uma solução factível entraria como parâmetro na função de sequência de chaveamento. Espera-se que esta ação melhore a resposta da solução final, já que o processo de sequência de chaveamento tenta minimizar o número de manobras. Logo, com mais parâmetros de entrada da função de sequência de chaveamento aumenta-se a probabilidade de encontrar um melhor PRE.

\subsection{Publicações Originadas desta Pesquisa}

i) MARQUES, L. T.; ZAN, J. C.; DELBEM, A. C. B.;LONDON, J. B. A. (2014). "Restabelecimento de energia em sistemas de distribuição de grande porte com priorização de chaves”. Congresso Brasileiro de Automática - CBA 2014. (Artigo Publicado).

ii) HEBling, G. M.; ZAN, J. C.; MARQUES, L. T.; LONDON, J. B. A. (2015) "Estudo para melhoria do desempenho computacional de um fluxo de carga de varredura direta-inversa”. SICEEL - Simpósio de Iniciação Científica da Engenharia Elétrica, 2015. (Resumo Publicado).

iii) ZAN, J. C.; MARQUES, L. T.; COIMBRA, A. M.; PEREIRA, D. H.; SILVA, M.; BENTO, C. R. C.; GOIS, A. M.; LONDON, J. B. A. (2015). "Restabelecimento de energia em sistemas de distribuição de grande porte considerando bancos de capacitores e reguladores de tensão". Simpósio Brasileiro de Automação $\begin{array}{lllll}\text { Inteligente } & - & \text { SBAI } & \text { 2015. Artigo } & \text { Publicado. }\end{array}$ Link: < http://www.sbai2015.dca.ufrn.br/evento/programacao/2/T1>). 



\section{Referências Bibliográficas}

AOKI, K. et. al. (1989). "A new algorithm for service restoration in distribution systems" Power Engineering Review, IEEE, 9(7), p. 69.

ASSOCIAÇÃO BRASILEIRA DE NORMAS TÉCNICAS, NBR 6935 (1985).

"Seccionador, chaves de terra e aterramento rápido". Rio de Janeiro: ABNT.

BARAN, M.; WU, F. (1989) "Optimal sizing of capacitors placed on a radial distribution system” Power Delivery, IEEE Transactions on, v. 4, n. 1, p. 735-743.

BENAYON, R.; de MONTGOLFIER, J.; TERGNY, J.; LARITCHEV, O. (1971). "Linear programming with multiple objective functions: step method (stem)". Mathematical Programming, v. 1, p. 366-375.

BORGES, H. F. (2013). "Otimização do processo de restabelecimento de energia em sistemas de distribuição de grande porte utilizando chaves automáticas". Dissertação de Mestrado - EESC/USP, São Carlos/SP, Brasil, p. 1 - 102.

CAMILLO, M. H. M. (2013). "Avaliação de uma metodologia para restabelecimento de energia baseada em algoritmos evolutivos multi-objetivos no sistema de distribuição de energia elétrica da Copel na cidade de Londrina." Dissertação de Mestrado EESC/USP, São Carlos/SP, Brasil, p. 1 - 107.

CAMILLO, M. H. M.; ROMERO, M. E. V.; FANUCCHI, R. Z.; LIMA, T. W.; DELBEM, A. B. C.; LONDON, J. B. A. (2015). "Exhaustive search and multi-objective evolutionary algorithm for single fault service restoration in a real large-scale distribution system". Power and Energy Society General Meeting, 2015 IEEE.

CHAKRAVORTY, S.; CHAKRAVORTY, J.; SARKAR, S. (2009). "Node voltage improvement by network reconfiguration: a soft computing approach". International Conference on Advances in Computing, Control, and Telecommunication Technologies.

CURCIC, S.; SZVEREN, C.; CROWE, L.; LO, P. (1996) "Electric power distribution network restoration: a survey of papers and a review of the restoration problem". Electric Power Systems Research, v. 35, n. 2, p. 73-86.

DEB, K. (2001). "Multi-Objective Optimization Using Evolutionary Algorithms". Chichester, UK: Wiley.

DEB, K.; PRATAP, A.; AGARWAL, S.; MEYARIVAN, T. (2002). "A fast and elitist multiobjective genetic algorithm: nsga-ii". Evolutionary Computation, IEEE Transactions on, [S.1.], v.6, n.2, p. 182-197. 
DELBEM, A. C. B.; CARVALHO, A. (2002). "Restabelecimento de energia em sistemas de distribuição por algoritmo evolucionário associado a cadeias de grafos".

Delbem, A. C. B.; CARVAlhO, A. C. P. L. F.; POliCASTRO, C.; PINTO, A. K. O.; GARCIA, A.; HONDA, K. (2004), "Node-depth Encoding for Evolutionary Algorithms Applied to Network Design", Genetic and Evolutionary Computation Conference.

FERREIRA, F. A. L. (2010). "Metodologia para reconfiguração de redes de distribuição trifásica assimétrica e não balanceadas com geração distribuída". Dissertação de Mestrado, PURS.

FUKUYAMA, Y. \& CHIANG, H.-D. (1995). "A parallel genetic algorithm for service restoration in electric power distribution systems". Fuzzy Systems, 1995. International Joint Conference of the Fourth IEEE International Conference on Fuzzy Systems and The Second International Fuzzy Engineering Symposium. Proceedings of 1995 IEEE International Conference on (Vol. 1, pp. 275-282 vol. 1).

KAGAN, N.; OLIVEIRA, C. C. B.; ROBBA, E. J. (2005). "Introdução aos sistemas de distribuição de energia elétrica". Edgard Blucher, São Paulo.

KASHEM, M. A.; GANAPATHY, V.; JASMON, G. B. (1999). "Network reconfiguration for load balancing in distribution networks". IEEE Proc.-Gener. Transm. Distrib., Vol. 146, No. 6.

KASHEM, M. A.; GANAPATHY, V.; JASMON, G. B. (2000). "Network reconfiguration for enhancement of voltage stability in distribution networks". Generation, Transmission and Distribution, IEE Proceedings. Vol. 147, p. 171-175.

KUMAR, Y.; DAS, B.; SHARMA, J. (2008). "Multiobjective, multiconstraint service restoration of electric power distribution system with priority customers". Power Delivery, IEEE Transactions on, v. 23, n. 1, p. 261-270.

LAND, A. H. \& DOIG, A. G. (1960). "An automatic method of solving discrete programming problems”. Econometrica, v. 28, n. 3, p. 497-520.

LIN, C. H. (2003). "Distribution network reconfiguration for load balancing with a coloured Petri net algorithm". Generation, Transmission and Distribution, IEE Proceedings. Vol. 150, p. 317-324.

MANSOUR, M. R.; SANTOS, A. C.; LONDON, J. B.; DELBEM, A. C. B.; \& BRETAS, N. G. (2009). "Energy restoration in distribution systems using multiobjective evolutionary algorithm and an efficient data structure". PowerTech, 2009 IEEE Bucharest (pp. 1-7).

MANSOUR, M. R.; SANTOS, A. C.; LONDON, J. B.; DELBEM, A. C. B.; \& BRETAS, N. G. (2010). "Node-depth encoding and evolutionary algorithms applied to 
service restoration in distribution systems". Power and Energy Society General Meeting, 2010 IEEE.

MARQUES, L. T. (2013). "Restabelecimento de energia por reconfiguração de redes em sistemas de distribuição de grande porte com priorização de chaves, consumidores e definição de sequência de chaveamentos". Dissertação de Mestrado - EESC/USP, São Carlos/SP, Brasil, p. 1 - 129.

MARQUES, L. T.; ZAN, J. C.; DELBEM, A. C. B.; LONDON, J. B. A. (2014). "Restabelecimento de energia em sistemas de distribuição de grande porte com priorização de chaves". Congresso Brasileiro de Automática - CBA 2014.

MARQUES, L. T. (2015). "Restabelecimento de energia em sistemas de distribuição considerando aspectos práticos". Exame de Qualificação de Doutorado - EESC/USP, São Carlos/SP, Brasil.

MENDOZA, F.; BERNAL-AGUSTIN, J. L.; DOMINGUEZ-NAVARRO, J. A. (2006). "NSGA and SPEA applied to multiobjective design of power distribution systems". IEEE Transactions on Power Systems, vol. 21, pp. 1938-1945.

MIRHOSEINI, S. H.; HOSSEINI, S. M.; GHANBARI, M.; AHMADI, M. (2014). “A new improved adaptive imperialist competitive algorithm to solve the reconfiguration problem of distribution systems for loss reduction and voltage profile improvement". Electrical Power and Energy Systems, p. 128-143.

MOAZAMI, E.; KADIR, M. Z. A. A.; HIZAM, H.; IZADI, M.; MIRZAEI, M. (2013). "Optimal penalty method in distribution service restoration using genetic algorithm". IEEE International Power Engineering and Optimization Conference (PEOCO).

OLIVEIRA, L. W.; OLIVEIRA, E. J.; GOMES, F. V.; SILVA Jr., I. C.; MARCATO, A. L. M. (2014). "Artificial Immune Systems applied to the reconfiguration of electrical power distribution networks for energy loss minimization". Electrical Power and Energy Systems, p. 64-74.

PEREIRA, D. H. (2014). "Fluxo de Potência de varredura direta/inversa para o problema de reconfiguração de redes em sistemas de distribuição". Trabalho de Conclusão de Curso em Engenharia Elétrica - EESC/USP, São Carlos/SP, Brasil, p. 1 95.

ROMERO, R.; FRANCO, J. F.; LEÃO, F. B.; RIDER, M. J.; SOUZA, E. S. (2015). “A new mathematical model for the restoration problem in balanced radial distribution systems".Power Systems, IEEE Transactions.

SANCHES, D. S.; MARQUES, L. T.; BORGES, H. F.; DELBEM, A. C. B.; \& LONDON, J. B. A. (2012). "Análise comparativa entre algoritmos evolutivos multiobjetivos aplicados ao problema de redução de perdas em sistemas de distribuição de grande porte". Congresso Brasileiro de Automática - CBA 2012. (pp. 1-8). 
SANCHES, D. S.; DELBEM, A. C. B.; LONDON, Jr, J. B. A. (2014). "Multi-objective evolutionary algorithm for single and multiple fault service restoration in large-scale distribution systems". Eletric Power Systems Research (Print) JCR, v. 110, p. 144-153.

SANTOS, A. C.; NANNI, M.; MANSOUR, M. R.; A.C.B. DELBEM; LONDON Jr., J. B. A.; BRETAS, N. G. (2008a). "A power flow method computationally efficient for large-scale distribution systems". In: 2008 IEEE PES Transmission and Distribution Conference and Exposition, 2008, Bogota. Proceedings (CD; 6 páginas), 2008.

SANTOS, A. C.; DELBEM, A.; \& BRETAS, N. G. (2008b). "Energy restoration for large-scale distribution system using EA and a new data structure". Power and Energy Society General Meeting - Conversion and Delivery of Electrical Energy in the 21st Century, 2008 IEEE (pp. 1-8).

SANTOS, A. C. (2009). "Algoritmo evolutivo computacionalmente eficiente para reconfiguração de sistemas de distribuição". Tese de Doutoramento, Engenharia Elétrica, EESC/USP, São Carlos/SP - Brasil, p. 1 - 166.

SANTOS, A. C.; DELBEM, A. C. B.; LONDON, JR., J. B. A.; BRETAS, N. G. (2010). "Node-Depth Encoding and Multiobjective Evolutionary Algorithm Applied to LargeScale Distribution System Reconfiguration". IEEE Transactions on Power Systems, p. $1-12$.

SCHAFFER, J. D. (1985) "Multiple objective optimization with vector evaluated genetic algorithms." Proceedings of the $1^{\text {st }}$ International Conference on Genetic Algorithms. Inc., 1985, p. 93-100.

SHIRMOHAMMADI, D.; HONG, H.; SEMLYEM, A.; LUO, G. (1988). "A compensation-based power flow method for weakly meshed distribution and transmission networks". Power Systems, IEEE Transactions on 3(2): 753-762. 


\section{Apêndice A - Otimização Multi-Objetivo}

\section{A.1 Otimização Multi-Objetivo}

Esta seção toma por base o texto de dissertação de Moussa Reda Mansour (Mansour, 2009).

Em geral, os problemas de otimização multi-objetivo, são assim classificados, pois possuem um conjunto de funções objetivo a serem otimizadas (minimizadas ou maximizadas). Possuem também, restrições que devem ser atendidas pelas soluções candidatas para que estas sejam factíveis ao problema. $O$ enunciado geral de um problema de otimização multi-objetivo pode ser ilustrado da seguinte forma (Deb, 2001):

$$
\begin{array}{rll}
\text { Minimizar/Maximizar: } & f_{m}(x) & m=1,2, \ldots, N_{o b j} ; \\
\text { Sujeito a: } & g_{j}(x) \leq 0 & j=1,2, \ldots, N R_{\text {des }} ; \\
& h_{k}(x)=0 & k=1,2, \ldots, N R_{\text {igu }} ; \\
& x_{i}^{(\text {inf })} \leq x_{i} \leq x_{i}^{(\text {sup })} & i=1,2, \ldots, N_{\text {var }} ;
\end{array}
$$

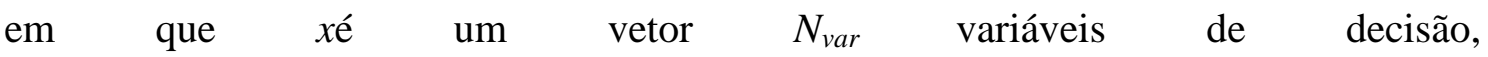

$x=\left(x_{1}, x_{2}, \ldots, x_{N v a r}\right)^{T}$, também denominado de solução. Os valores $x_{i}^{(i n f)}$ e $x_{i}^{(\text {sup })}$ representam os limites inferior e superior, respectivamente, para a variável $x_{i}$. Esses limites definem o espaço de variáveis de decisão ou espaço de decisão $S_{d e c}$. As $N R_{d e s}$ desigualdades $\left(g_{j}\right)$ e as $N R_{i g u}$ igualdades $\left(h_{k}\right)$ são chamadas de funções de restrição. Uma solução $x$ factível satisfaz as $N R_{i g u}+N R_{\text {des }}$ funções de restrição e os $2 N_{v a r}$ limites. Caso contrário, a solução não será factível. O conjunto de todas as soluções factíveis formam a região factível ou espaço de busca factível, $S_{f a c t}$. Cada função $f_{m}(x)$ pode ser maximizada ou minimizada. Porém, para trabalhar com os algoritmos de otimização é necessário converter todas as funções para serem apenas de maximização ou de minimização.

As funções objetivo empregadas nos problemas de otimização multi-objetivo são, em sua maioria, conflitantes entre si. Sabe-se que uma função objetivo $f_{l}$ é conflitante com uma outra função $f_{2}$ quando não é possível melhorar o valor de $f_{1}$ sem 
piorar o valor da função $f_{2}$. Um exemplo de objetivos conflitantes é, por exemplo:economia de compra e qualidade de equipamentos. Em geral, os equipamentos de maior economia de compra são os que possuem pior qualidade, como por exemplo, a compra de computadores. Assim, em uma compra devem ser considerados vários modelos de computadores com diversos valores nos objetivos de economia e qualidade. Se ambos os objetivos possuem a mesma importância, não há como afirmar que certo aumento na economia compensa a redução da qualidade.

Em problemas de otimização multi-objetivo é comum empregar-se o conceito de Dominância de Pareto a fim de comparar duas soluções factíveis de um problema. Dadas duas soluções $x$ e $y$, diz-se que $x$ domina $y$ se as seguintes condições forem satisfeitas (Mansour, 2009):

i) A solução $x$ é no mínimo igual a $y$ em todas as funções objetivo;

ii) A solução $x$ é melhor que $y$ em pelo menos uma função objetivo.

Assim, existe um conjunto de soluções que possuem vantagens em qualidade, mas que não são melhores em economia e vice-versa. Ou seja, existe um conjunto de alternativas ótimas que são não dominadas entre si nos objetivos de economia e qualidade. Em um problema de otimização multi-objetivo, o conjunto de soluções não dominadas é chamado de conjunto Pareto-ótimo, que representa as soluções ótimas do problema. A fronteira de Pareto é o conjunto dos valores das funções objetivo das soluções do conjunto Pareto-ótimo.

Em Deb (2001) são destacadas três importantes metas em otimização multiobjetivo:

i) Encontrar um conjunto de soluções que esteja o mais próximo possível da fronteira de Pareto;

ii) Encontrar um conjunto de soluções com a maior diversidade possível;

iii) Realizar as duas metas anteriores com a maior eficiência computacional possível.

Encontrar a maior diversidade dentro das soluções (meta ii) é meta específica para otimização multi-objetivo, e que consiste em assegurar a maior cobertura possível da fronteira com as soluções o mais uniformemente distribuídas possível. 
Entretanto, encontrar um conjunto de soluções uniformemente distribuídas é uma tarefa que pode consumir consideráveis recursos computacionais (Deb, 2001), motivo pelo qual deve-se considerar a meta de obter tais soluções com a maior eficiência computacional possível.

Por fim, os aspectos que diferenciam a otimização multi-objetivo da otimização mono-objetivo podem ser identificadas por três (Deb, 2001):

i) Nos problemas de otimização com um único objetivo tem-se como meta encontrar uma solução ótima global (máximo ou mínimo). Se a função objetivo desses problemas for multimodal, poderá existir mais de um ótimo global. Neste caso, todos os ótimos são equivalentes. Por outro lado, em problemas de otimização com vários objetivos a determinação do conjunto de soluções da fronteira de Pareto é tão importante quanto preservar a diversidade neste conjunto. Assim sendo, um algoritmo eficiente para otimização multi-objetivo deve considerar ambos os aspectos;

ii) Nos problemas de otimização multi-objetivo trabalha-se com dois espaços, o espaço das variáveis e o dos objetivos. Por outro lado, os problemas de otimização mono-objetivo trabalham unicamente no espaço dos objetivos. Manter a diversidade em ambos espaços complica mais o problema, dado que a proximidade de duas soluções no espaço de variáveis não implica proximidade no espaço de objetivos;

iii) Os métodos tradicionais de otimização multi-objetivo reduzem o conjunto de funções objetivo a uma função simples com uma ponderação para cada objetivo. Estes métodos podem também tratar cada objetivo separadamente, utilizando os demais objetivos como restrições. Portanto, um problema de otimização multi-objetivo pode ser convertido, por meio de algumas técnicas, em um problema de otimização simples.

\section{A.2 Algoritmos Evolutivos para Otimização Multi-Objetivo}

Esta seção toma por base o texto de dissertação de Leandro Tolomeu Marques, (Marques, 2013):

A primeira implementação de AEs para problemas de otimização multi-objetivo foi proposta por Schaffer (1985). Desde então uma diversidade de AEMOs foram 
propostos baseando-se naquelas ideias iniciais. A principal diferença dos AEMOs em relação aos AEs tradicionais é o operador de seleção, dado que a comparação entre duas soluções é efetuada com base no conceito de dominância de Pareto (Mansour, 2009).

De acordo com Deb (2001), os AEMOs podem ser classificados em:

$\checkmark$ Elitistas: a melhor solução ou o conjunto com as melhores soluções é guardado de uma geração para outra;

$\checkmark$ Não elitistas: a melhor solução ou o conjunto com as melhores soluções não é necessariamente preservado de uma geração para outra.

Existem vários AEMOs disponíveis na literatura, entre eles alguns dos mais importantes: Non-Dominated Sorting Genetic Algorithm (NSGA), NSGA-II, Strength Pareto Evolutionary Algorithm (SPEA2) e o utilizado nesta dissertação, o método de tabelas.

\section{Método de Tabelas}

Conforme citado anteriormente, as funções objetivo dos problemas de otimização multi-objetivo são, em geral, conflitantes entre si. Nesse caso, torna-se difícil definir uma prioridade entre elas e, consequentemente, dizer qual das soluções candidatas possui a melhor adequação considerando simultaneamente todos os objetivos. Por esse motivo, é difícil também definir pesos que ponderem os objetivos a fim de converter o problema multi-objetivo em um mono-objetivo e penalizar soluções que violem as restrições do problema.

Assim, foi proposto por Benayoun et al. (1971) um AEMO que otimiza paralelamente todos os objetivos de um problema, sem a necessidade de definição de pesos. Assim, em todas as gerações, a população é dividida em $N_{o b j}$ subpopulações, formadas pelos indivíduos que possuem a melhor adequação para cada objetivo em específico do problema.

Essas subpopulações são armazenadas em tabelas, conhecidas como tabelas de subpopulações, e por isso essa técnica é conhecida como "Método de Tabelas". Para exemplificar como essa abordagem de otimização funciona, considere o AEMT (Santos et al., 2010), que é baseado nesse Método de Tabelas, bem como um problema de otimização com vários objetivos.

A escolha de um indivíduo para reprodução pode ser selecionado em qualquer uma das tabelas. Segundo Santos et al. (2010), essa estratégia aumenta a diversidade 
entre as soluções. Consequentemente, diminui-se a possibilidade do processo de busca ficar preso em ótimos locais e consequentemente, explorar mais o espaço de busca. 



\section{Apêndice B - Exemplo Fluxo de Carga}

Para melhor entendimento do processo dos cálculos do FC considerando a presença de BCs e de RTs, apresenta-se neste Apêndice, um exemplo didático, considerando o sistema de 4 barras apresentado na figura a seguir:

Figura B.1: SD do exemplo didático de 4 barras.

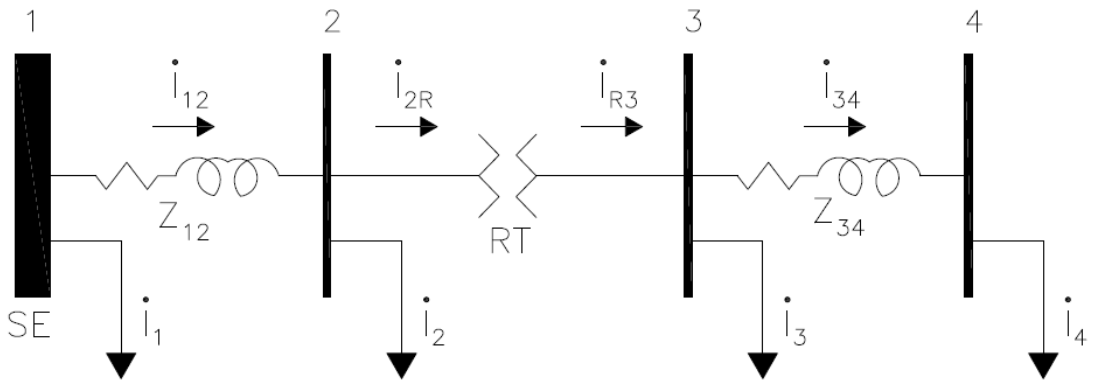

Fonte: Elaborado pelo autor.

A Figura B.1 apresenta um SD constituído de um único alimentador que possui um RT entre as barras 2 e 3, um banco de capacitores trifásicos na barra 4 de $150 \mathrm{kVAr}$ e uma carga trifásica também conectada na barra 4 que demanda: $2.000 \mathrm{~kW}$ de potência ativa e $1.000 \mathrm{kVAr}$ de potência reativa indutiva trifásica. A impedância no trecho 1-2, $Z_{12}$, é: $1,71+j 3,42 \Omega$ e a impedância no trecho $3-4, Z_{34}$, também é de: $1,71+j 3,42 \Omega$. O valor da corrente nominal do RT é de 100A.

Destaca-se que para este exemplo o teste de convergência do programa de FC foi realizado considerando uma tolerância de $10^{-3}$ e a modelagem de carga utilizada é a de potência constante com a tensão. A tensão de linha adotada foi de $13,8 \mathrm{kV}$, assim, a tolerância para a magnitude da tensão em volts será de 7,97V, ou seja, a tensão de fase da barra da subestação multiplicada pela tolerância $10^{-3}$, logo, se o erro da magnitude da tensão for menor que $7,97 \mathrm{~V}$ a convergência foi alcançada neste critério. Já para o ângulo da tensão os valores trabalhados foram em radianos, portanto este critério é alcançado quando o erro for menor que a própria tolerância $\left(10^{-3}\right)$. Para finalizar o cálculo do FC os dois critérios de convergência devem ser atendidos, ou seja, o módulo e o ângulo da tensão. 


\section{Resolução do exemplo:}

Primeiramente adota-se a tensão de fase da barra da subestação em todas as barras do sistema $(13.800 / \sqrt{3})$ :

$$
\dot{V}_{1}^{(d a S E)}=\dot{V}_{2}^{(d a S E)}=\dot{V}_{3}^{(d a S E)}=\dot{V}_{4}^{(d a S E)}=7.967,43[V]
$$

O tap do RT é iniciado na posição zero, pois com o valor base da tensão da subestação em todas as barras, a faixa da tensão de linha estabelecida (Eqs. 4.8 e 4.9) é respeitada e, portanto, não é necessário que o RT regule a tensão das barras à sua jusante neste momento.

\section{$1^{\text {a }}$ Iteração}

\section{Passo 1 - Atualização das correntes de carga nas barras:}

Neste passo calculam-se as correntes de carga de cada barra $i$ do sistema através da Equação 4.1 (seção 4.2.2):

$$
\dot{I}_{i}^{(1)}=\left(\frac{S_{i}^{(\text {nominal })}}{\dot{V}_{i}^{(d a S E)}}\right)^{*}-Y_{i}^{s h} \dot{V}_{i}^{(d a S E)}
$$

sendo que: $i=1,2,3$ e 4 .

Como descrito no enunciado do exemplo, apenas a barra 4 possui carga e um banco de capacitores, logo:

$$
S_{1}=S_{2}=S_{3}=0
$$

Outro ponto importante é que, no exemplo, não é considerado nenhuma admitância shunt $\left(Y_{i}^{s h}\right)$ no SD. Assim a segunda parte da equação (4.1) é nula para todas as barras.

Assim, considerando estas duas ressalvas tem-se que para as três primeiras barras:

$$
\dot{I}_{1}^{(1)}=\dot{I}_{2}^{(1)}=\dot{I}_{3}^{(1)}=0
$$

Obs.: Este resultado continuará sendo o mesmo para as demais iterações, visto que não existe carga ligada as três primeiras barras. 
Agora, com o intuito de calcular a corrente demandada pela barra 4, primeiramente calcula-se o valor de sua potência aparente complexa, já considerando o BC.

Assim, a potência aparente complexa (monofásica) demandada pela barra 4 em VA é:

$$
S_{4 \_1 \phi}=\frac{(2000+j 850) \cdot 1000}{3}=666.666,66+j 283 \cdot 333,33[\mathrm{VA}]
$$

Obs.: observe que a potência reativa (trifásica) da barra 4 é a diferença entre a potência reativa indutiva da carga e a potência reativa capacitiva do BC. É importante ressaltar também que o modelo de carga utilizado neste exemplo é o de potência constante, assim este resultado é o mesmo para todas as iterações.

Finalmente, calcula-se a corrente de carga da barra 4:

$$
\begin{aligned}
& \dot{I}_{4}^{(1)}=\left(\frac{S_{4 \_1 \Phi}}{\dot{V}_{4}^{(\text {daSE }}}\right)^{*}-Y_{4}^{S h} \dot{V}_{4}^{(\text {da SE })} \\
& \dot{I}_{4}^{(1)}=\left(\frac{S_{4 \_1 \Phi}}{\dot{V}_{4}^{(\text {daSE }}}\right)^{*}-0 \\
& \dot{I}_{4}^{(1)}=\left(\frac{S_{4 \_1 \phi}}{\dot{V}_{4}^{(\text {daSE) }}}\right)^{*}=83,67-j 35,56[A]
\end{aligned}
$$

\section{Passo 2 - Etapa Inversa (backward):}

Neste passo são calculadas as correntes em cada trecho do SD, começando dos ramos mais afastados da subestação (SE), assim:

Para o trecho 3-4:

$$
\begin{aligned}
& \dot{I}_{3-4}^{(1)}=\dot{I}_{4}^{(1)} \\
& \dot{I}_{3-4}^{(1)}=83,67-j 35,56[A]
\end{aligned}
$$

Para o trecho secundário do RT (R-3):

$$
\begin{aligned}
& \dot{I}_{R-3}^{(1)}=\dot{I}_{3-4}^{(1)}+\dot{I}_{3}^{(1)} \\
& \dot{I}_{R-3}^{(1)}=\dot{I}_{3-4}^{(1)}+0=83,67-j 35,56[A]
\end{aligned}
$$


Para o trecho primário do RT (2-R), o cálculo obedece a equação (4.7) como segue:

$$
\begin{array}{ll}
\dot{I}_{2-R}^{(1)}=\dot{I}_{R-3}^{(1)}(1+\text { passo } * \text { tap }) & \text {, sendo tap }=0 \\
\dot{I}_{2-R}^{(1)}=83,67-j 35,56[A] &
\end{array}
$$

e para o trecho 1-2:

$$
\begin{aligned}
& \dot{I}_{1-2}^{(1)}=\dot{I}_{2-R}^{(1)}+\dot{I}_{2}^{(1)} \\
& \dot{I}_{1-2}^{(1)}=\dot{I}_{2-R}^{(1)}+0=83,67-j 35,56[A]
\end{aligned}
$$

\section{Passo 3 - Etapa Direta (forward):}

Neste passo calcula-se as tensões nas barras, começando com a barra mais próxima da SE.

A barra raiz do alimentador (barra da subestação) sempre terá o valor da tensão base da SE:

$$
\dot{V}_{1}^{(1)}=7.967,43[V]
$$

Para a barra 2:

$\dot{V}_{2}^{(1)}=\dot{V}_{1}^{(1)}-Z_{1-2} * \dot{I}_{1-2}^{(1)}$

$\dot{V}_{2}^{(1)}=(7.967,43)-(1,71+j 3,42) *(83,67-j 35,56)=7.702,73-j 225,35[V]$

Para a barra 3, o cálculo obedece a equação (4.6), pois no trecho 2-3 se encontra um RT, logo:

$$
\begin{array}{ll}
\dot{V}_{3}^{(1)}=\dot{V}_{2}^{(1)}(1+\text { passo } * \text { tap }) & \text {, sendo tap }=0 \\
\dot{V}_{3}^{(1)}=7.702,73-j 225,35[\mathrm{~V}] &
\end{array}
$$

Análise para o ajuste do tap:

Obs.: Depois do cálculo da tensão na barra 3 o programa faz a análise para verificar a necessidade de alteração do tap.

Primeiramente calcula-se o módulo da tensão de linha da barra 3:

$$
V_{L 3}^{(1)}=\sqrt{3} \cdot\left|\dot{V}_{3}^{1}\right|=13.347,23[V]
$$


Verifica-se que essa tensão está abaixo do limite inferior, equação (4.8), que é de 13.491V. Portanto, deve-se ajustar o tap do RT para que a tensão na barra 3 seja regulada com o intuito de voltar a faixa de tensão desejada.

Aplicando-se a equação (4.10), tem-se:

$$
\text { tap }=\frac{1}{\text { passo }} \cdot\left(\frac{13.491}{\left|V_{L 2(1)}\right|}-1\right)=1,72
$$

sendo que o passo é uma constante e igual a 0,00625, como apresentado na seção 4.2.3.

Como a tensão na barra 3 foi menor que o limite inferior, deve-se arredondar o tap para um valor inteiro acima (tap é um valor discreto), assim:

$$
\text { tap }=2
$$

Com o tap encontrado, deve-se calcular o valor do carregamento do RT e verificar se o valor do tap não extrapola seu limite conforme a tabela 4.1, assim:

$$
\text { Carregamento } R T=\frac{\left|I_{2 R}{ }^{(1)}\right|}{\text { Corrente Nominal do } R T}=\frac{\left|I_{2 R}^{\cdot(1)}\right|}{100}=0,91
$$

Conforme a tabela 4.1, como o carregamento encontrado é menor que 1 então o limite máximo da posição do tap é 16 e -16. Logo o valor da posição do tap calculado $($ tap $=2)$ não extrapola o limite.

Por fim, calcula-se novamente o valor da tensão na barra 3 considerando o ajuste do tap, ou seja, tap = 2:

$$
\dot{V}_{3}^{(1)}=\dot{V}_{2}^{(1)}(1+\text { passo } * \text { tap })=7.999,02-j 228,17[V]
$$

Nota-se que houve alteração na posição do tap de 0 para 2.

Para a barra 4:

$$
\begin{aligned}
& \dot{V}_{4}^{(1)}=\dot{V}_{3}^{(1)}-Z_{3-4} * \dot{I}_{3-4}^{(1)} \\
& \dot{V}_{4}^{(1)}=(7.999,02-j 228,17)-(1,71+j 3,42) *(83,67-j 35,56) \\
& \dot{V}_{4}^{(1)}=7.534,31-j 453,53[V]
\end{aligned}
$$


Durante a análise para ajuste do tap houve alteração na posição do mesmo, assim deve-se necessariamente fazer mais uma iteração para a atualização das correntes e tensões no alimentador do SD.

\section{$2^{\text {a }}$ Iteração}

\section{Passo 1 - Atualização das correntes de carga nas barras:}

Como descrito detalhadamente no passo 1 da iteração anterior ( $1^{\mathrm{a}}$ iteração) a única corrente de carga se encontra na barra 4, portanto:

$$
\dot{I}_{1}^{(2)}=\dot{I}_{2}^{(2)}=\dot{I}_{3}^{(2)}=0
$$

e a corrente demandada pela barra 4 é:

$$
\dot{I}_{4}^{(2)}=\left(\frac{S_{4_{-} 1 \phi}}{\dot{V}_{4}^{(1)}}\right)^{*}=85,91-j 42,78[A]
$$

\section{Passo 2 - Etapa Inversa (backward):}

Neste passo são calculadas as correntes em cada trecho do SD, começando dos ramos mais afastados da subestação (SE), assim:

Para o trecho 3-4:

$$
\begin{aligned}
& \dot{I}_{3-4}^{(2)}=\dot{I}_{4}^{(2)} \\
& \dot{I}_{3-4}^{(2)}=85,91-j 42,78[A]
\end{aligned}
$$

Para o trecho secundário do RT (R-3):

$$
\begin{aligned}
& \dot{I}_{R-3}^{(2)}=\dot{I}_{3-4}^{(2)}+\dot{I}_{3}^{(2)} \\
& \dot{I}_{R-3}^{(2)}=\dot{I}_{3-4}^{(2)}+0=85,91-j 42,78[A]
\end{aligned}
$$

Para o trecho primário do RT (2-R), o cálculo obedece a equação (4.7) como segue:

$$
\begin{array}{ll}
\dot{I}_{2-R}^{(2)}=\dot{I}_{R-3}^{(2)}(1+\text { passo } * \text { tap }) & \text {, sendo tap }=2 \\
\dot{I}_{2-R}^{(2)}=86,98-j 43,31[A] &
\end{array}
$$


e para o trecho 1-2:

$$
\begin{aligned}
& \dot{I}_{1-2}^{(2)}=\dot{I}_{2-R}^{(2)}+\dot{I}_{2}^{(2)} \\
& \dot{I}_{1-2}^{(2)}=86,98-j 43,31[A]
\end{aligned}
$$

\section{Passo 3 - Etapa Direta (forward):}

Neste passo calcula-se as tensões nas barras, começando com a barra mais próxima da SE.

A barra raiz do alimentador (barra da subestação) sempre terá o valor da tensão base da SE:

$$
\dot{V}_{1}^{(2)}=7.967,43[V]
$$

Para a barra 2:

$$
\begin{aligned}
& \dot{V}_{2}^{(2)}=\dot{V}_{1}^{(2)}-Z_{1-2} * \dot{I}_{1-2}^{(2)} \\
& \dot{V}_{2}^{(2)}=7.670,57-j 223,42[\mathrm{~V}]
\end{aligned}
$$

Para a barra 3, o cálculo obedece a equação (4.6), pois no trecho 2-3 se encontra um RT, logo:

$$
\begin{array}{ll}
\dot{V}_{3}^{(2)}=\dot{V}_{2}^{(2)}(1+\text { passo } * \text { tap }) & \text {, sendo tap }=2 \\
\dot{V}_{3}^{(2)}=7.766,45-j 226,21[\mathrm{~V}] &
\end{array}
$$

Análise para o ajuste do tap:

Primeiramente calcula-se o módulo da tensão de linha da barra 3:

$$
V_{L 3}^{(2)}=\sqrt{3} \cdot\left|\dot{V}_{3}^{2}\right|=13.457,59[V]
$$

Verifica-se que essa tensão está abaixo do limite inferior, equação (4.8), que é de 13.491V. Portanto, deve-se ajustar o tap do RT para que a tensão em 3 seja regulada com o intuito de voltar a faixa de tensão desejada.

Aplicando-se a equação (4.10), tem-se:

$$
\text { tap }=\frac{1}{\text { passo }} \cdot\left(\frac{13.491}{\left|V_{L 2(1)}\right|}-1\right)=2,40
$$


Como a tensão na barra 3 foi menor que o limite inferior, deve-se arredondar o tap para um valor inteiro acima (tap é um valor discreto), assim:

$$
\text { tap }=3
$$

Com o tap encontrado, deve-se calcular o valor do carregamento do RT e verificar se o valor do tap não extrapola seu limite conforme a tabela 4.1, assim:

$$
\text { Carregamento } R T=\frac{\left|I_{2 R}{ }^{(2)}\right|}{\text { Corrente Nominal do } R T}=\frac{\left|I_{2 R}{ }^{(2)}\right|}{100}=0,97
$$

Conforme a tabela 4.1, como o carregamento encontrado é menor que 1 então o limite máximo da posição do tap é 16 e -16. Logo o valor da posição do tap calculado $(\operatorname{tap}=3)$ não extrapola o limite.

Por fim, calcula-se novamente o valor da tensão na barra 3 considerando o ajuste do tap, ou seja, tap = 3:

$$
\dot{V}_{3}^{(2)}=\dot{V}_{2}^{(2)}(1+\text { passo } * \text { tap })=7.814,39-j 227,61[\mathrm{~V}]
$$

Nota-se que houve alteração na posição do tap de 2 para 3.

Para a barra 4:

$$
\begin{aligned}
& \dot{V}_{4}^{(2)}=\dot{V}_{3}^{(2)}-Z_{3-4} * \dot{I}_{3-4}^{(2)} \\
& \dot{V}_{4}^{(2)}=7.521,19-j 448,27[V]
\end{aligned}
$$

Durante a análise para ajuste do tap houve alteração na posição do mesmo, assim deve-se necessariamente fazer mais uma iteração para a atualização das correntes e tensões no alimentador do SD.

\section{$3^{\text {a }}$ Iteração}

\section{Passo 1 - Atualização das correntes de carga nas barras:}

Como descrito anteriormente a única corrente de carga se encontra na barra 4 , portanto:

$$
\dot{I}_{1}^{(3)}=\dot{I}_{2}^{(3)}=\dot{I}_{3}^{(3)}=0
$$


e a corrente demandada pela barra 4 é:

$$
\dot{I}_{4}^{(3)}=\left(\frac{S_{4 \_1 \phi}}{\dot{V}_{4}^{(2)}}\right)^{*}=86,09-j 42,80[A]
$$

\section{Passo 2 - Etapa Inversa (backward):}

Neste passo são calculadas as correntes em cada trecho do SD, começando dos ramos mais afastados da subestação (SE), assim:

Para o trecho 3-4:

$$
\begin{aligned}
& \dot{I}_{3-4}^{(3)}=\dot{I}_{4}^{(3)} \\
& \dot{I}_{3-4}^{(3)}=86,09-j 42,80[A]
\end{aligned}
$$

Para o trecho secundário do RT (R-3):

$$
\begin{aligned}
& \dot{I}_{R-3}^{(3)}=\dot{I}_{3-4}^{(3)}+\dot{I}_{3}^{(3)} \\
& \dot{I}_{R-3}^{(3)}=86,09-j 42,80[A]
\end{aligned}
$$

Para o trecho primário do RT (2-R), o cálculo obedece a equação (4.7) como segue:

$$
\begin{array}{ll}
\dot{I}_{2-R}^{(3)}=\dot{I}_{R-3}^{(3)}(1+\text { passo } * \text { tap }) & \text {, sendo tap }=3 \\
\dot{I}_{2-R}^{(3)}=87,70-j 43,60[A] &
\end{array}
$$

e para o trecho 1-2:

$$
\begin{aligned}
& \dot{I}_{1-2}^{(3)}=\dot{I}_{2-R}^{(3)}+\dot{I}_{2}^{(3)} \\
& \dot{I}_{1-2}^{(3)}=87,70-j 43,60[A]
\end{aligned}
$$

\section{Passo 3 - Etapa Direta (forward):}

Neste passo calcula-se as tensões nas barras, começando com a barra mais próxima da SE.

A barra raiz do alimentador (barra da subestação) sempre terá o valor da tensão base da SE:

$$
\dot{V}_{1}^{(3)}=7.967,43[V]
$$


Para a barra 2:

$$
\begin{aligned}
& \dot{V}_{2}^{(3)}=\dot{V}_{1}^{(3)}-Z_{1-2} * \dot{I}_{1-2}^{(3)} \\
& \dot{V}_{2}^{(3)}=7.668,34-j 225,38[\mathrm{~V}]
\end{aligned}
$$

Para a barra 3, o cálculo obedece a equação (4.6), pois no trecho 2-3 se encontra um RT, logo:

$$
\begin{array}{ll}
\dot{V}_{3}^{(3)}=\dot{V}_{2}^{(3)}(1+\text { passo } * \text { tap }) & \text {, sendo tap }=3 \\
\dot{V}_{3}^{(3)}=7.812,12-j 229,60[\mathrm{~V}] &
\end{array}
$$

Análise para o ajuste do tap:

Primeiramente calcula-se o módulo da tensão de linha da barra 3:

$$
V_{L 3}^{(3)}=\sqrt{3} \cdot\left|\dot{V}_{3}^{(3)}\right|=13.536,83[V]
$$

Verifica-se que essa tensão está dentro da faixa aceitável (Eqs. 4.8 e 4.9), ou seja, entre $13.491 \mathrm{~V}$ e $13.763 \mathrm{~V}$, assim não é necessário a atualização da posição do tap.

Para a barra 4:

$$
\begin{aligned}
& \dot{V}_{4}^{(3)}=\dot{V}_{3}^{(3)}-Z_{3-4} * \dot{I}_{3-4}^{(3)} \\
& \dot{V}_{4}^{(3)}=7.518,52-j 450,83[V]
\end{aligned}
$$

Durante a análise para ajuste do tap não houve alteração na posição do mesmo, assim deve-se fazer a análise de convergência.

\section{Análise de Convergência (Erros):}

Nesta etapa do FC calculam-se os erros dos módulos e dos ângulos das tensões em cada barra entre a iteração atual e a iteração anterior:

Erros na magnitude de tensão:

$$
\begin{array}{ll}
|| \dot{V}_{2}^{(3)}|-| \dot{V}_{2}^{(2)}|| & =2,18[V] \quad \text { (convergiu*) } \\
|| \dot{V}_{3}^{(3)}|-| \dot{V}_{3}^{(2)}|| & =2,21[V] \quad \text { (convergiu) }
\end{array}
$$


||$\dot{V}_{4}^{(3)}|-| \dot{V}_{4}^{(2)}||=2,51[V] \quad$ (convergiu)

* Todos menores que 7,97V.

Erros no ângulo da tensão:

$\left|\hat{a ̂ n g u l o}{ }_{2}^{(3)}-\operatorname{ângulo}_{2}^{(2)}\right|=2,63 \cdot 10^{-4}[\mathrm{rad}] \quad\left(\right.$ convergiu** $\left.^{* *}\right)$

$\mid$ ângulo $o_{3}^{(3)}-\hat{a ̂ n g u l o}_{3}^{(2)} \mid=2,63 \cdot 10^{-4}[\mathrm{rad}] \quad$ (convergiu)

$\mid \hat{a ̂ n g u l o}_{4}^{(3)}-$ ângulo $_{4}^{(2)} \mid=3,60 \cdot 10^{-4}[\mathrm{rad}] \quad$ (convergiu)

** Todos menores que $10^{-3}$.

Analisa-se acima que todos os erros atingiram a tolerância especificada, assim finaliza-se o cálculo do FC.

Obs.: Se o exemplo do SD fosse maior que 1 alimentador deveria fazer este processo de cálculos e análises para cada um dos alimentadores do SD.

\section{Tabela Resumo:}

Apresenta-se, a seguir, uma tabela com os valores das tensões complexas em cada barra, após a convergência do programa de FC:

Tabela B.1: Tensões complexas nas barras após convergência do FC.

\begin{tabular}{|c|c|c|}
\hline Barra & Magnitude da tensão [V]* & Ângulo da tensão [rad] \\
\hline 1 & $7.967,43$ & 0,0000 \\
\hline 2 & $7.671,65$ & $-0,0294$ \\
\hline 3 & $7.815,49$ & $-0,0294$ \\
\hline 4 & $7.532,03$ & $-0,0599$ \\
\hline
\end{tabular}

* Valores da tensão de fase. 



\section{Apêndice C - Resultados para Faltas Simples no SD de Londrina.}

Como descrito na seção 5.4, foram analisados 18 setores críticos em falta no SD de Londrina/PR, e apresentados no corpo da dissertação apenas dois, o setor com os melhores (Setor 2684) e o com os piores (Setor 3036) resultados de PREs. Assim, neste Apêndice, serão descritos os resultados dos demais setores (16).

Os resultados apresentados neste apêndice foram divididos em duas partes: $i$ ) aqueles setores em falta que a metodologia obteve respostas factíveis e ii) aqueles setores em falta que a metodologia não obteve respostas factíveis.

\section{C.1 Respostas Factíveis}

\section{Setor crítico 2:}

Os números de manobras, os valores das restrições operacionais e das perdas ativas para a primeira configuração factível são apresentados na Tabela C.1:

Tabela C.1: Valores das manobras, das restrições operacionais e das perdas ativas para a primeira configuração factível.

\begin{tabular}{c|cccc}
\hline & Mínimo & Médio & Máximo & DP* \\
\hline Manobras Totais & 3,00 & 4,74 & 5,00 & 0,68 \\
Número Ponderado de Manobras & 2,10 & 3,17 & 4,10 & 0,51 \\
Manobras em CCR & 1,00 & 1,74 & 2,00 & 0,44 \\
Manobras em CCM & 2,00 & 3,00 & 4,00 & 0,51 \\
Carreg. da Rede (\%) & 85,94 & 127,90 & 163,57 & 29,47 \\
Carreg. do Transformador (\%) & 96,62 & 96,62 & 96,62 & 0,00 \\
Queda de Tensão (\%) & 2,68 & 7,67 & 13,82 & 4,18 \\
Perdas (kW) & $3.737,89$ & $3.991,76$ & $4.348,12$ & 228,46 \\
\hline Desvio Padrão & & & &
\end{tabular}

Os resultados da melhor solução após o processo evolutivo são apresentados na Tabela C.2: 
Tabela C.2: Valores das manobras, das restrições operacionais e das perdas ativas para a melhor solução após o processo evolutivo.

\begin{tabular}{c|cccc}
\hline & Mínimo & Médio & Máximo & DP* \\
\hline Manobras Totais & 5,00 & 5,20 & 7,00 & 0,60 \\
Número Ponderado de Manobras & 2,30 & 2,32 & 2,50 & 0,06 \\
Manobras em CCR & 3,00 & 3,20 & 5,00 & 0,60 \\
Manobras em CCM & 2,00 & 2,00 & 2,00 & 0,00 \\
Carreg. da Rede (\%) & 88,09 & 91,30 & 97,14 & 3,00 \\
Carreg. do Transformador $(\boldsymbol{\%})$ & 96,62 & 96,62 & 96,62 & 0,00 \\
Queda de Tensão $(\%)$ & 4,75 & 5,25 & 9,52 & 0,75 \\
Perdas (kW) & $3.767,81$ & $3.816,68$ & $3.986,95$ & 22,67 \\
Tempo Processo Evolutivo (s) & 32,186 & 47,500 & 56,428 & 4,093 \\
\hline
\end{tabular}

* Desvio Padrão

Os resultados da solução final (após a função de sequência de chaveamento) são apresentados na Tabela C.3:

Tabela C.3: Valores das manobras, das restrições operacionais e das perdas ativas para a solução final.

\begin{tabular}{c|cccc}
\hline & Mínimo & Médio & Máximo & DP* \\
\hline Manobras Totais & 4,00 & 4,98 & 5,00 & 0,14 \\
Número Ponderado de Manobras & 2,20 & 2,30 & 2,30 & 0,01 \\
Manobras em CCR & 2,00 & 2,98 & 3,00 & 0,14 \\
Manobras em CCR com Carga & 2,00 & 2,00 & 2,00 & 0,00 \\
Manobras em CCR com Curto & 0,00 & 0,98 & 1,00 & 0,14 \\
Manobras em CCM & 2,00 & 2,00 & 2,00 & 0,00 \\
Manobras em CCM Seca & 1,00 & 1,00 & 1,00 & 0,00 \\
Manobras em CCM com Carga & 1,00 & 1,00 & 1,00 & 0,00 \\
Manobras em CCM com Curto & 0,00 & 0,00 & 0,00 & 0,00 \\
Carreg. da Rede (\%) & 85,94 & 92,08 & 99,29 & 3,89 \\
Carreg. do Transformador $(\%)$ & 96,62 & 96,62 & 96,62 & 0,00 \\
Queda de Tensão $(\%)$ & 7,12 & 7,12 & 7,12 & 0,00 \\
& & & & $($ continua) \\
\hline
\end{tabular}




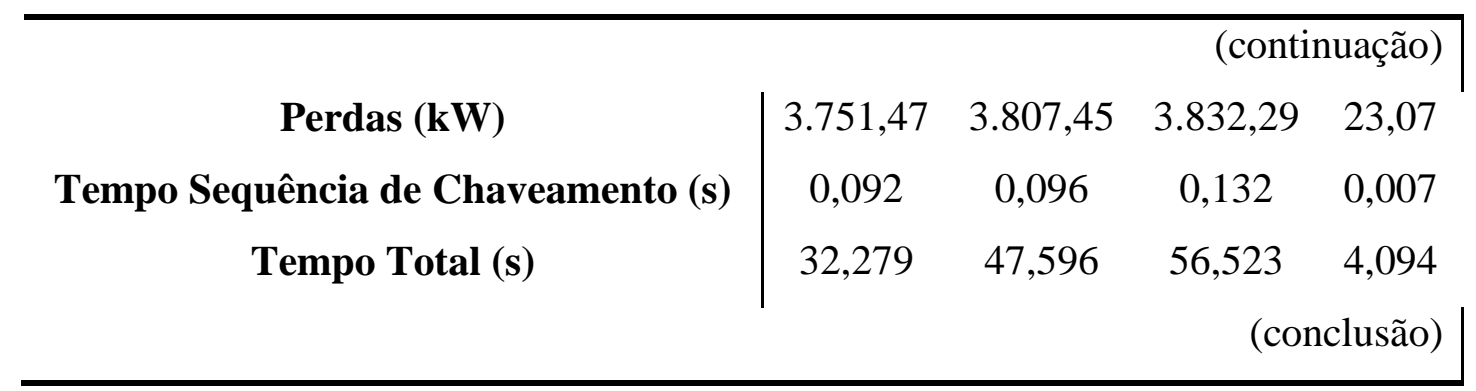

* Desvio Padrão

A melhor solução entre as 100 execuções do programa está apresentada na Tabela C.4, a mesma é encontrada 1 vez durante a execução do teste para este setor em falta.

Tabela C.4: Valores das manobras, das restrições operacionais e das perdas ativas para a melhor resposta entre as 100 execuções.

\begin{tabular}{c|c}
\hline & Valores \\
\hline Manobras Totais & 4,00 \\
Número Ponderado de Manobras & 2,20 \\
Manobras em CCR & 2,00 \\
Manobras em CCR com Carga & 2,00 \\
Manobras em CCR com Curto & 0,00 \\
Manobras em CCM & 2,00 \\
Manobras em CCM Seca & 1,00 \\
Manobras em CCM com Carga & 1,00 \\
Manobras em CCM com Curto & 0,00 \\
Carreg. da Rede (\%) & 88,09 \\
Carreg. do Transformador (\%) & 96,62 \\
Queda de Tensão (\%) & 7,12 \\
Perdas (kW) & $3.803,10$ \\
\hline
\end{tabular}

$\checkmark$ Setor crítico 430:

Os números de manobras, os valores das restrições operacionais e das perdas ativas para a primeira configuração factível são apresentados na Tabela C.5: 
Tabela C.5: Valores das manobras, das restrições operacionais e das perdas ativas para a primeira configuração factível.

\begin{tabular}{c|cccc}
\hline & Mínimo & Médio & Máximo & DP* \\
\hline Manobras Totais & 3,00 & 4,80 & 5,00 & 0,60 \\
Número Ponderado de Manobras & 2,10 & 3,68 & 4,10 & 0,67 \\
Manobras em CCR & 1,00 & 1,25 & 3,00 & 0,46 \\
Manobras em CCM & 2,00 & 3,55 & 4,00 & 0,69 \\
Carreg. da Rede (\%) & 77,33 & 116,08 & 269,54 & 22,49 \\
Carreg. do Transformador (\%) & 96,62 & 96,62 & 96,62 & 0,00 \\
Queda de Tensão (\%) & 3,43 & 8,34 & 16,88 & 2,85 \\
Perdas (kW) & $3.793,39$ & $3.988,07$ & $4.810,30$ & 149,42 \\
\hline
\end{tabular}

* Desvio Padrão

Os resultados da melhor solução após o processo evolutivo são apresentados na Tabela C.6:

Tabela C.6: Valores das manobras, das restrições operacionais e das perdas ativas para a melhor solução após o processo evolutivo.

\begin{tabular}{c|cccc}
\hline & Mínimo & Médio & Máximo & DP* \\
\hline Manobras Totais & 5,00 & 5,46 & 7,00 & 0,85 \\
Número Ponderado de Manobras & 2,30 & 2,54 & 4,30 & 0,52 \\
Manobras em CCR & 1,00 & 3,24 & 5,00 & 1,08 \\
Manobras em CCM & 2,00 & 2,22 & 4,00 & 0,58 \\
Carreg. da Rede (\%) & 79,76 & 90,01 & 99,65 & 3,41 \\
Carreg. do Transformador (\%) & 96,62 & 96,62 & 96,62 & 0,00 \\
Queda de Tensão (\%) & 4,04 & 7,51 & 8,50 & 0,75 \\
Perdas (kW) & $3.789,81$ & $3.944,82$ & $4.068,18$ & 37,53 \\
Tempo Processo Evolutivo (s) & 20,025 & 26,169 & 54,877 & 7,388 \\
\hline
\end{tabular}

* Desvio Padrão

Os resultados da solução final (após a função de sequência de chaveamento) são apresentados na Tabela C.7: 
Tabela C.7: Valores das manobras, das restrições operacionais e das perdas ativas para a solução final.

\begin{tabular}{c|cccc}
\hline & Mínimo & Médio & Máximo & DP* \\
\hline Manobras Totais & 4,00 & 6,95 & 9,00 & 0,98 \\
Número Ponderado de Manobras & 1,30 & 2,92 & 8,10 & 2,00 \\
Manobras em CCR & 1,00 & 4,48 & 5,00 & 1,27 \\
Manobras em CCR com Carga & 0,00 & 2,63 & 3,00 & 0,92 \\
Manobras em CCR com Curto & 1,00 & 1,85 & 2,00 & 0,36 \\
Manobras em CCM & 1,00 & 2,47 & 8,00 & 2,12 \\
Manobras em CCM Seca & 1,00 & 2,47 & 8,00 & 2,12 \\
Manobras em CCM com Carga & 0,00 & 0,00 & 0,00 & 0,00 \\
Manobras em CCM com Curto & 0,00 & 0,00 & 0,00 & 0,00 \\
Carreg. da Rede (\%) & 84,57 & 90,17 & 94,34 & 2,20 \\
Carreg. do Transformador $(\%)$ & 96,62 & 96,62 & 96,62 & 0,00 \\
Queda de Tensão $(\%)$ & 7,12 & 7,63 & 8,40 & 0,17 \\
Perdas (kW) & $3.677,53$ & $3.937,15$ & $3.976,88$ & 44,47 \\
Tempo Sequência de Chaveamento (s) & 0,039 & 0,054 & 0,117 & 0,014 \\
Tempo Total (s) & 20,074 & 26,224 & 54,962 & 7,400 \\
\hline
\end{tabular}

* Desvio Padrão

A melhor solução entre as 100 execuções do programa está apresentada na Tabela C.8, a mesma é encontrada apenas $\mathbf{1}$ vez durante toda a execução do teste para este setor em falta.

Tabela C.8: Valores das manobras, das restrições operacionais e das perdas ativas para a melhor resposta entre as 100 execuções.

\begin{tabular}{c|c}
\hline & Valores \\
\hline Manobras Totais & 4,00 \\
Número Ponderado de Manobras & 1,30 \\
Manobras em CCR & 3,00 \\
Manobras em CCR com Carga & 2,00 \\
Manobras em CCR com Curto & 1,00 \\
Manobras em CCM & 1,00 \\
& (continua) \\
\hline
\end{tabular}




\begin{tabular}{c|c|}
\hline \multicolumn{2}{c}{ (continuação) } \\
Manobras em CCM Seca & 1,00 \\
Manobras em CCM com Carga & 0,00 \\
Manobras em CCM com Curto & 0,00 \\
Carreg. da Rede (\%) & 84,57 \\
Carreg. do Transformador (\%) & 96,62 \\
Queda de Tensão (\%) & 7,12 \\
Perdas (kW) & $3.677,53$ \\
\multicolumn{2}{c}{ (conclusão) } \\
\hline
\end{tabular}

Setor crítico 431:

Os números de manobras, os valores das restrições operacionais e das perdas ativas para a primeira configuração factível são apresentados na Tabela C.9:

Tabela C.9: Valores das manobras, das restrições operacionais e das perdas ativas para a primeira configuração factível.

\begin{tabular}{c|cccc}
\hline & Mínimo & Médio & Máximo & DP* \\
\hline Manobras Totais & 5,00 & 5,00 & 5,00 & 0,00 \\
Número Ponderado de Manobras & 2,30 & 3,89 & 4,10 & 0,40 \\
Manobras em CCR & 1,00 & 1,23 & 3,00 & 0,45 \\
Manobras em CCM & 2,00 & 3,77 & 4,00 & 0,45 \\
Carreg. da Rede (\%) & 81,93 & 116,98 & 186,51 & 18,49 \\
Carreg. do Transformador (\%) & 96,62 & 96,62 & 96,62 & 0,00 \\
Queda de Tensão (\%) & 3,36 & 8,11 & 11,18 & 2,73 \\
Perdas (kW) & $3.785,97$ & $3.973,85$ & $4.261,79$ & 112,69 \\
\hline
\end{tabular}

* Desvio Padrão

Os resultados da melhor solução após o processo evolutivo são apresentados na Tabela C.10: 
Tabela C.10: Valores das manobras, das restrições operacionais e das perdas ativas para a melhor solução após o processo evolutivo.

\begin{tabular}{c|cccc}
\hline & Mínimo & Médio & Máximo & DP* \\
\hline Manobras Totais & 5,00 & 5,54 & 9,00 & 0,94 \\
Número Ponderado de Manobras & 2,30 & 2,62 & 4,10 & 0,62 \\
Manobras em CCR & 1,00 & 3,24 & 7,00 & 1,30 \\
Manobras em CCM & 2,00 & 2,30 & 4,00 & 0,70 \\
Carreg. da Rede (\%) & 79,76 & 89,84 & 94,34 & 3,45 \\
Carreg. do Transformador (\%) & 96,62 & 96,62 & 96,62 & 0,00 \\
Queda de Tensão $(\%)$ & 4,04 & 7,53 & 8,22 & 0,54 \\
Perdas (kW) & $3.789,81$ & $3.944,29$ & $4.017,39$ & 33,41 \\
Tempo Processo Evolutivo (s) & 20,371 & 24,895 & 31,476 & 2,373 \\
\hline
\end{tabular}

* Desvio Padrão

Os resultados da solução final (após a função de sequência de chaveamento) são apresentados na Tabela C.11:

Tabela C.11: Valores das manobras, das restrições operacionais e das perdas ativas para a solução final.

\begin{tabular}{c|cccc}
\hline & Mínimo & Médio & Máximo & DP* \\
\hline Manobras Totais & 6,00 & 7,04 & 9,00 & 0,96 \\
Número Ponderado de Manobras & 1,50 & 3,34 & 8,10 & 2,04 \\
Manobras em CCR & 1,00 & 4,11 & 5,00 & 1,38 \\
Manobras em CCR com Carga & 0,00 & 2,55 & 4,00 & 1,08 \\
Manobras em CCR com Curto & 1,00 & 1,56 & 2,00 & 0,50 \\
Manobras em CCM & 1,00 & 2,93 & 8,00 & 2,18 \\
Manobras em CCM Seca & 1,00 & 2,29 & 4,00 & 0,71 \\
Manobras em CCM com Carga & 0,00 & 0,00 & 0,00 & 0,00 \\
Manobras em CCM com Curto & 0,00 & 0,00 & 0,00 & 0,00 \\
Carreg. da Rede (\%) & 84,57 & 90,33 & 94,34 & 2,13 \\
Carreg. do Transformador $(\%)$ & 96,62 & 96,62 & 96,62 & 0,00 \\
Queda de Tensão $(\%)$ & 7,12 & 7,62 & 8,22 & 0,16 \\
Perdas (kW) & $3.700,59$ & $3.938,79$ & $3.974,59$ & 40,08 \\
& & & & $($ continua)
\end{tabular}




\begin{tabular}{c|cccc|}
\hline \multicolumn{1}{|c}{$\begin{array}{c}\text { (continuação) } \\
\text { Tempo Sequência de Chaveamento (s) } \\
\text { Tempo Total (s) }\end{array}$} & 0,039 & 0,050 & 0,068 & 0,004 \\
& 20,430 & 24,945 & 31,526 & 2,372 \\
(conclusão) \\
\hline
\end{tabular}

* Desvio Padrão

A melhor solução entre as 100 execuções do programa está apresentada na Tabela C.12, a mesma é encontrada apenas 1 vez durante toda a execução do teste para este setor em falta.

Tabela C.12: Valores das manobras, das restrições operacionais e das perdas ativas para a melhor resposta entre as 100 execuções.

\begin{tabular}{c|c}
\hline & Valores \\
\hline Manobras Totais & 6,00 \\
Número Ponderado de Manobras & 1,50 \\
Manobras em CCR & 5,00 \\
Manobras em CCR com Carga & 4,00 \\
Manobras em CCR com Curto & 1,00 \\
Manobras em CCM & 1,00 \\
Manobras em CCM Seca & 1,00 \\
Manobras em CCM com Carga & 0,00 \\
Manobras em CCM com Curto & 0,00 \\
Carreg. da Rede (\%) & 88,84 \\
Carreg. do Transformador (\%) & 96,62 \\
Queda de Tensão (\%) & 7,12 \\
Perdas (kW) & $3.700,59$ \\
\hline
\end{tabular}

$\checkmark$ Setor crítico 2172:

Os números de manobras, os valores das restrições operacionais e das perdas ativas para a primeira configuração factível são apresentados na Tabela C.13: 
Tabela C.13: Valores das manobras, das restrições operacionais e das perdas ativas para a primeira configuração factível.

\begin{tabular}{c|cccc}
\hline & Mínimo & Médio & Máximo & DP* \\
\hline Manobras Totais & 3,00 & 4,84 & 5,00 & 0,55 \\
Número Ponderado de Manobras & 1,20 & 3,28 & 4,10 & 0,86 \\
Manobras em CCR & 1,00 & 1,73 & 3,00 & 0,74 \\
Manobras em CCM & 1,00 & 3,11 & 4,00 & 0,92 \\
Carreg. da Rede (\%) & 84,76 & 134,83 & 288,00 & 48,91 \\
Carreg. do Transformador (\%) & 96,62 & 96,70 & 97,61 & 0,27 \\
Queda de Tensão (\%) & 2,16 & 6,42 & 17,76 & 3,93 \\
Perdas (kW) & $3.743,73$ & $4.014,89$ & $5.007,50$ & 320,89 \\
\hline
\end{tabular}

* Desvio Padrão

Os resultados da melhor solução após o processo evolutivo são apresentados na Tabela C.14:

Tabela C.14: Valores das manobras, das restrições operacionais e das perdas ativas para a melhor solução após o processo evolutivo.

\begin{tabular}{c|cccc}
\hline & Mínimo & Médio & Máximo & DP* \\
\hline Manobras Totais & 5,00 & 5,10 & 7,00 & 0,44 \\
Número Ponderado de Manobras & 2,30 & 2,31 & 2,50 & 0,04 \\
Manobras em CCR & 3,00 & 3,10 & 5,00 & 0,44 \\
Manobras em CCM & 2,00 & 2,00 & 2,00 & 0,00 \\
Carreg. da Rede (\%) & 89,37 & 93,59 & 99,65 & 5,08 \\
Carreg. do Transformador $(\%)$ & 96,62 & 96,62 & 96,62 & 0,00 \\
Queda de Tensão $(\%)$ & 4,58 & 5,02 & 5,34 & 0,37 \\
Perdas (kW) & $3.845,17$ & $3.865,08$ & $3.967,68$ & 26,74 \\
Tempo Processo Evolutivo (s) & 37,893 & 49,556 & 56,590 & 3,564 \\
\hline
\end{tabular}

* Desvio Padrão

Os resultados da solução final (após a função de sequência de chaveamento) são apresentados na Tabela C.15: 
Tabela C.15: Valores das manobras, das restrições operacionais e das perdas ativas para a solução final.

\begin{tabular}{c|cccc}
\hline & Mínimo & Médio & Máximo & DP* \\
\hline Manobras Totais & 4,00 & 5,17 & 7,00 & 0,77 \\
Número Ponderado de Manobras & 2,20 & 2,55 & 4,30 & 0,68 \\
Manobras em CCR & 2,00 & 2,91 & 3,00 & 0,29 \\
Manobras em CCR com Carga & 2,00 & 2,00 & 2,00 & 0,00 \\
Manobras em CCR com Curto & 0,00 & 0,91 & 1,00 & 0,29 \\
Manobras em CCM & 2,00 & 2,26 & 4,00 & 0,68 \\
Manobras em CCM Seca & 1,00 & 1,44 & 4,00 & 0,99 \\
Manobras em CCM com Carga & 0,00 & 0,82 & 3,00 & 0,46 \\
Manobras em CCM com Curto & 0,00 & 0,00 & 0,00 & 0,00 \\
Carreg. da Rede (\%) & 89,37 & 93,53 & 99,65 & 5,04 \\
Carreg. do Transformador $(\%)$ & 96,62 & 96,62 & 96,62 & 0,00 \\
Queda de Tensão $(\%)$ & 7,12 & 7,12 & 7,12 & 0,00 \\
Perdas (kW) & $3.802,31$ & $3.859,53$ & $3.881,61$ & 14,39 \\
Tempo Sequência de Chaveamento (s) & 0,092 & 0,099 & 0,158 & 0,010 \\
Tempo Total (s) & 37,990 & 49,654 & 56,686 & 3,565 \\
\hline
\end{tabular}

* Desvio Padrão

A melhor solução entre as 100 execuções do programa está apresentada na Tabela C.16, a mesma é encontrada 9 vezes repetidamente durante a execução do teste para este setor em falta.

Tabela C.16: Valores das manobras, das restrições operacionais e das perdas ativas para a melhor resposta entre as 100 execuções.

\begin{tabular}{c|c}
\hline & Valores \\
\hline Manobras Totais & 4,00 \\
Número Ponderado de Manobras & 2,20 \\
Manobras em CCR & 2,00 \\
Manobras em CCR com Carga & 2,00 \\
Manobras em CCR com Curto & 0,00 \\
Manobras em CCM & 2,00 \\
& (continua) \\
\hline
\end{tabular}




\begin{tabular}{c|c|}
\hline \multicolumn{2}{c}{ (continuação) } \\
Manobras em CCM Seca & 1,00 \\
Manobras em CCM com Carga & 1,00 \\
Manobras em CCM com Curto & 0,00 \\
Carreg. da Rede (\%) & 99,65 \\
Carreg. do Transformador (\%) & 96,62 \\
Queda de Tensão (\%) & 7,12 \\
Perdas (kW) & $3.848,18$ \\
\multicolumn{2}{c}{ (conclusão) } \\
\hline
\end{tabular}

Setor crítico 2269:

Os números de manobras, os valores das restrições operacionais e das perdas ativas para a primeira configuração factível são apresentados na Tabela C.17:

Tabela C.17: Valores das manobras, das restrições operacionais e das perdas ativas para a primeira configuração factível.

\begin{tabular}{c|cccc}
\hline & Mínimo & Médio & Máximo & DP* \\
\hline Manobras Totais & 5,00 & 5,00 & 5,00 & 0,00 \\
Número Ponderado de Manobras & 4,10 & 4,96 & 5,00 & 0,20 \\
Manobras em CCR & 0,00 & 0,05 & 1,00 & 0,22 \\
Manobras em CCM & 4,00 & 4,95 & 5,00 & 0,22 \\
Carreg. da Rede (\%) & 99,56 & 127,89 & 314,73 & 31,51 \\
Carreg. do Transformador (\%) & 96,62 & 96,62 & 96,62 & 0,00 \\
Queda de Tensão (\%) & 2,86 & 4,64 & 9,12 & 1,34 \\
Perdas (kW) & $3.774,43$ & $3.884,13$ & $4.219,12$ & 76,50 \\
\hline
\end{tabular}

* Desvio Padrão

Os resultados da melhor solução após o processo evolutivo são apresentados na Tabela C.18: 
Tabela C.18: Valores das manobras, das restrições operacionais e das perdas ativas para a melhor solução após o processo evolutivo.

\begin{tabular}{c|cccc}
\hline & Mínimo & Médio & Máximo & DP* \\
\hline Manobras Totais & 5,00 & 5,12 & 7,00 & 0,48 \\
Número Ponderado de Manobras & 4,10 & 4,77 & 5,00 & 0,38 \\
Manobras em CCR & 0,00 & 0,39 & 3,00 & 0,78 \\
Manobras em CCM & 4,00 & 4,73 & 5,00 & 0,45 \\
Carreg. da Rede (\%) & 84,75 & 88,94 & 99,65 & 3,92 \\
Carreg. do Transformador $(\%)$ & 96,62 & 96,62 & 96,62 & 0,00 \\
Queda de Tensão $(\%)$ & 2,85 & 3,84 & 5,34 & 0,55 \\
Perdas (kW) & $3.784,40$ & $3.826,31$ & $3.923,11$ & 30,46 \\
Tempo Processo Evolutivo $(\mathbf{s})$ & 15,038 & 18,409 & 22,610 & 1,823 \\
\hline
\end{tabular}

* Desvio Padrão

Os resultados da solução final (após a função de sequência de chaveamento) são apresentados na Tabela C.19:

Tabela C.19: Valores das manobras, das restrições operacionais e das perdas ativas para a solução final.

\begin{tabular}{c|cccc}
\hline & Mínimo & Médio & Máximo & DP* \\
\hline Manobras Totais & 4,00 & 5,62 & 7,00 & 0,94 \\
Número Ponderado de Manobras & 4,00 & 4,77 & 5,20 & 0,47 \\
Manobras em CCR & 0,00 & 0,95 & 2,00 & 0,86 \\
Manobras em CCR com Carga & 0,00 & 0,95 & 2,00 & 0,86 \\
Manobras em CCR com Curto & 0,00 & 0,00 & 0,00 & 0,00 \\
Manobras em CCM & 4,00 & 4,67 & 5,00 & 0,47 \\
Manobras em CCM Seca & 1,00 & 2,28 & 3,00 & 0,49 \\
Manobras em CCM com Carga & 2,00 & 2,39 & 3,00 & 0,49 \\
Manobras em CCM com Curto & 0,00 & 0,00 & 0,00 & 0,00 \\
Carreg. da Rede (\%) & 84,75 & 88,67 & 93,23 & 3,11 \\
Carreg. do Transformador $(\%)$ & 96,62 & 96,62 & 96,62 & 0,00 \\
Queda de Tensão (\%) & 7,12 & 7,12 & 7,12 & 0,00 \\
Perdas (kW) & $3.784,40$ & $3,819,96$ & $3.844,65$ & 24,62 \\
& & & & $($ continua) \\
\hline
\end{tabular}




\begin{tabular}{c|cccc|}
\hline \multicolumn{2}{|c}{} & & \multicolumn{2}{c|}{ (continuação) } \\
Tempo Sequência Chaveamento (s) & 0,048 & 0,052 & 0,071 & 0,004 \\
Tempo Total (s) & 15,088 & 18,461 & 22,659 & 1,823 \\
& & & & (conclusão) \\
\hline
\end{tabular}

* Desvio Padrão

A melhor solução entre as 100 execuções do programa está apresentada na Tabela C.20, a mesma é encontrada 2 vezes repetidamente durante a execução do teste para este setor em falta.

Tabela C.20: Valores das manobras, das restrições operacionais e das perdas ativas para a melhor resposta entre as 100 execuções.

\begin{tabular}{c|c}
\hline & Valores \\
\hline Manobras Totais & 4,00 \\
Número Ponderado de Manobras & 4,00 \\
Manobras em CCR & 0,00 \\
Manobras em CCR com Carga & 0,00 \\
Manobras em CCR com Curto & 0,00 \\
Manobras em CCM & 4,00 \\
Manobras em CCM Seca & 1,00 \\
Manobras em CCM com Carga & 3,00 \\
Manobras em CCM com Curto & 0,00 \\
Carreg. da Rede (\%) & 91,83 \\
Carreg. do Transformador (\%) & 96,62 \\
Queda de Tensão (\%) & 7,12 \\
Perdas (kW) & $3.844,65$ \\
\hline
\end{tabular}

$\checkmark$ Setor crítico 2607:

Os números de manobras, os valores das restrições operacionais e das perdas ativas para a primeira configuração factível são apresentados na Tabela C.21: 
Tabela C.21: Valores das manobras, das restrições operacionais e das perdas ativas para a primeira configuração factível.

\begin{tabular}{c|cccc}
\hline & Mínimo & Médio & Máximo & DP* \\
\hline Manobras Totais & 3,00 & 4,96 & 5,00 & 0,28 \\
Número Ponderado de Manobras & 3,00 & 4,56 & 5,00 & 0,59 \\
Manobras em CCR & 0,00 & 0,44 & 2,00 & 0,61 \\
Manobras em CCM & 3,00 & 4,52 & 5,00 & 0,64 \\
Carreg. da Rede (\%) & 79,65 & 123,46 & 204,57 & 30,62 \\
Carreg. do Transformador (\%) & 96,62 & 96,62 & 96,62 & 0,00 \\
Queda de Tensão (\%) & 4,85 & 8,01 & 13,81 & 2,24 \\
Perdas (kW) & $3.740,43$ & $3.958,31$ & $4.412,68$ & 158,32 \\
\hline
\end{tabular}

* Desvio Padrão

Os resultados da melhor solução após o processo evolutivo são apresentados na Tabela C.22:

Tabela C.22: Valores das manobras, das restrições operacionais e das perdas ativas para a melhor solução após o processo evolutivo.

\begin{tabular}{c|cccc}
\hline & Mínimo & Médio & Máximo & DP* \\
\hline Manobras Totais & 5,00 & 5,18 & 7,00 & 0,58 \\
Número Ponderado de Manobras & 3,20 & 3,22 & 3,40 & 0,06 \\
Manobras em CCR & 2,00 & 2,18 & 4,00 & 0,58 \\
Manobras em CCM & 3,00 & 3,00 & 3,00 & 0,00 \\
Carreg. da Rede (\%) & 79,65 & 95,58 & 98,69 & 4,92 \\
Carreg. do Transformador (\%) & 96,62 & 96,64 & 98,51 & 0,19 \\
Queda de Tensão (\%) & 5,48 & 7,62 & 8,50 & 1,15 \\
Perdas (kW) & $3.846,32$ & $3.919,73$ & $3.993,92$ & 36,50 \\
Tempo Processo Evolutivo (s) & 41,055 & 52,317 & 75,604 & 6,309 \\
\hline
\end{tabular}

* Desvio Padrão

Os resultados da solução final (após a função de sequência de chaveamento) são apresentados na Tabela C.23: 
Tabela C.23: Valores das manobras, das restrições operacionais e das perdas ativas para a solução final.

\begin{tabular}{c|cccc}
\hline & Mínimo & Médio & Máximo & DP* \\
\hline Manobras Totais & 4,00 & 5,36 & 7,00 & 0,87 \\
Número Ponderado de Manobras & 2,20 & 3,38 & 5,20 & 0,75 \\
Manobras em CCR & 2,00 & 2,20 & 4,00 & 0,60 \\
Manobras em CCR com Carga & 1,00 & 2,07 & 3,00 & 0,36 \\
Manobras em CCR com Curto & 0,00 & 0,13 & 1,00 & 0,34 \\
Manobras em CCM & 2,00 & 3,16 & 5,00 & 0,76 \\
Manobras em CCM Seca & 1,00 & 2,61 & 5,00 & 1,07 \\
Manobras em CCM com Carga & 0,00 & 0,55 & 1,00 & 0,50 \\
Manobras em CCM com Curto & 0,00 & 0,00 & 0,00 & 0,00 \\
Carreg. da Rede (\%) & 84,57 & 95,74 & 98,69 & 4,44 \\
Carreg. do Transformador $(\%)$ & 96,62 & 96,62 & 96,62 & 0,00 \\
Queda de Tensão (\%) & 7,12 & 7,97 & 8,50 & 0,63 \\
Perdas (kW) & $3.846,32$ & $3.917,66$ & $3.957,76$ & 36,10 \\
Tempo Sequência de Chaveamento (s) & 0,092 & 0,097 & 0,136 & 0,008 \\
Tempo Total (s) & 41,150 & 52,415 & 75,705 & 6,308 \\
\hline
\end{tabular}

* Desvio Padrão

A melhor solução entre as 100 execuções do programa está apresentada na Tabela C.24, a mesma é encontrada 3 vezes durante a execução do teste para este setor em falta.

Tabela C.24: Valores das manobras, das restrições operacionais e das perdas ativas para a melhor resposta entre as 100 execuções.

\begin{tabular}{c|c}
\hline & Valores \\
\hline Manobras Totais & 4,00 \\
Número Ponderado de Manobras & 2,20 \\
Manobras em CCR & 2,00 \\
Manobras em CCR com Carga & 2,00 \\
Manobras em CCR com Curto & 0,00 \\
Manobras em CCM & 2,00 \\
Manobras em CCM Seca & 1,00 \\
& (continua) \\
\hline
\end{tabular}




\begin{tabular}{c|c|}
\hline \multicolumn{2}{c|}{ (continuação) } \\
Manobras em CCM com Carga & 1,00 \\
Manobras em CCM com Curto & 0,00 \\
Carreg. da Rede (\%) & 93,58 \\
Carreg. do Transformador (\%) & 96,62 \\
Queda de Tensão (\%) & 7,12 \\
Perdas (kW) & $3.849,90$ \\
\multicolumn{2}{c}{ (conclusão) } \\
\hline
\end{tabular}

\section{C.2 Respostas Infactíveis}

$\checkmark$ Setor crítico 388:

Os números de manobras, os valores das restrições operacionais e das perdas ativas para a primeira configuração factível são apresentados na Tabela C.25:

Tabela C.25: Valores das manobras, das restrições operacionais e das perdas ativas para a primeira configuração factível.

\begin{tabular}{c|cccc}
\hline & Mínimo & Médio & Máximo & DP* \\
\hline Manobras Totais & 7,00 & 7,00 & 7,00 & 0,00 \\
Número Ponderado de Manobras & 3,40 & 4,50 & 5,20 & 0,61 \\
Manobras em CCR & 2,00 & 2,78 & 4,00 & 0,68 \\
Manobras em CCM & 3,00 & 4,22 & 5,00 & 0,68 \\
Carreg. da Rede (\%) & 77,79 & 81,66 & 101,51 & 7,31 \\
Carreg. do Transformador (\%) & 96,62 & 96,62 & 96,62 & 0,00 \\
Queda de Tensão (\%) & 16,75 & 16,82 & 18,56 & 0,18 \\
Perdas (kW) & $3.966,75$ & $4.001,72$ & $4.111,23$ & 43,94 \\
\hline
\end{tabular}

* Desvio Padrão

Os resultados da melhor solução após o processo evolutivo são apresentados na Tabela C.26: 
Tabela C.26: Valores das manobras, das restrições operacionais e das perdas ativas para a melhor solução após o processo evolutivo.

\begin{tabular}{c|cccc}
\hline & Mínimo & Médio & Máximo & DP* \\
\hline Manobras Totais & 5,00 & 5,00 & 5,00 & 0,00 \\
Número Ponderado de Manobras & 2,30 & 2,72 & 3,20 & 0,45 \\
Manobras em CCR & 2,00 & 2,53 & 3,00 & 0,50 \\
Manobras em CCM & 2,00 & 2,47 & 3,00 & 0,50 \\
Carreg. da Rede (\%) & 78,56 & 78,56 & 78,56 & 0,00 \\
Carreg. do Transformador $(\%)$ & 96,62 & 96,62 & 96,62 & 0,00 \\
Queda de Tensão $(\%)$ & 16,80 & 16,80 & 16,80 & 0,00 \\
Perdas (kW) & $3.967,78$ & $3.970,94$ & $3.974,51$ & 3,38 \\
Tempo Processo Evolutivo $(\mathbf{s})$ & 60,104 & 69,629 & 80,011 & 3,687 \\
\hline
\end{tabular}

* Desvio Padrão

\section{Setor crítico 389:}

Os números de manobras, os valores das restrições operacionais e das perdas ativas para a primeira configuração factível são apresentados na Tabela C.27:

Tabela C.27: Valores das manobras, das restrições operacionais e das perdas ativas para a primeira configuração factível.

\begin{tabular}{c|cccc}
\hline & Mínimo & Médio & Máximo & DP* \\
\hline Manobras Totais & 5,00 & 5,00 & 5,00 & 0,00 \\
Número Ponderado de Manobras & 2,30 & 3,64 & 4,10 & 0,75 \\
Manobras em CCR & 1,00 & 1,51 & 3,00 & 0,83 \\
Manobras em CCM & 2,00 & 3,49 & 4,00 & 0,83 \\
Carreg. da Rede (\%) & 42,98 & 58,19 & 73,80 & 11,74 \\
Carreg. do Transformador (\%) & 96,62 & 96,62 & 96,62 & 0,00 \\
Queda de Tensão (\%) & 11,17 & 11,78 & 13,68 & 0,54 \\
Perdas (kW) & $3.806,02$ & $3.823,21$ & $3.878,99$ & 18,60 \\
\hline
\end{tabular}

* Desvio Padrão

Os resultados da melhor solução após o processo evolutivo são apresentados na Tabela C.28: 
Tabela C.28: Valores das manobras, das restrições operacionais e das perdas ativas para a melhor solução após o processo evolutivo.

\begin{tabular}{c|cccc}
\hline & Mínimo & Médio & Máximo & DP* \\
\hline Manobras Totais & 3,00 & 3,00 & 3,00 & 0,00 \\
Número Ponderado de Manobras & 2,10 & 2,10 & 2,10 & 0,00 \\
Manobras em CCR & 1,00 & 1,00 & 1,00 & 0,00 \\
Manobras em CCM & 2,00 & 2,00 & 2,00 & 0,00 \\
Carreg. da Rede (\%) & 42,32 & 42,32 & 42,32 & 0,00 \\
Carreg. do Transformador (\%) & 96,62 & 96,62 & 96,62 & 0,00 \\
Queda de Tensão $(\%)$ & 11,60 & 11,60 & 11,60 & 0,00 \\
Perdas (kW) & $3,806,58$ & $3.806,58$ & $3.806,58$ & 0,00 \\
Tempo Processo Evolutivo (s) & 56,860 & 64,822 & 80,035 & 4,807 \\
\hline
\end{tabular}

* Desvio Padrão

\section{Setor crítico 642:}

Os números de manobras, os valores das restrições operacionais e das perdas ativas para a primeira configuração factível são apresentados na Tabela C.29:

Tabela C.29: Valores das manobras, das restrições operacionais e das perdas ativas para a primeira configuração factível.

\begin{tabular}{c|cccc}
\hline & Mínimo & Médio & Máximo & DP* \\
\hline Manobras Totais & 7,00 & 7,00 & 7,00 & 0,00 \\
Número Ponderado de Manobras & 6,10 & 6,77 & 7,00 & 0,40 \\
Manobras em CCR & 0,00 & 0,26 & 1,00 & 0,44 \\
Manobras em CCM & 6,00 & 6,74 & 7,00 & 0,44 \\
Carreg. da Rede (\%) & 58,17 & 85,77 & 171,00 & 43,06 \\
Carreg. do Transformador (\%) & 96,62 & 96,62 & 96,62 & 0,00 \\
Queda de Tensão (\%) & 12,04 & 13,89 & 17,71 & 2,03 \\
Perdas (kW) & $3.763,52$ & $3.852,92$ & $4.068,01$ & 111,49 \\
\hline
\end{tabular}

* Desvio Padrão

Os resultados da melhor solução após o processo evolutivo são apresentados na Tabela C.30: 
Tabela C.30: Valores das manobras, das restrições operacionais e das perdas ativas para a melhor solução após o processo evolutivo.

\begin{tabular}{c|cccc}
\hline & Mínimo & Médio & Máximo & DP* \\
\hline Manobras Totais & 5,00 & 5,00 & 5,00 & 0,00 \\
Número Ponderado de Manobras & 5,00 & 5,00 & 5,00 & 5,00 \\
Manobras em CCR & 0,00 & 0,00 & 0,00 & 0,00 \\
Manobras em CCM & 5,00 & 5,00 & 5,00 & 0,00 \\
Carreg. da Rede (\%) & 45,68 & 45,69 & 46,78 & 0,11 \\
Carreg. do Transformador (\%) & 96,62 & 96,62 & 96,62 & 0,00 \\
Queda de Tensão (\%) & 11,90 & 11,90 & 11,90 & 0,00 \\
Perdas (kW) & $3.754,57$ & $3.754,57$ & $3.754,57$ & 0,00 \\
Tempo Processo Evolutivo (s) & 99,408 & 114,246 & 134,088 & 6,585 \\
\hline Des
\end{tabular}

* Desvio Padrão

$\checkmark$ Setor crítico 1662:

Os números de manobras, os valores das restrições operacionais e das perdas ativas para a primeira configuração factível são apresentados na Tabela C.31:

Tabela C.31: Valores das manobras, das restrições operacionais e das perdas ativas para a primeira configuração factível.

\begin{tabular}{c|cccc}
\hline & Mínimo & Médio & Máximo & DP* \\
\hline Manobras Totais & 5,00 & 5,00 & 5,00 & 0,00 \\
Número Ponderado de Manobras & 3,20 & 4,00 & 4,10 & 0,28 \\
Manobras em CCR & 1,00 & 1,11 & 2,00 & 0,31 \\
Manobras em CCM & 3,00 & 3,89 & 4,00 & 0,31 \\
Carreg. da Rede (\%) & 86,19 & 100,96 & 199,41 & 34,88 \\
Carreg. do Transformador (\%) & 109,84 & 109,84 & 109,84 & 0,00 \\
Queda de Tensão (\%) & 3,63 & 4,21 & 6,42 & 0,83 \\
Perdas (kW) & $3.746,14$ & $3.773,39$ & $3.880,32$ & 39,80 \\
\hline
\end{tabular}

* Desvio Padrão 
Os resultados da melhor solução após o processo evolutivo são apresentados na Tabela C.32:

Tabela C.32: Valores das manobras, das restrições operacionais e das perdas ativas para a melhor solução após o processo evolutivo.

\begin{tabular}{c|cccc}
\hline & Mínimo & Médio & Máximo & DP* \\
\hline Manobras Totais & 3,00 & 3,00 & 3,00 & 0,00 \\
Número Ponderado de Manobras & 2,10 & 2,10 & 2,10 & 0,00 \\
Manobras em CCR & 1,00 & 1,00 & 1,00 & 0,00 \\
Manobras em CCM & 2,00 & 2,00 & 2,00 & 0,00 \\
Carreg. da Rede (\%) & 90,22 & 90,22 & 90,22 & 0,00 \\
Carreg. do Transformador (\%) & 109,84 & 109,84 & 109,84 & 0,00 \\
Queda de Tensão (\%) & 3,70 & 3,70 & 3,70 & 0,00 \\
Perdas (kW) & $3.747,55$ & $3.747,55$ & $3.747,55$ & 0,00 \\
Tempo Processo Evolutivo (s) & 54,246 & 62,558 & 74,420 & 3,402 \\
\hline
\end{tabular}

* Desvio Padrão

$\checkmark$ Setor crítico 1663:

Os números de manobras, os valores das restrições operacionais e das perdas ativas para a primeira configuração factível são apresentados na Tabela C.33:

Tabela C.33: Valores das manobras, das restrições operacionais e das perdas ativas para a primeira configuração factível.

\begin{tabular}{c|cccc}
\hline & Mínimo & Médio & Máximo & DP* $^{*}$ \\
\hline Manobras Totais & 5,00 & 5,00 & 5,00 & 0,00 \\
Número Ponderado de Manobras & 4,10 & 4,10 & 4,10 & 0,00 \\
Manobras em CCR & 1,00 & 1,00 & 1,00 & 0,00 \\
Manobras em CCM & 4,00 & 4,00 & 4,00 & 0,00 \\
Carreg. da Rede (\%) & 86,19 & 90,06 & 90,22 & 0,79 \\
Carreg. do Transformador (\%) & 109,84 & 109,84 & 109,84 & 0,00 \\
Queda de Tensão (\%) & 3,63 & 3,71 & 4,25 & 0,08 \\
Perdas (kW) & $3.744,30$ & $3.747,98$ & $3.773,72$ & 3,72 \\
\hline
\end{tabular}

* Desvio Padrão 
Os resultados da melhor solução após o processo evolutivo são apresentados na Tabela C.34:

Tabela C.34: Valores das manobras, das restrições operacionais e das perdas ativas para a melhor solução após o processo evolutivo.

\begin{tabular}{c|cccc}
\hline & Mínimo & Médio & Máximo & DP* \\
\hline Manobras Totais & 3,00 & 3,00 & 3,00 & 0,00 \\
Número Ponderado de Manobras & 2,10 & 2,10 & 2,10 & 0,00 \\
Manobras em CCR & 1,00 & 1,00 & 1,00 & 0,00 \\
Manobras em CCM & 2,00 & 2,00 & 2,00 & 0,00 \\
Carreg. da Rede (\%) & 90,22 & 90,22 & 90,22 & 0,00 \\
Carreg. do Transformador (\%) & 109,84 & 109,84 & 109,84 & 0,00 \\
Queda de Tensão (\%) & 3,70 & 3,70 & 3,70 & 0,00 \\
Perdas (kW) & $3.747,55$ & $3.747,55$ & $3.747,55$ & 0,00 \\
Tempo Processo Evolutivo (s) & 50,425 & 57,625 & 68,758 & 3,494 \\
\hline
\end{tabular}

* Desvio Padrão

$\checkmark$ Setor crítico 2832:

Os números de manobras, os valores das restrições operacionais e das perdas ativas para a primeira configuração factível são apresentados na Tabela C.35:

Tabela C.35: Valores das manobras, das restrições operacionais e das perdas ativas para a primeira configuração factível.

\begin{tabular}{c|cccc}
\hline & Mínimo & Médio & Máximo & DP* $^{*}$ \\
\hline Manobras Totais & 5,00 & 5,00 & 5,00 & 0,00 \\
Número Ponderado de Manobras & 5,00 & 5,00 & 5,00 & 0,00 \\
Manobras em CCR & 0,00 & 0,00 & 0,00 & 0,00 \\
Manobras em CCM & 5,00 & 5,00 & 5,00 & 0,00 \\
Carreg. da Rede (\%) & 202,86 & 202,86 & 202,86 & 0,00 \\
Carreg. do Transformador (\%) & 96,62 & 96,62 & 96,62 & 0,00 \\
Queda de Tensão $(\%)$ & 10,84 & 11,08 & 11,42 & 0,27 \\
Perdas (kW) & $4.175,27$ & $4.186,44$ & $4.200,73$ & 11,65 \\
\hline
\end{tabular}

* Desvio Padrão 
Os resultados da melhor solução após o processo evolutivo são apresentados na Tabela C.36:

Tabela C.36: Valores das manobras, das restrições operacionais e das perdas ativas para a melhor solução após o processo evolutivo.

\begin{tabular}{c|cccc}
\hline & Mínimo & Médio & Máximo & DP* \\
\hline Manobras Totais & 3,00 & 3,00 & 3,00 & 0,00 \\
Número Ponderado de Manobras & 3,00 & 3,00 & 3,00 & 0,00 \\
Manobras em CCR & 0,00 & 0,00 & 0,00 & 0,00 \\
Manobras em CCM & 3,00 & 3,00 & 3,00 & 0,00 \\
Carreg. da Rede (\%) & 202,86 & 202,86 & 202,86 & 0,00 \\
Carreg. do Transformador (\%) & 96,62 & 96,62 & 96,62 & 0,00 \\
Queda de Tensão (\%) & 9,12 & 9,12 & 9,12 & 0,00 \\
Perdas (kW) & $4.030,82$ & $4.030,82$ & $4.030,82$ & 0,00 \\
Tempo Processo Evolutivo (s) & 59,939 & 64,803 & 71,530 & 2,818 \\
\hline
\end{tabular}

* Desvio Padrão

$\checkmark$ Setor crítico 2834:

Os números de manobras, os valores das restrições operacionais e das perdas ativas para a primeira configuração factível são apresentados na Tabela C.37:

Tabela C.37: Valores das manobras, das restrições operacionais e das perdas ativas para a primeira configuração factível.

\begin{tabular}{c|cccc}
\hline & Mínimo & Médio & Máximo & DP* $^{*}$ \\
\hline Manobras Totais & 5,00 & 5,00 & 5,00 & 0,00 \\
Número Ponderado de Manobras & 5,00 & 5,00 & 5,00 & 0,00 \\
Manobras em CCR & 0,00 & 0,00 & 0,00 & 0,00 \\
Manobras em CCM & 5,00 & 5,00 & 5,00 & 0,00 \\
Carreg. da Rede (\%) & 202,86 & 202,86 & 202,86 & 0,00 \\
Carreg. do Transformador (\%) & 96,62 & 96,62 & 96,62 & 0,00 \\
Queda de Tensão (\%) & 9,12 & 9,37 & 11,42 & 0,68 \\
Perdas (kW) & $4.031,14$ & $4.049,72$ & $4.200,73$ & 50,72 \\
\hline
\end{tabular}

* Desvio Padrão 
Os resultados da melhor solução após o processo evolutivo são apresentados na Tabela C.38:

Tabela C.38: Valores das manobras, das restrições operacionais e das perdas ativas para a melhor solução após o processo evolutivo.

\begin{tabular}{c|cccc}
\hline & Mínimo & Médio & Máximo & DP* \\
\hline Manobras Totais & 3,00 & 3,00 & 3,00 & 0,00 \\
Número Ponderado de Manobras & 3,00 & 3,00 & 3,00 & 0,00 \\
Manobras em CCR & 0,00 & 0,00 & 0,00 & 0,00 \\
Manobras em CCM & 3,00 & 3,00 & 3,00 & 0,00 \\
Carreg. da Rede (\%) & 202,86 & 202,86 & 202,86 & 0,00 \\
Carreg. do Transformador (\%) & 96,62 & 96,62 & 96,62 & 0,00 \\
Queda de Tensão (\%) & 9,12 & 9,12 & 9,12 & 0,00 \\
Perdas (kW) & $4.030,82$ & $4.030,82$ & $4.030,82$ & 0,00 \\
Tempo Processo Evolutivo (s) & 32,477 & 40,892 & 53,744 & 2,544 \\
\hline
\end{tabular}

* Desvio Padrão

$\checkmark$ Setor crítico 2835:

Os números de manobras, os valores das restrições operacionais e das perdas ativas para a primeira configuração factível são apresentados na Tabela C.39:

Tabela C.39: Valores das manobras, das restrições operacionais e das perdas ativas para a primeira configuração factível.

\begin{tabular}{c|cccc}
\hline & Mínimo & Médio & Máximo & DP* $^{*}$ \\
\hline Manobras Totais & 7,00 & 7,00 & 7,00 & 0,00 \\
Número Ponderado de Manobras & 7,00 & 7,00 & 7,00 & 0,00 \\
Manobras em CCR & 0,00 & 0,00 & 0,00 & 0,00 \\
Manobras em CCM & 7,00 & 7,00 & 7,00 & 0,00 \\
Carreg. da Rede (\%) & 201,48 & 201,48 & 201,48 & 0,00 \\
Carreg. do Transformador (\%) & 96,62 & 96,62 & 96,62 & 0,00 \\
Queda de Tensão (\%) & 10,33 & 10,54 & 12,64 & 0,62 \\
Perdas (kW) & $4.063,78$ & $4.078,76$ & $4.232,48$ & 45,25 \\
\hline
\end{tabular}

* Desvio Padrão 
Os resultados da melhor solução após o processo evolutivo são apresentados na Tabela C.40:

Tabela C.40: Valores das manobras, das restrições operacionais e das perdas ativas para a melhor solução após o processo evolutivo.

\begin{tabular}{c|cccc}
\hline & Mínimo & Médio & Máximo & DP* \\
\hline Manobras Totais & 5,00 & 5,00 & 5,00 & 0,00 \\
Número Ponderado de Manobras & 5,00 & 5,00 & 5,00 & 0,00 \\
Manobras em CCR & 0,00 & 0,00 & 0,00 & 0,00 \\
Manobras em CCM & 5,00 & 5,00 & 5,00 & 0,00 \\
Carreg. da Rede (\%) & 201,48 & 201,48 & 201,48 & 0,00 \\
Carreg. do Transformador (\%) & 96,62 & 96,62 & 96,62 & 0,00 \\
Queda de Tensão (\%) & 10,33 & 10,33 & 10,33 & 0,00 \\
Perdas (kW) & $4.063,46$ & $4.063,46$ & $4.063,46$ & 0,00 \\
Tempo Processo Evolutivo (s) & 30,466 & 37,321 & 47,457 & 3,668 \\
\hline
\end{tabular}

* Desvio Padrão

$\checkmark$ Setor crítico 2907:

Os números de manobras, os valores das restrições operacionais e das perdas ativas para a primeira configuração factível são apresentados na Tabela C.41:

Tabela C.41: Valores das manobras, das restrições operacionais e das perdas ativas para a primeira configuração factível.

\begin{tabular}{c|cccc}
\hline & Mínimo & Médio & Máximo & DP* \\
\hline Manobras Totais & 5,00 & 5,00 & 5,00 & 0,00 \\
Número Ponderado de Manobras & 4,10 & 4,62 & 5,00 & 0,45 \\
Manobras em CCR & 0,00 & 0,42 & 1,00 & 0,50 \\
Manobras em CCM & 4,00 & 4,58 & 5,00 & 0,50 \\
Carreg. da Rede (\%) & 43,59 & 55,79 & 122,09 & 17,14 \\
Carreg. do Transformador (\%) & 100,09 & 101,20 & 111,60 & 3,01 \\
Queda de Tensão (\%) & 2,14 & 3,25 & 4,04 & 0,77 \\
Perdas (kW) & $3.727,81$ & $3.742,09$ & $3.776,41$ & 14,37 \\
\hline
\end{tabular}

* Desvio Padrão 
Os resultados da melhor solução após o processo evolutivo são apresentados na Tabela C.42:

Tabela C.42: Valores das manobras, das restrições operacionais e das perdas ativas para a melhor solução após o processo evolutivo.

\begin{tabular}{c|cccc}
\hline & Mínimo & Médio & Máximo & DP* \\
\hline Manobras Totais & 3,00 & 3,00 & 3,00 & 0,00 \\
Número Ponderado de Manobras & 3,00 & 3,00 & 3,00 & 0,00 \\
Manobras em CCR & 0,00 & 0,00 & 0,00 & 0,00 \\
Manobras em CCM & 3,00 & 3,00 & 3,00 & 0,00 \\
Carreg. da Rede (\%) & 43,01 & 43,33 & 46,15 & 0,56 \\
Carreg. do Transformador (\%) & 100,09 & 102,95 & 111,60 & 4,76 \\
Queda de Tensão (\%) & 1,99 & 2,66 & 4,09 & 0,70 \\
Perdas (kW) & $3.724,69$ & $3.724,69$ & $3.724,69$ & 0,00 \\
Tempo Processo Evolutivo (s) & 39,703 & 45,200 & 56,120 & 3,110 \\
\hline
\end{tabular}

* Desvio Padrão

$\checkmark$ Setor crítico 3017:

Os números de manobras, os valores das restrições operacionais e das perdas ativas para a primeira configuração factível são apresentados na Tabela C.43:

Tabela C.43: Valores das manobras, das restrições operacionais e das perdas ativas para a primeira configuração factível.

\begin{tabular}{c|cccc}
\hline & Mínimo & Médio & Máximo & DP* \\
\hline Manobras Totais & 5,00 & 5,00 & 5,00 & 0,00 \\
Número Ponderado de Manobras & 4,10 & 4,87 & 5,00 & 0,32 \\
Manobras em CCR & 0,00 & 0,15 & 1,00 & 0,36 \\
Manobras em CCM & 4,00 & 4,85 & 5,00 & 0,36 \\
Carreg. da Rede (\%) & 57,50 & 67,74 & 172,49 & 15,51 \\
Carreg. do Transformador (\%) & 96,62 & 96,62 & 96,62 & 0,00 \\
Queda de Tensão (\%) & 16,88 & 20,09 & 27,27 & 2,09 \\
Perdas (kW) & $3.945,55$ & $4.010,56$ & $4.368,63$ & 56,49 \\
\hline
\end{tabular}

* Desvio Padrão 
Os resultados da melhor solução após o processo evolutivo são apresentados na Tabela C.44:

Tabela C.44: Valores das manobras, das restrições operacionais e das perdas ativas para a melhor solução após o processo evolutivo.

\begin{tabular}{c|cccc}
\hline & Mínimo & Médio & Máximo & DP* \\
\hline Manobras Totais & 3,00 & 3,00 & 3,00 & 0,00 \\
Número Ponderado de Manobras & 3,00 & 3,00 & 3,00 & 0,00 \\
Manobras em CCR & 0,00 & 0,00 & 0,00 & 0,00 \\
Manobras em CCM & 3,00 & 3,00 & 3,00 & 0,00 \\
Carreg. da Rede (\%) & 57,57 & 70,35 & 71,39 & 3,32 \\
Carreg. do Transformador (\%) & 96,62 & 96,65 & 99,91 & 0,33 \\
Queda de Tensão (\%) & 17,35 & 17,98 & 22,18 & 1,53 \\
Perdas (kW) & $3.952,50$ & $3.963,56$ & $4.039,85$ & 27,24 \\
Tempo Processo Evolutivo (s) & 46,381 & 60,573 & 72,041 & 5,385 \\
\hline
\end{tabular}

* Desvio Padrão 